\title{
BALANCE AND MOBILITY IN CLINICALLY RECOVERED CHILDREN AND ADOLESCENTS AFTER A MILD TRAUMATIC BRAIN INJURY
}

\section{KRITHIKA SAMBASIVAN}

School of Physical and Occupational Therapy,

McGill University, Montréal

April, 2014

\begin{abstract}
A thesis submitted to McGill University in partial fulfillment of the requirements of the degree of Master of Science in Rehabilitation Science
\end{abstract}

(C) Krithika Sambasivan 2014. 


\section{TABLE OF CONTENTS}

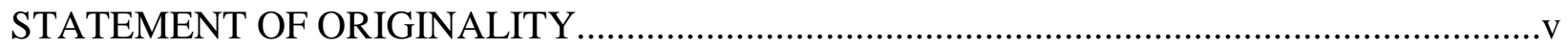

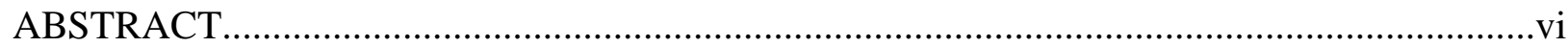

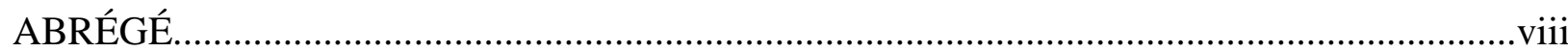

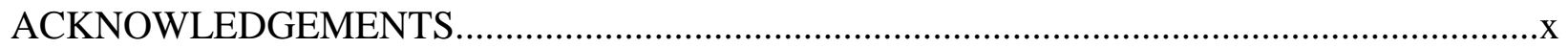

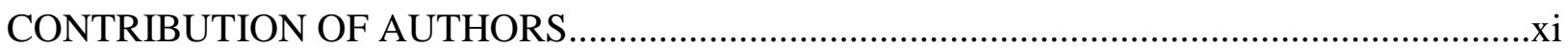

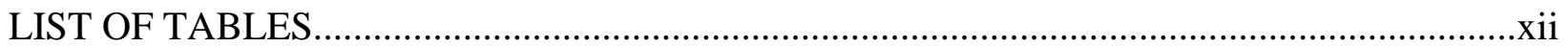

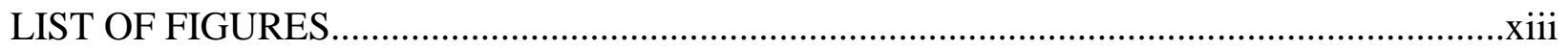

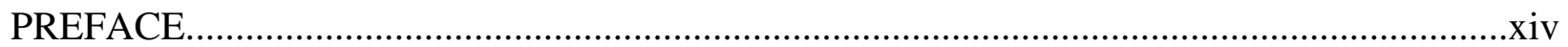

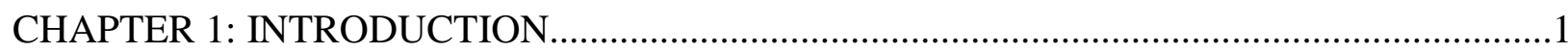

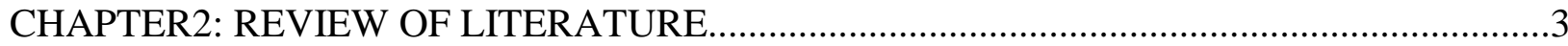

1.0. What is a Mild Traumatic Brain Injury(mTBI)

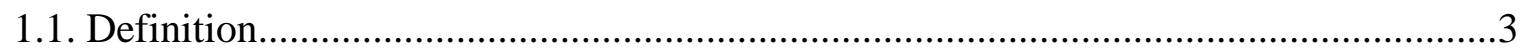

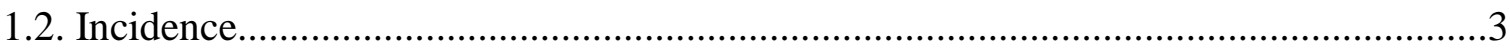

1.3. Etiology and major risk factors in children and youth...............................................

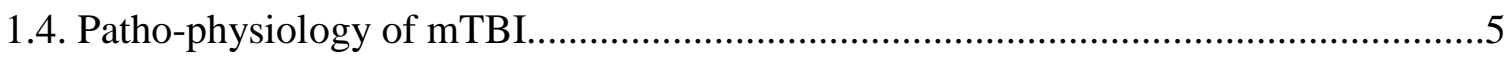

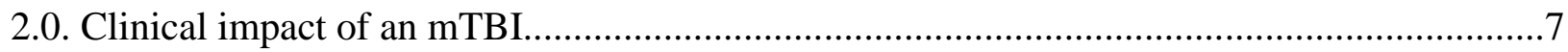

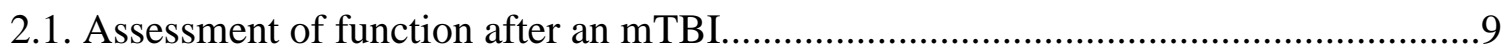

3.0. Return to physical activities guidelines............................................................................11

4.0. Balance

4.1. Definition of balance. .14 
4.2. Static and dynamic balance.

4.3. Systems involved in maintaining postural control and balance................................15

4.4. Development of postural control................................................................. 16

4.5. Balance after an mTBI

4.5.1. Patho-physiology of balance problems after an $m$ TBI...................................16

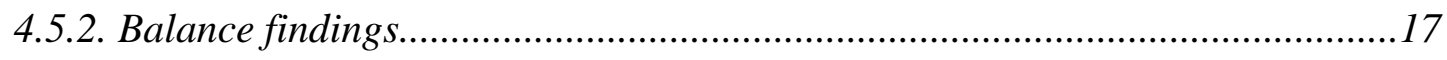

4.6. Assessment of balance in children and adolescents after an mTBI.........................32

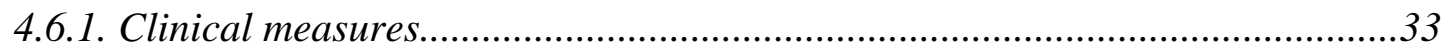

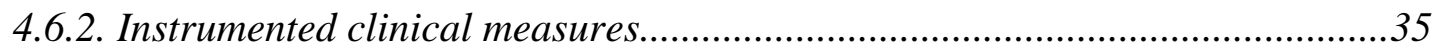

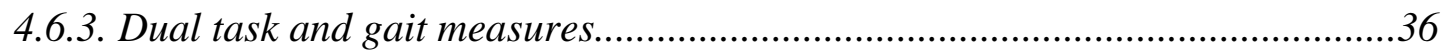

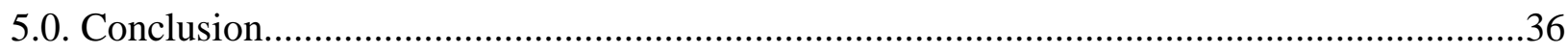

CHAPTER 3: OBJECTIVE, HYPOTHESIS AND EXPECTED CONTRIBUTIONS................38

CHAPTER 4: MANUSCRIPT: Assessing Balance in Children After a Mild Traumatic Brain Injury: Choosing the Right Assessment

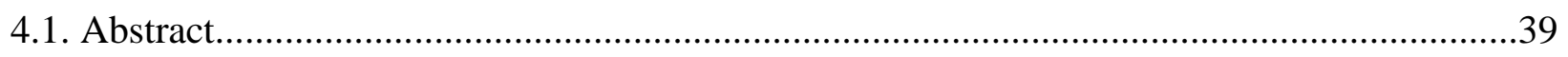

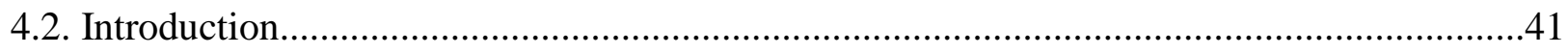

4.3. Methodology

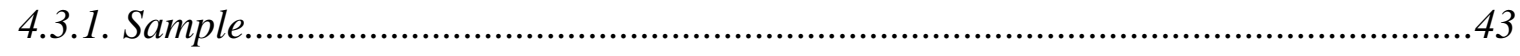

4.3.2. Measures of balance and mobility..................................................................44

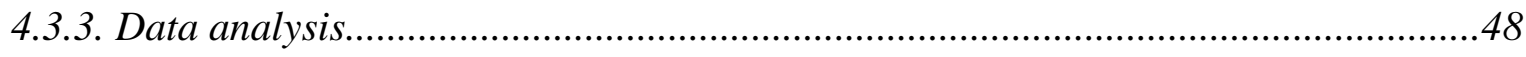

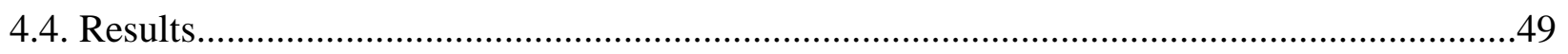

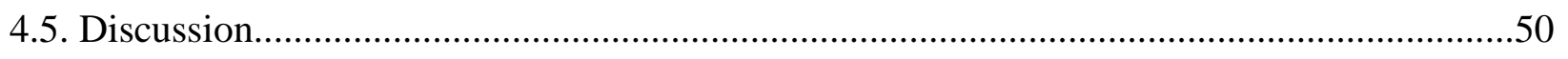




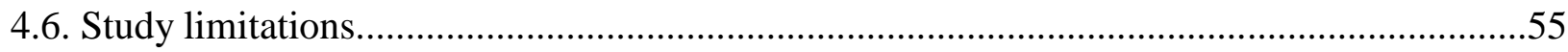

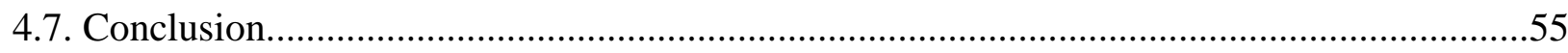

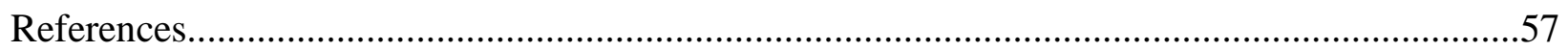

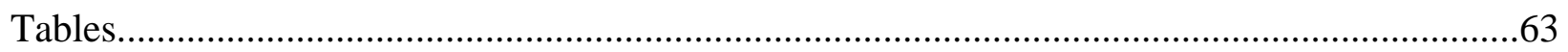

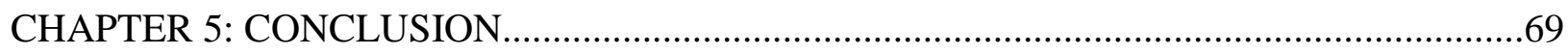

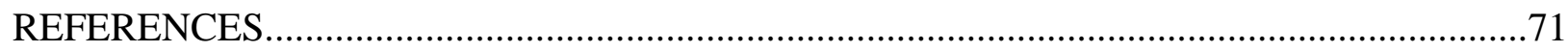

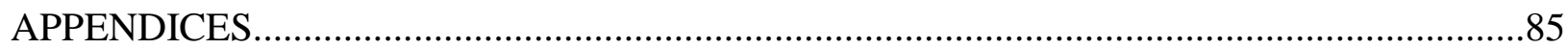

Authorization letter from Research Ethics Board.................................................................85

Consent form for the mTBI group English Version....................................................... 86

Assent form for mTBI group English Version.............................................................90

Recruitment letter for the control group.................................................................... 94 


\section{STATEMENT OF ORIGINALITY}

I hereby attest that the thesis contains no material that is previously published or written by another person, except where references are made.

Elements of this Master's thesis provides original contributions to knowledge of balance and mobility in the children with Mild Traumatic Brain Injuries (mTBI) after they are clinically recovered, compared to healthy children. 


\begin{abstract}
Research has shown that balance deficits can be seen in children months after an mTBI, when using high technology assessment tools. These balance problems often outlast the resolution of self-reported post-concussion symptoms and can remain undetected by current clinical assessment. It has also been observed that gait assessment under single and dual task conditions can lead to the detection of further deficits in the absence of post-concussion symptoms. Despite this, clinical decision-making regarding confirmation of recovery continues to rely heavily on the resolution of post-concussion symptoms that are self-reported, while brief balance and cognitive assessments are usually included in post-concussion assessments, they are performed with tests shown to be sensitive mostly in the acute phase post-injury. Our clinical inability to identify children who have persisting balance difficulties before we allow them to return to high-risk sports or physical activity could be one of the causes of re-injury in this population. It is therefore essential that sensitive and easy to administer tools be proposed to clinicians to improve their confidence in the fact that children are completely deficit-free before their return to pre-injury levels of participation.
\end{abstract}

The objective of this study was to compare the ability of selected static and dynamic balance measures to detect differences between children who have been declared clinically recovered from an mTBI and healthy controls.

A cross-sectional study was conducted at the Montreal Children's Hospital with 29 children aged 8-17 years, who were clinically recovered after an mTBI, 22 age and gender matched controls. Three clinical balance measures were used: the Bruininks-Osteresky Test, Second Edition (BOT2)- balance subtest, the Balance Error Scoring System (BESS), and Community Balance and Mobility (CB\&M) Scale. Additionally, three gait paradigms were performed: Self-Selected Pace (SSP), Obstacle Crossing (OC), Tandem Walking (TW) using the GAITRite walkway® under single and dual task conditions. Dual task performance was measured using a simple cognitive arithmetic task during all gait paradigms. Independent sample t-tests at $\alpha=0.05$ with Bonferroni corrections was used to analyse differences between the groups on all balance and mobility assessments. Discriminant function analysis was used to identify the balance measures that best predicted which group an individual belonged to. Further, differences in Dual Task Cost (DTC) 
on motor and cognitive tasks between groups were analysed using repeated measures ANOVA and independent sample t-tests.

Results showed that the recovered mTBI group reported no remaining post-concussion symptoms but performed significantly worse than the control group on the three clinical measures $(p<0.05)$ and on certain gait parameters under all three paradigms $(p<0.05)$. Deficits were most prominent in tasks performed under conditions of restricted base of support, in the absence of visual information and when planning more complex motor tasks. The BESS and tandem walking were found to be the best predictors of recovery on balance measures. There were no significant differences in DTC between both groups on motor tasks, whereas DTC was found to be significantly different with the mTBI group performing worse on the cognitive task in the accuracy percentage during SSP walking.

From the above results it is seen that children and adolescents present with balance difficulties that tend to outlast their post-concussive symptoms and was detected using various clinical measures of balance. This study highlights that it is important to test various components of balance included under static and dynamic abilities, as they are seen to have issues in tasks involving both proactive and reactive strategies to maintain good balance. Assessing these aspects of balance will help provide clinicians with a more objective measure to base return to physical activity decisions. 


\begin{abstract}
ABRÉGÉ
Des déficits d'équilibre peuvent être identifiés chez les enfants et adolescents, même plusieurs mois après un traumatisme craniocérébral léger (TCCL), lorsqu'ils sont évalués à l'aide d'outils sensibles et sophistiqués. Ces problèmes d'équilibre perdurent souvent au-delà de la résolution des symptômes post-commotionnels auto-rapportés par les enfants et peuvent passer inaperçus lors de l'évaluation clinique couramment utilisée. Malgré tout, la prise de décision clinique en ce qui concerne la récupération post-TCCL et le retour aux activités physiques continue de s'appuyer fortement sur la résolution des symptômes post-commotionnels et, bien que les évaluations comprennent parfois un aspect de l'équilibre, elles sont réalisées avec des tests avérés sensibles principalement en période aiguë post-TCCL. Notre incapacité clinique à identifier les enfants qui ont des difficultés persistantes au niveau de l'équilibre, avant de leur permettre de retourner aux sports à haut risque ou à l'activité physique pourrait être l'une des causes de blessures à répétition chez cette population.

L'objectif de cette étude était donc de comparer la capacité de mesures d'équilibre statique et dynamique à détecter des différences entre des enfants considérés comme récupérés suite à un TCCL et des enfants sains.

Une étude transversale fut menée à l'Hôpital de Montréal pour enfants avec 29 enfants et adolescents âgés de 8 à 17 ans, ayant récupéré suite à un TCCL, et 22 enfants témoins appariés selon l'âge, le genre et le niveau d'activités physiques. Trois mesures cliniques d'équilibre furent utilisées : le Bruininks- Osteresky Test, Second Edition-balance subtest (BOT-2), le Balance Error Scoring System (BESS), et le Community Balance and Mobility Scale (CB\&M). De plus, trois paradigmes de marche ont été réalisés: vitesse confortable, marche par dessus un obstacle, et marche en tandem en utilisant le tapis GAITRite ${ }^{\circledR}$ dans des conditions de simple et double tâche. La double tâche était mesurée à l'aide d'une tâche cognitive arithmétique simple, lors de tous les paradigmes de marche. Des tests de t pour échantillons indépendants avec un $\alpha$ fixé à 0,05 furent effectués pour analyser les différences entre les groupes au niveau de la performance aux évaluations de l'équilibre et de la mobilité. Une analyse de fonction discriminante a ensuite été utilisée pour identifier les mesures de l'équilibre qui arrivaient le mieux à prédire à quel groupe (TCCL récupéré vs enfants témoins sains) un individu appartenait. Finalement, les différences de coûts attentionnel et moteur lors de la double tâche ont été analysées en utilisant
\end{abstract}


des ANOVA pour mesures répétées et des tests de $\mathrm{t}$ pour échantillons indépendants, selon les variables.

Les résultats montrent que les enfants post-TCCL ne rapportaient pas de symptômes postcommotionnels, mais présentaient des difficultés au niveau de l'équilibre identifiées à l'aide des trois tests cliniques et de certains paramètres de marche. Les déficits les plus saillants furent identifiés lors des tâches effectuées dans des conditions de base de support restreinte, en l'absence d'information visuelle et lors de tâches demandant une planification motrice plus complexe.

D'après les résultats de cette étude, il est clair que certains problèmes d'équilibre ont tendance à durer plus longtemps que les symptômes post-commotionnels et peuvent être détectés à l'aide de diverses mesures d'équilibre. Cette étude souligne qu'il est important de tester à la fois l'équilibre statique et dynamique chez les enfants et les adolescents afin de fournir aux cliniciens une mesure plus objective leur permettant de prendre des décisions éclairées au sujet du retour aux activités physiques, ce qui pourrait contribuer à prévenir d'autres blessures. 


\section{ACKNOWLEDGEMENTS}

There are many people who contributed to the completion of the thesis and without whose help and support this would have not been possible. Firstly, my biggest thank you goes to Dr. Isabelle Gagnon, for being my guide and mentor through my Master's program. She has helped me from the stages of conception of this project, to its completion. Her contribution to my learning the basics of research and about the field of Mild Traumatic Brain Injury in children, has been immense.

I would like to thank Dr. Anouk Lamontagne and Ms. Lisa Grilli, for being on my supervisory committee and guiding me throughout the project. I want to specially thank Ms. Grilli for helping me through the stages of data collection and constantly giving me tips and cues on improving my study.

I thank OPPQ-REPAR for funding our project and Dr. Gagnon for helping me financially through the course of my Master's. I greatly appreciate the help of the School of P\&OT and Dr. Eva Kehayia for all the moral and financial support given during tough times.

I thank the trauma team at the Montreal Children's Hospital for helping me complete my data collection with success. I would like to thank my lab mates, Laurie-Ann C. Berrigan, Vishwa Buch and Shikha Saxena who have given me their support and valuable input time and again. I thank Laurie-Ann specifically, for orienting me to the use of the GAITRite walkway.

Lastly, I thank my parents, my sister and brother-in-law for their unending love, encouragement and support. I thank my friends in Canada and abroad for believing in me and loving me throughout. 


\section{CONTRIBUTIONS OF AUTHORS}

The thesis is written in a manuscript format based on the guidelines of the Graduate and Postdoctoral Studies, McGill University and contains one main manuscript to be submitted for publication. There are three co-authors for the manuscript described in the thesis. Dr. Isabelle Gagnon and Ms. Lisa Grilli were responsible for the conception of the idea for this project. Dr. Gagnon and I were responsible for designing the protocol. Ms. Grilli was part of the team during data collection, by helping in the recruitment process. I was responsible for data collection, preparation of the text as well as performing the analyses. Dr. Gagnon guided me on the analyses section. The manuscript was reviewed and approved by both senior authors. 


\section{LIST OF TABLES}

Table 2.1 Common self-reported symptoms of a concussion....................................................8

Table 2.2.Assessment tools and scales after an mTBI....................................................

Table 2.3.Zurich guidelines for Return to Play (RTP), Adapted from the paper.......................12

Table 2.4. Studies showing the balance findings after an mTBI (static and dynamic balance)....18

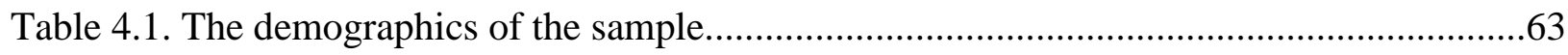

Table 4.2. Group performance (mean \pm SD) on the three clinical balance measures along with gait parameters measured under single task conditions and dual task conditions............................64

Table 4.3. Classification results of the discriminant analysis...............................................67

Table 4.4. Means and SDs of DTC variables used in repeated measures ANOVA....................68 


\section{LIST OF FIGURES}

Figure 2.1. Patho-physiological cascade seen after an mTBI in the rat model.............................6 


\section{PREFACE}

In accordance with McGill University Faculty of Graduate Studies and Research's guidelines for thesis preparation, a manuscript-based style has been adopted for this thesis. The original paper is presented as prepared for submission to the Journal of Head Trauma Rehabilitation.

Chapter 1 provides a brief introduction to the issue of balance assessment after mild traumatic brain injury, and included the rationale for the study.

Chapter $\mathbf{2}$ is a brief review of the existing literature covering mild traumatic brain injury in children and adolescents, the assessment of balance and issues around return to activities after the injury.

Chapter 3 describes the objective, hypothesis and expected contribution of the study

Chapter 4 is the original manuscript of the study. It describes the study exploring balance in children and adolescents after an mTBI and proposes the best balance measures to be incorporated in clinical practice. This paper is intended to be submitted for publication to the Journal of Head Trauma Rehabilitation.

Chapter 5 provides a summary of the research findings and the overall conclusion of the study as well as implications of the findings for clinical practice.

A reference list for Chapters 1,2 and 5 is provided at the end of the thesis.

Appendices: Contains the letter of approval from the Research Ethics Board at the Montreal Children's Hospital, McGill University Health Center for the project, the consent and assent forms used in the study as well as the recruitment letter for the control group. Similar consent and assent forms were given to the control group, but there was no access to their hospital records for the study. All forms had a French version. 


\section{CHAPTER 1: INTRODUCTION}

Mild Traumatic Brain Injury (mTBI), has generated a lot of attention in the last decade both in research and in the public. There is a lot of controversy regarding the definition of an mTBI and often used interchangeably with concussions. The definitions are based more on the context of how the injury was sustained. Concussion is used mainly in sport related injuries, whereas mTBI covers a broader context of sustaining the injury in both competitive and recreational physical activity or other causes. For this thesis, the two terms will be used interchangeably. There is an increasing number of children and youth who are reported to suffer from a concussion due to participation in competitive sports ${ }^{1}$. The Center of Disease Control reports that about 200,000 athletes with mTBI are seen in Emergency Departments (ED) each year, with 65\% of the cases being between the age of 5-18 years ${ }^{2}$.

Due to the nature of the injury, traditionally more attention was focussed on self-reported symptoms and on the cognitive consequences of an $\mathrm{mTBI}^{3}$. More recently it has been better recognized that individuals present with balance and mobility issues immediately after the injury $^{4}$. Balance is an essential part of everyday activity. The ability to maintain proper balance is essential to perform physical activities effectively. Although post-concussion assessment tools such as the Sport Concussion Assessment Tool (SCAT-3) include a component of balance testing, the importance of assessing both static and dynamic balance as well as the usefulness of testing both components and how sensitive they are at detecting balance deficits are not fully understood ${ }^{4}$.

Despite the increased awareness and recognition of balance problems related to mTBI, recovery of postural control and mobility after the injury are poorly understood, especially in children and adolescents. Recent literature in young collegiate athletes, has found that simple balance tests, such as those included as part of the SCAT-3 for example, may yield results that would indicate complete recovery but that when individuals were tested using more sophisticated balance measures or tested with increased task complexity, it clearly led to identification of residual balance deficits ${ }^{5-8}$. Similarly, in children and youth, balance deficits have been identified up-to three months after the injury, in the absence of self-reported post-concussion symptoms, using various balance measures ${ }^{9}$ which fail to be used in clinical practice where decisions regarding clinical recovery post-injury and return to pre-injury level of activity continue to be made largely 
on the basis of self-reported symptoms. Moreover, self-reported symptoms have been found to be unreliable in younger children ${ }^{10}$, and return to physical activity decisions based on the individual's recovery from symptoms alone may prove to be problematic.

It has recently been recommended that return to physical activity decisions be a multi-modal approach, incorporating symptom scales, neuropsychological testing as well as balance testing and that more conservative management be adopted for children and youth ${ }^{4,11}$. Clinicians are therefore faced with having to choose balance assessments that are sensitive enough to detect subtle deficits in postural control, and while some common clinical measures have shown their usefulness in ascertaining problems in the acute period post-concussion, very little is known about which tools could lead to confident decision-making once most other signs and symptoms have resolved.

A lack of proper balance could be one of the causes contributing to the elevated risk of re-injury in this group. Furthermore, multiple concussions can lead to more complex long term consequences including cognitive and emotional deficits, as well as persistent problems in maintaining proper postural control and mobility ${ }^{12}$.

Hence, the overall purpose of the study is to provide additional evidence to empower clinicians in their choice of balance assessment tools that would be sensitive to persistent balance impairments in children and youth, and increase their confidence when making return to activity decisions. To address the topic in the thesis, the following chapter includes a review of the literature pertinent to the objective of the study. Chapter 3 includes the objective, hypothesis and expected contribution of the study. Chapter 4 is the manuscript that describes the study. Chapter 5 is a final conclusion to the thesis. 


\section{CHAPTER 2: REVIEW OF LITERATURE}

\subsection{What is a Mild Traumatic Brain Injury?}

\subsection{Definition:}

Many definitions have been proposed in an attempt to better circumscribe mTBI. The issue of case definition is further compounded by the fact that different terms are used depending on the context where injuries occur. Indeed sport-related injuries are usually referred to as concussions while those occurring in the playground or as a result of a motor vehicle collision are classified as $\mathrm{mTBI}^{13,14}$. In the context of this thesis, both terms will be used interchangeably.

The World Hearlth Organization Task Force on $\mathrm{mTBI}^{15}$ proposes to define mTBI as "an acute brain injury resulting from mechanical energy to the head from external physical forces." The Task Force further suggests operational criteria for the clinical identification of mTBI cases and those include:"“(1) 1 or more of the following: confusion or disorientation, LOC for 30 min or less, posttraumatic amnesia for less than $24 \mathrm{~h}$, and/or other transient neurological abnormalities such as focal signs, seizure, and intracranial lesion not requiring surgery; (2) Glasgow Coma Scale score of 13-15 after 30 min post-injury or later upon presentation for healthcare". This is the definition we will adopt in the context of our work.

\subsection{Incidence:}

Mild TBI is a very common occurrence in children and adolescents ${ }^{16}$. Although there have been several censuses on concussion injuries in children and adolescents, it is believed to be largely under-reported since many individuals never seek care for their injury. Gessel et al. (2007) reported that mTBIs accounts for $8.9 \%$ of all high school athletic injuries ${ }^{17}$. Data from the U.S. National Hospital Ambulatory Medical Care Survey, obtained between 2002-2006, found that 144,000 children aged between 0-19 years ${ }^{18}$ presenting to the Emergency Department (ED) are related specifically to mTBI. The CDC reports that between 1.6 and 3.8 million sport-related concussions occur in the United States every year ${ }^{19}$ while Bakhos et al. (2010) reports that 200,000 athletes in the United Sates are seen at the ER every year, with $65 \%$ of the them being between the age of 5-18 years. Others report that up to $25 \%$ of concussion injuries in the 8-13 age group are found to be related to organized sports such as football, hockey, soccer, baseball 
and basketball while $75 \%$ of the injuries occur in the context of leisure activities such as bicycling, skiing, horse riding, sledding or play ground activities ${ }^{20}$.

In Canada, according to the Canadian Institute of Health Information, sports and recreational activities were the third leading cause of brain injuries that required hospitalization in the general population for the years $2003-2004^{21}$. In a study conducted to describe the nation-wide epidemiology of mTBI in Canada, it was found that 110 individuals per $100000(95 \%$ Confidence Interval (CI):80-140) reported a concussion and that those who did were younger than those who didn't (age 16-34 years) and more commonly male.. In the same study authors found that $54 \%$ of all reported concussion were sports-related (95\%CI: 39\%-67\%) ${ }^{22}$.

Locally, The Montreal Children's Hospital (MCH) Trauma Programs' statistics show that over 2500 children and adolescents with an mTBI are seen in the ED every year ${ }^{23}$. From that number, between $35 \%-40 \%$ are sustained during sport or recreational physical activity ${ }^{24}$.

\subsection{Etiology and major risk factors in children and youth:}

Mild TBI in children and youth is often associated with sports or recreational activities ${ }^{1}$ but can also be sustained during falls or motor vehicle accidents ${ }^{25}$.

There are several factors that have been reported as increasing the risk for sustaining an mTBI. The following section will present the ones considered relevant for our study population.

a. Age: Relative immaturity of the brain in children and adolescents along with decreased myelination $^{26}$, combined with thinner frontal and temporal bones, greater head to body ratio, with weaker neck muscles, makes them more vulnerable to concussions when they sustain an injury $^{27,28}$.

b. Previous injury: It has been noted that children and adolescents who sustain a head injury are at a higher risk (Odds Ration=1.7) of re-injury with-in 6 months of injury vs. any other type of injury $^{29}$. In a study conducted on collegiate athletes it was found that individuals with more than 3 previous concussions were 3.8 times more likely to sustain another injury compared to those with one or two previous injuries (2.8 times than those who sustained no injury) ${ }^{30}$. These findings were replicated in a study conducted in high school football players $^{31}$. 
c. Gender: In the context of sport-related concussions, girls are reported to have a higher risk of injury when compared to boys of a similar age practicing the same sport ${ }^{32,33}$. This could be due to the fact that females have less neck girth and lower head masses compared to their male counterparts, which leads to a greater risk of injury due to higher head-neck acceleration $^{34,35}$. This higher risk of $\mathrm{mTBI}$ has not been replicated in the general pediatric and adolescent population, where boys continue to represent a majority of the cases ${ }^{1,31}$.

d. Sports: Other risk factors in sports include organized sports as opposed to leisure activity, actual game vs. practice sessions, subgroups of high school athletes compared to collegiate or university level athletes ${ }^{27,36,37}$ Football is said to account for the highest rates of concussion injuries in the United States ${ }^{17}$. Soccer and basketball cause a high incidence of injuries amongst the girls. Finally, sports like ice hockey, rugby and lacrosse also cause high number of injuries $^{38,39}$.

\subsection{Patho-physiology of mTBI:}

An mTBI is currently considered more of a metabolic injury rather than a structural one ${ }^{40}$, although recent advances in neuro-imaging techniques could change this view. It is described as a patho-physiological cascade consisting of abrupt neuronal depolarization, that leads to release of excitatory neurotransmitters and ionic shifts, that further leads to changes in glucose metabolism and alters the cerebral blood flow which finally affects the axonal function ${ }^{40}$.

Many animal model studies describe the actual changes that occur in the animal brain during an mTBI ${ }^{11}$. The most popular model that helps researchers study the changes that take place during an injury is the Lateral Fluid Percussion (LPF) model $^{41}$. The experiment involves producing an injury to the animal brain (usually a rat) using a device that drives fluid against the intact dura mater which produces a small focal contusion and a small hemorrhage. The focal injury produced by the device is said to mimic a moderate to severe brain injury, and to produce secondary metabolic effects in other areas that are more distant ${ }^{41}$. This secondary metabolic inflammatory response is considered equivalent to an mTBI and may explain why symptoms may not be apparent immediately after injury but worsen over the first 6 to 24 hours after injury.

The cascade of events related to the mTBI that are seen in the rat model is illustrated in Figure 2.1 and detailed in the following paragraph. 


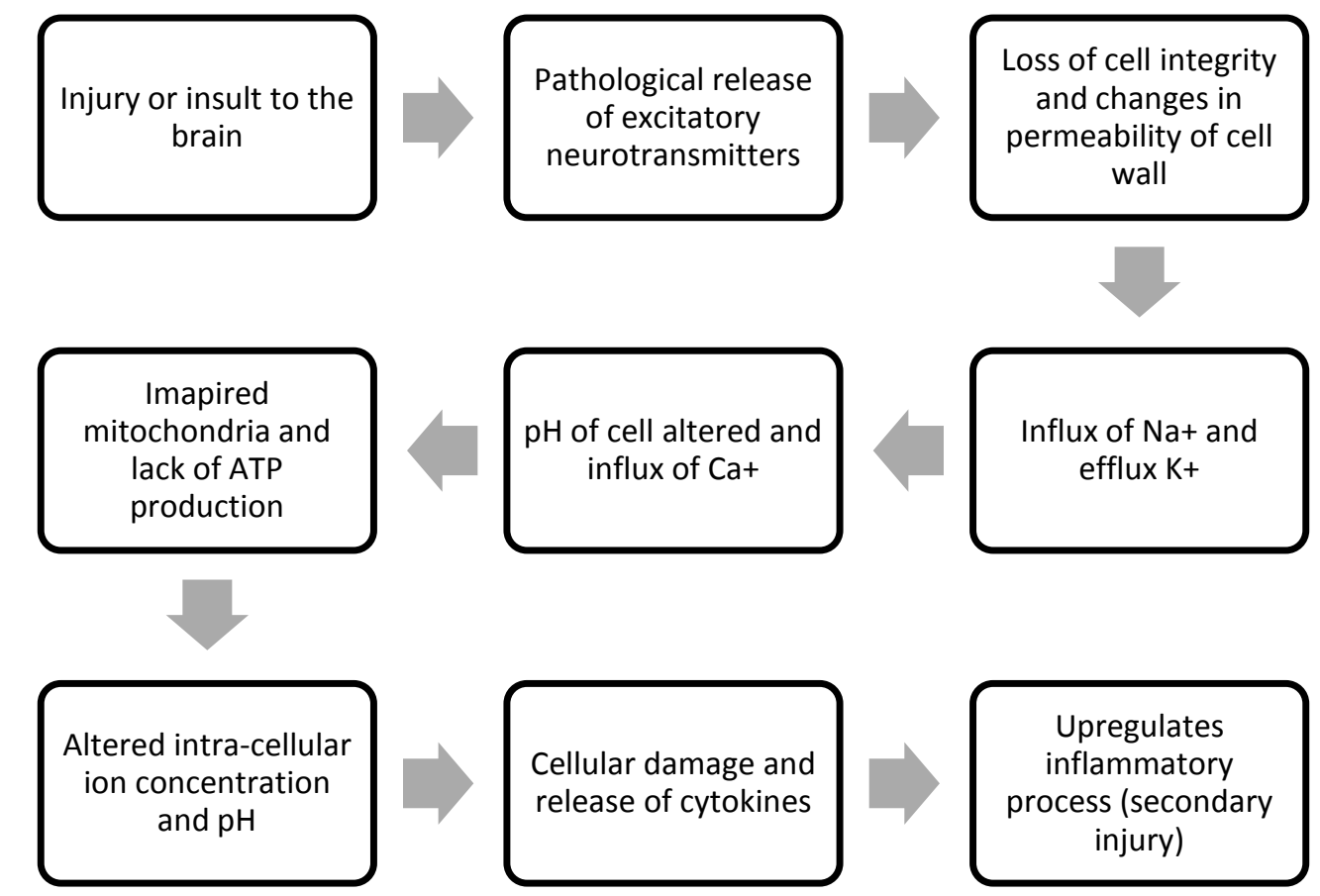

Figure 2.1: Patho-physiological cascade seen after an mTBI in the rat model ${ }^{11,42,43}$

The post-concussive effects of the injury cause an altered metabolic demand of the cells. The injury leads to an increased glucose requirement of the cells. The injured cells up regulate $\mathrm{Na} / \mathrm{K}$ ATPase proteins that are fueled by glucose. This restores the intracellular $\mathrm{pH}$ balance ${ }^{44}$. Hence, the glucose delivery via cerebral blood flow after a brain injury is crucial to restore the ion balance and cell membrane healing. The cerebral blood circulation is regulated by various mechanisms such as cerebral blood flow and flow metabolism coupling ${ }^{45}$. After a brain injury there is a restriction of cerebral blood flow and metabolic coupling disruption due to inappropriate cellular responses. ${ }^{11}$ When the demands are low cerebral perfusion and glucose delivery are sufficient to meet the baseline cellular needs, but a strain on the system causes an increase in metabolic demands, which leads to lack of cerebral blood flow that restricts delivery of glucose and basic demands of the cells are not met. This leads to a 'metabolic mismatch'11.

The increased metabolic needs combined with functional decrease in ATP production is the basis for acute management after an $\mathrm{mTBI}^{46}$. It has been found that cerebral glucose metabolism can remain abnormal for about 2 weeks in animal models. During the acute healing phase, where the metabolic needs are unmet by cerebral blood flow, the brain could be vulnerable to additional 
stress and even slight physical trauma could worsen the cell injury cascade causing a more severe condition. ${ }^{47}$ For example, prolonged concentration on a cognitive task or physical activities could lead to metabolic demands of the brain cell. Physical activity is known to change blood pressure and blood flow patterns that tend to exacerbate the symptoms ${ }^{48}$. This concept of brain vulnerability is the basis for cognitive (limited school activity) and physical rest (no strenuous activity) while symptomatic, especially during the early phase of healing ${ }^{49}$ aiming to minimize the cerebral glucose demands and avoiding additional strain on the cerebral blood flow $^{50}$.

Besides the above patho-physiology concussions may also cause Diffuse Axonal Injuries $(\mathrm{DAI})^{51}$. These changes may not be seen on initial presentation or with conventional neuroimaging. It is observed through Diffuse Tensor Imaging in patients who have persistent symptoms and presents as subtle white matter abnormalities ${ }^{52}$. There is an increased susceptibility during the first 24 hours after injury and a second injury during this period can induce sodium channelopathy which in turn increases already present axonal damage ${ }^{53}$.

Due to the nature of the injury described above and the patho-physiological changes, regular neuro-imaging technology such as CT and MRI scans are unable to detect subtle structural changes in the brain. Although some research imaging has shown changes ${ }^{54-62}$, diagnosis and management of mTBI are based largely on the clinical presentation of the child or adolescent.

\subsection{Clinical impact of an mTBI:}

The impact of an mTBI on children's functioning is usually described in 3 broad categories: selfreported symptoms, cognitive difficulties and motor impairments.

Common self-reported symptoms are usually organized around 4 main domains: physical, cognitive, emotional and sleep. They are presented in Table 2.1. Headaches are the most commonly reported symptom ${ }^{63}$. Cognitive and emotional self-reported symptoms are often confused with underlying pathologies and they may be exacerbated in children who already have an underlying mental disorder or learning disability ${ }^{10}$. 
Table 2.1: Common self-reported symptoms after a concussion ${ }^{4,10,36,64}$

\begin{tabular}{|l|l|l|l|}
\hline Physical & Cognitive & Emotional & Sleep disturbances \\
\hline$\bullet$ Headache & $\bullet$ Difficulty in concentrating & $\bullet$ Lability & $\bullet$ Inability to fall asleep \\
$\bullet$ Vomiting & $\bullet$ Disorientation & $\bullet$ Irritability & $\bullet$ Less/excess sleep \\
$\bullet$ Impairment of & $\bullet$ Slow reaction time & $\bullet$ Sadness & $\bullet$ Drowsiness \\
balance, gait and & $\bullet$ Anterograde/retrograde & \\
coordination & amnesia & \\
$\bullet$ Visual problems & $\bullet$ Repeats questions or & \\
$\bullet$ Vertigo & answers slowly & & \\
$\bullet$ Fatigue & $\bullet$ Poor neuropsychological test & & \\
$\bullet$ Photophobia & scores & & \\
$\bullet$ Phonophobia & & & \\
$\bullet$ Tinnitus & & & \\
\hline
\end{tabular}

Cognitive difficulties: Cognitive functioning including working memory, executive planning, attention and processing speed has been found to be affected in children and adolescents after an $\mathrm{mTBI}^{65-67}$. It has been recommended that while the individual is symptomatic cognitive rest (scholastic work and video games or text messaging) is mandatory ${ }^{64}$. Cognitive functioning was found to have obvious decrements 24 hours after injury in athletes, but was found to resolve approximately 10 days later ${ }^{68}$. There is existing debate on the clinical utility of the neuropsychological tests in the pediatric population especially related to the return to physical activity decision making ${ }^{69}$. Diffuse Tensor Imaging (DTI) and fMRI performed in conjunction with various neuropsychological tests, has been identified as an objective method of assessing recovery from cognitive functions ${ }^{52,70-74}$. These methods are presently used widely in research.

Motor impairments: Balance is the most commonly reported motor difficulty after an mTBI. It has been reported that We will discuss specific balance problems after mTBI in children in a 
later section of this review. Other reported motor problems are deficits in coordination and mobility $^{75,76}$.

\subsection{Assessment of functioning after an mTBI:}

Common clinical guidelines state that a thorough post-mTBI evaluation generally should include a complete history of pre-injury functioning, structural imaging in selected cases to rule out surgical emergencies, neuropsychological testing to ascertain cognitive function, standardized self-reported symptom assessment, as well as postural control and balance testing ${ }^{77}$. Though these recommendations should apply for both the adult and pediatric populations, it is generally recognized that some of the proposed assessment tools have yet to be validated in children ${ }^{64,78}$. Table 2.2 presents a summary of assessment tools commonly recommended to describe functioning and determine the level of recovery post-injury.

Table 2.2: Assessment tools and scales after an mTBI

\begin{tabular}{|c|c|c|c|}
\hline $\begin{array}{l}\text { Self-reported } \\
\text { symptoms }\end{array}$ & Cognitive Function & Balance & $\begin{array}{l}\text { Structural } \\
\text { imaging }\end{array}$ \\
\hline $\begin{array}{l}\text { - SCAT3 symptom } \\
\text { scale }^{4} \\
\text { - Post Concussion } \\
\text { Scale-Revised } \\
\text { (PCS-R) }{ }^{79} \\
\text { - Acute Concussion } \\
\text { Evaluation (ACE) } \\
\text { symptom scale }^{80}\end{array}$ & $\begin{array}{l}\text { - Immediate Post } \\
\text { Concussion } \\
\text { Assessment } \\
\text { (ImPACT) }{ }^{81} \\
\text { - CogSport }{ }^{82} \\
\text { - Head-Minder } \\
\text { Resolution Index }_{\text {- Automated }}^{83} \\
\text { Neuropsychological } \\
\text { Assessment Metrics } \\
\text { (ANAM) } \\
\text { - Standard paper pencil } \\
\text { tests of specific } \\
\text { functions }\end{array}$ & $\begin{array}{l}\text { - } \text { Balance Error } \\
\text { Scoring System } \\
(\text { BESS })^{85} \\
\text { - Bruininks-Oseretsky } \\
\text { Test of Motor } \\
\text { Proficiency-2 } \\
\text { edition, Balance } \\
\text { subtest (BOT-2) }\end{array}$ & $\begin{array}{l}\text { - Computerized } \\
\text { Tomography } \\
\text { (CT) scan } \\
\text { - Magnetic } \\
\text { Resonance } \\
\text { Imaging (MRI) }\end{array}$ \\
\hline
\end{tabular}


Several problems have been identified when using the available tools with the pediatric and adolescent population. For example, younger children and adolescents have been shown to under-report or over-report their symptoms on self-report scales, making it a less reliable method than in the adult population ${ }^{87}$.

Neuropsychological tests are useful and widely accepted for return to activities decisions ${ }^{64}$. In testing, the current scores are compared to the baseline scores, however they remain difficult to interpret unless administered by a neuropsychologist. Computer based tests have not been developed for children below the age of 12 years and there are no standard protocols for the administration of these tests ${ }^{10}$.

The balance tests commonly used are the BESS and BOT-2. The BESS measures static balance which may not be a true indicator for the actual balance of the individual ${ }^{88}$. Functional balance is not commonly measured in clinics as part of routine protocols.

Imaging studies are not found to be very useful as the injury is treated more as an metabolic injury. Neuroimaging is useful only when there is suspicion of a fracture or worsening of symptoms, or there is a focal neurological deficit. CT is the most commonly used imaging technique and useful within the first 24-48 hours after the injury to test for any intra-cranial hemorrhage ${ }^{89}$. MRI helps in detecting any cerebral contusion, petechial hemorrhage, or white matter injury ${ }^{90}$ but is of little help in characterizing more subtle lesions. Other neuro-imaging techniques have been used in research and appear promising, although not available to the clinician who has to make return to activities decisions ${ }^{91}$. These techniques may help predict recovery but further research and greater availability of this imaging modality is needed before it is recommended ${ }^{92,93}$.

Special considerations regarding the clinical impact of mTBI in children and adolescents:

a) Age: It is now recognized that children and adolescents take a longer time to recover after an mTBI. Typically adults and professional athletes are reported to return to baseline levels of functioning in 3-5 days after the injury, while collegiate athletes take about 5-7 days and the majority of younger adolescents need at least 10-14 days to recover ${ }^{94}$. 
Although very little is known about the recovery curve of younger children, it is currently postulated that they could require longer periods to achieve pre-injury functioning ${ }^{50}$. The reason for slower recovery is that the brain is still developing and vulnerable to stress and exertion as seen in the risk factors of an mTBI in the previous section. The developing brain is said to be more susceptible to pathological release of excitatory amino acid neurotransmitters (glutamate and aspartate) than in an adult brain ${ }^{95}$.

b) Gender: The gender of the individual is said to have an influence on the recovery of the individual from the injury ${ }^{50}$. In a meta-analysis study done by Farace et al., $(2000)^{96}$ with 20 clinical outcomes after a brain injury authors found that females have poorer outcomes in $85 \%$ of the tests as compared to their male counterparts.

Grady., (2010) ${ }^{50}$ noted that females are seen to perform better in verbal memory tests rather than on visual memory tests. In the same paper, the author reported that baseline scores on the neuropsychological tests were found to be lower for females compared to males and they showed greater decrease in reaction time as well as higher self-reported symptoms. But it is unclear whether this score difference is due to severity of injury or gender differences.

c) History of previous mTBI: Individuals with a history of greater than 3 mTBIs are known to have poorer prognosis and increased severity of injury ${ }^{31}$. This leads to decreased reaction times and higher risk for further injury ${ }^{30}$. Covassin et al., (2008) ${ }^{97}$ noted that there is a clear decrease in cognitive functions after 4 concussions as compared to individuals with a history of one concussion. Also, neuropsychological tests showed that individuals with at least 2 past concussions have poorer performances than those who have not suffered a concussion. Finally, balance testing showed that individuals with 2 or more concussions had a delayed healing time ${ }^{98}$.

\subsection{Return to physical activities guidelines:}

One of the ultimate goals of intervention programs after mTBI is the return to pre-injury levels of physical activity. Based on the above description of functioning and available clinical guidelines, return to physical activity decisions are made by various health professionals. The mainstay for the current guidelines is that the individual must be asymptomatic at rest and on exertion and all cognitive as well as other neurological difficulties must be resolved ${ }^{99}$. Cognitive tests are 
compared to pre-injury scores, if those are available, and if not, then they are compared to normal values for that age group. Exertion tests are done to ensure none of the symptoms such as headache, nausea or mental fogginess return during physical exertion ${ }^{99,100}$.

Concussion management and return to physical activity decisions are still challenging in children and adolescents. The Canadian Pediatric Society guidelines suggest that the children and adolescents should be asymptomatic at rest for several days before exertion testing is done ${ }^{100}$. The difficulty with such recommendations lies in the fact that it may be challenging to determine when a child is asymptomatic. As stated previously, relying on self-reported symptoms may lead to an incomplete portrait of recovery, but we lack the tools to assess more complete recovery. While there are more studies done with adolescents age 14-18 years, there is a lack of information regarding the recovery process of younger children. Currently, there is no validated return to physical activity guidelines in children ${ }^{87}$ and the existing ones are modeled on adult versions. A more conservative approach is suggested, the modalities of which remain to be defined.

The Zurich Guidelines for return to play is the most accepted and followed protocol for gradual return to physical activity after an mTBI and is presented in Table 2.3. The protocol is designed in such a way that progression through the steps are made every 24 hours, provided the individual is symptom free at that stage. If the symptoms are reported in any one stage of progression the individual is returned to the previous level for at least another 24 hours of rest. This protocol is structured to allow for the process of healing ${ }^{64}$.

Table 2.3: Zurich guidelines for Return to Play (RTP) ${ }^{4}$ Adapted from the paper

\begin{tabular}{|l|l|l|}
\hline Rehabilitation stage & $\begin{array}{l}\text { Functional exercise at each stage } \\
\text { of rehabilitation }\end{array}$ & Objective of each stage \\
\hline No activity & Symptom limited physical and & Recovery \\
& cognitive rest & \\
\hline
\end{tabular}




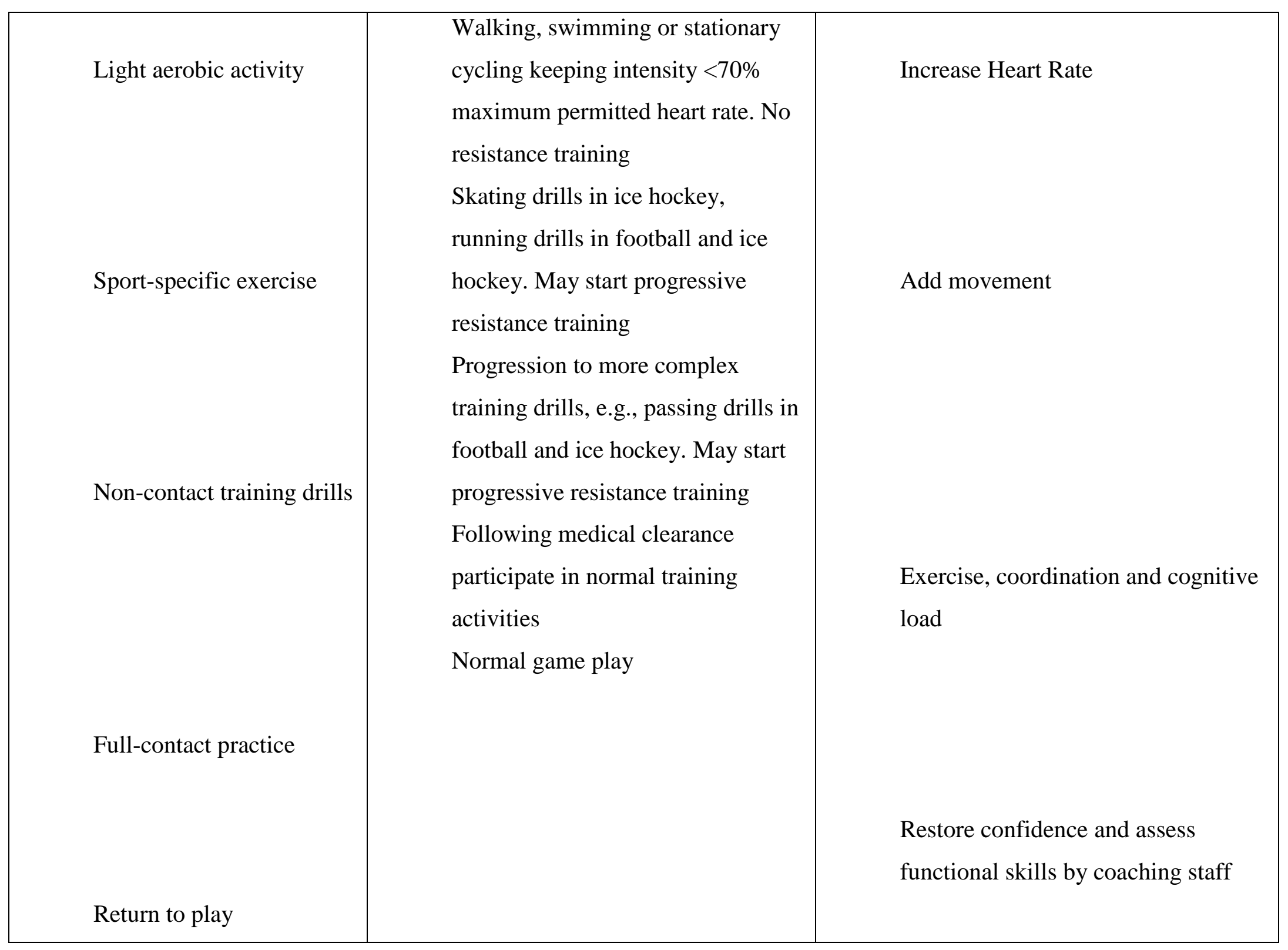




\subsection{Balance:}

Performance in exercise and physical activities has been described as an all-inclusive term that includes aspects of agility, balance, coordination, speed, strength, and endurance. Performance achievements in high level sports or physical activities requires greater balance and it has been reported that individuals who take part in these activities are found to have better balance abilities ${ }^{101}$. Lack of balance has also been reported to be a risk factor for injury and although it is a skill that can be retrained ${ }^{102}$, it is an important aspect to consider before returning individuals to physical activities post-injury. Poor balance at stages of recovery may have an impact on clinical decision making, where clinicians may consider delaying the rapid progression of return to physical activity.

\subsection{Definition of Balance:}

Postural stability or balance is the ability to control an individual's Center of Mass (CoM) in relationship to his Base of Support $(\mathrm{BoS})^{103}$. CoM is defined as a point that is at the center of the total body mass, which is determined by finding the weighted average of CoM of each body segment. BoS is defined as the area of the body that is in contact with the support surface ${ }^{103}$. Another connotation of balance is that, when the Line of Gravity (LoG), defined as the vertical line running through the Center of Gravity $(\mathrm{CoG}){ }^{104}$, falls within the BoS then the body is said to be well balanced. But when the LoG falls outside the BoS, it leads to imbalance. The human body counteracts this imbalance using muscular forces to prevent falling ${ }^{105}$. This is the concept of 'balance control' or 'postural control'.

\subsection{Static and Dynamic balance:}

Balance or postural control is said to be static or dynamic in nature ${ }^{106}$. Static balance refers to the ability to maintain the CoG over the BoS during quiet standing or sitting ${ }^{107}$. Dynamic balance otherwise known as 'moving balance' involves the maintenance of balance when the $\mathrm{CoG}$ and BoS are in motion such as a change in position of the body or the surface beneath ${ }^{106}$. The processes involved in postural control are reactive or compensatory, proactive or anticipatory or both $^{108,109}$. Reactive or compensatory responses occurs as a reaction to external forces that tend to displace the CoM of the body ${ }^{108}$. These forces are generally unexpected and are in response to 
instability such as a perturbation or a change in supporting surface ${ }^{106}$. Proactive or anticipatory reactions occur during in anticipation of an internally generated destabilization force caused due to the body's own movement ${ }^{108,110}$. Optimal balance requires both reactive and anticipatory responses such that the demands of the individual while either being stationary or moving is $\operatorname{met}^{106}$.

\subsection{Systems involved in maintaining postural control and balance:}

Postural control is not considered just a reflex response which is produced by activation of the sensory systems ${ }^{108}$. It is rather an assessment and control of the body in response to internal or external disturbances, by the central nervous system (CNS). Maintenance of postural control involves the use of muscular forces after obtaining feedback from the sensory systems ${ }^{111}$. Hence, it is thought of as a fundamental motor skill learned by the CNS over a period of time ${ }^{108}$.

The three main sources of sensory information used for postural control are visual, somatosensory (tactile, deep pressure, joint receptors and muscle proprioceptors) and vestibular $^{112,113}$. The following is a brief description of each and of its role in the control of posture.

1. Visual system: It measures the orientation of the eyes and head in relation to its surroundings and helps in perception of movement as well as provides stability during dynamic conflicts $^{114,115}$. Visual function of simple stimuli develops at an early age but perception of complex stimuli and of movement reaches adult levels at the age of 15 years ${ }^{116}$.

2. Somatosensory system: It provides information on the orientation of body parts in relation to each other as well as orients the body parts in relation to the supporting surface ${ }^{114}$. The somatosensory system matures around the age of 4-6 years ${ }^{117}$.

3. Vestibular system: It consists of three semi-circular canals and otolith organs called utricles and saccules. The semicircular canals detect angular acceleration during head movements, while otolith organs detect vertical orientation, linear movement and contribute to the sense of verticality ${ }^{118}$. The vestibular system helps maintain stable vision during head movement via the Vestibular Occular Reflex (VOR) by moving the eyes in the opposite direction to that of the head ${ }^{119}$. When the visual and somatosensory systems are intact the vestibular system plays a minor role in the maintenance of balance, acting as an internal reference for the other 
systems ${ }^{120,121}$. The primary role of the vestibular system during normal conditions is to provide independent and precise control of the head and eye positions which are critical in complex motor activities such as sports ${ }^{114}$. This system becomes crucial when the inputs from the visual and somatosensory systems becomes misleading or unavailable ${ }^{122}$. This system is highly reliable under such conditions to identify and avoid any misleading information and maintain orientation of the body in relation to gravity ${ }^{123}$. The vestibular system continues to mature through adolescence ${ }^{116}$.

\subsection{Development of postural control:}

The overall balance capabilities of the child increases from birth to the age of 6-10 years but only reaches complete maturation in adolescence. It has been noted in several studies that there is a improvement in balance control in children around the age of 7-8 years ${ }^{124}$. It is during these years that the child develops adult-like gait patterns and postural control strategies that involves head and trunk coordination ${ }^{125,126}$. It has been also concluded that children first learn the various postural control strategies and eventually learn to select the right postural strategy in anticipation of a particular movement, so as to maintain proper balance ${ }^{127}$.

In a study by Rival et al., (2005), it was shown that the ability to maintain postural stability during quiet standing with eyes closed, appears by the age of 6 years but continues to improve until age $10^{128}$. Sutherland et al., (1997), described immature walking and found that the step length, cadence and walking velocity show maturation until the age of 4 years. Step factor (step length divided by leg length) increases until the age of 4 years. Changes in velocity, cadence and step length is attributed to changes in limb length after the age of 4 years ${ }^{129}$.

\subsection{Balance after an MTBI:}

\subsubsection{Patho-physiology of balance problems after an MTBI:}

As described earlier mTBI is thought to be a metabolic injury. One theory that may explain balance disruptions in the context of this metabolic injury is that the injury causes a functional disturbance in the cortex and the reticular formation of the brain stem which usually work together to integrate, weigh, and respond to the constant incoming sensory information ${ }^{130}$. The main function of the reticular formation is that it is responsible for alertness, sleep, postural 
control, muscle tone and pain modulation ${ }^{131}$. Hence, any disturbance caused by the mTBI can result in autonomic, motor and postural impairments ${ }^{130,132}$. Any injury to the brain can lead to a loss of integration between the visual, somatosensory and vestibular systems which can leads to postural instability ${ }^{133}$. The symptoms that are associated with the lack of integration of the sensory systems involved in balance are dizziness, vertigo, tinnitus, light-headedness, blurring of vision or photophobia, all of which are also commonly reported after an mTBI ${ }^{132,134-137}$.

\subsubsection{Balance findings after an mTBI:}

Balance could be affected in mTBI due to the affection of a single sensory system or due to loss of communication between the three systems namely: visual, vestibular and somatosensory, that leads to postural instability ${ }^{133}$. Various studies have been done to show the balance deficits in individuals after an mTBI. Studies were chosen based on keywords such as balance, postural control, children and adolescents, mTBI and concussion. Papers were selected from MEDLINE, CINHAL, Pub Med databases. There is a paucity in literature investigating balance deficits in children and adolescents after an mTBI or concussion. Most studies have been done in collegiate athletes and young adults. Many studies have identified dynamic balance deficits seen at various stages of recovery after the injury, but very little is known about the mechanisms of these deficits. Although not exhaustive, Table 2.4 presents the recent studies performed with both children and young adults reporting findings related to balance after an mTBI.

The table is organised in the following order, the initial studies focus on clinical balance measures in children and adolescents, the consecutive studies are done in collegiate athletes and young adults where, balance is tested using high technology tools. Following studies highlight gait findings in young athletes with concussions under single task and dual task conditions. 
Table 2.4: Studies showing balance findings after an mTBI (static and dynamic balance)

\begin{tabular}{|c|c|c|c|c|c|c|}
\hline Author & Population & Sample Size & Measures used & Comparison & Outcomes & Results \\
\hline $\begin{array}{l}\text { Gagnon et } \\
\text { al., }(2004)^{9}\end{array}$ & $\begin{array}{l}\text { 7-16 yrs (mean } \\
12.2 \pm 2.8 \text { yrs) } \\
\text { children with } \\
\text { MTBI, Avg. GCS } \\
\text { score 14.8, normal } \\
\text { on neurological } \\
\text { exam on discharge }\end{array}$ & $\begin{array}{l}80 \text { children } \\
\text { (40 MTBI } \\
\text { group, } 40 \\
\text { uninjured) }\end{array}$ & $\begin{array}{l}\text { Balance subtest of } \\
\text { BOTMP-2, } \\
\text { Postural Stress } \\
\text { Test(PST), P- } \\
\text { CTSIB, Rivermead } \\
\text { PCS }\end{array}$ & $\begin{array}{l}\text { Uninjured } \\
\text { friends of } \\
\text { children } \\
\text { with MTBI } \\
\text { matched for } \\
\text { age, sex and } \\
\text { Level of PA }\end{array}$ & $\begin{array}{l}\text { Balance scores at } 1 \\
\text { week, } 4 \text { weeks and } 12 \\
\text { weeks post injury }\end{array}$ & $\begin{array}{l}\text { MTBI children } \\
\text { performed } \\
\text { significantly worse } \\
\text { than uninjured } \\
\text { children, } \\
\text { BOTMP(P<0.001) } \\
\text { and PST }(\mathrm{P}=0.031) \text {, } \\
\text { and tandem } \\
\text { position with eyes } \\
\text { closed(P=.05) on } \\
\text { the } \mathrm{P}-\mathrm{CTSIB} \text { at } 12 \\
\text { weeks after injury }\end{array}$ \\
\hline $\begin{array}{l}\text { Gagnon et } \\
\text { al., }(2001)^{138}\end{array}$ & $\begin{array}{l}11 \text { year old child } \\
\text { (female) }\end{array}$ & Case study & $\begin{array}{l}\text { Balance subtest of } \\
\text { BOTMP-2, } \\
\text { Postural Stress } \\
\text { Test(PST), P- } \\
\text { CTSIB, Rivermead } \\
\text { PCS(RPCS) }\end{array}$ & $\begin{array}{l}\text { No } \\
\text { comparison }\end{array}$ & $\begin{array}{l}\text { Balance scores } 5 \text { days } \\
\text { before injury, at } 1 \\
\text { week, } 4 \text { weeks and } 12 \\
\text { weeks post-injury }\end{array}$ & $\begin{array}{l}\text { One week after } \\
\text { MTBI, there was a } \\
\text { decrease in the } \\
\text { BOTMP scores } \\
\text { compared to } \\
\text { previous pre-injury } \\
\text { levels, at } 4 \text { weeks }\end{array}$ \\
\hline
\end{tabular}




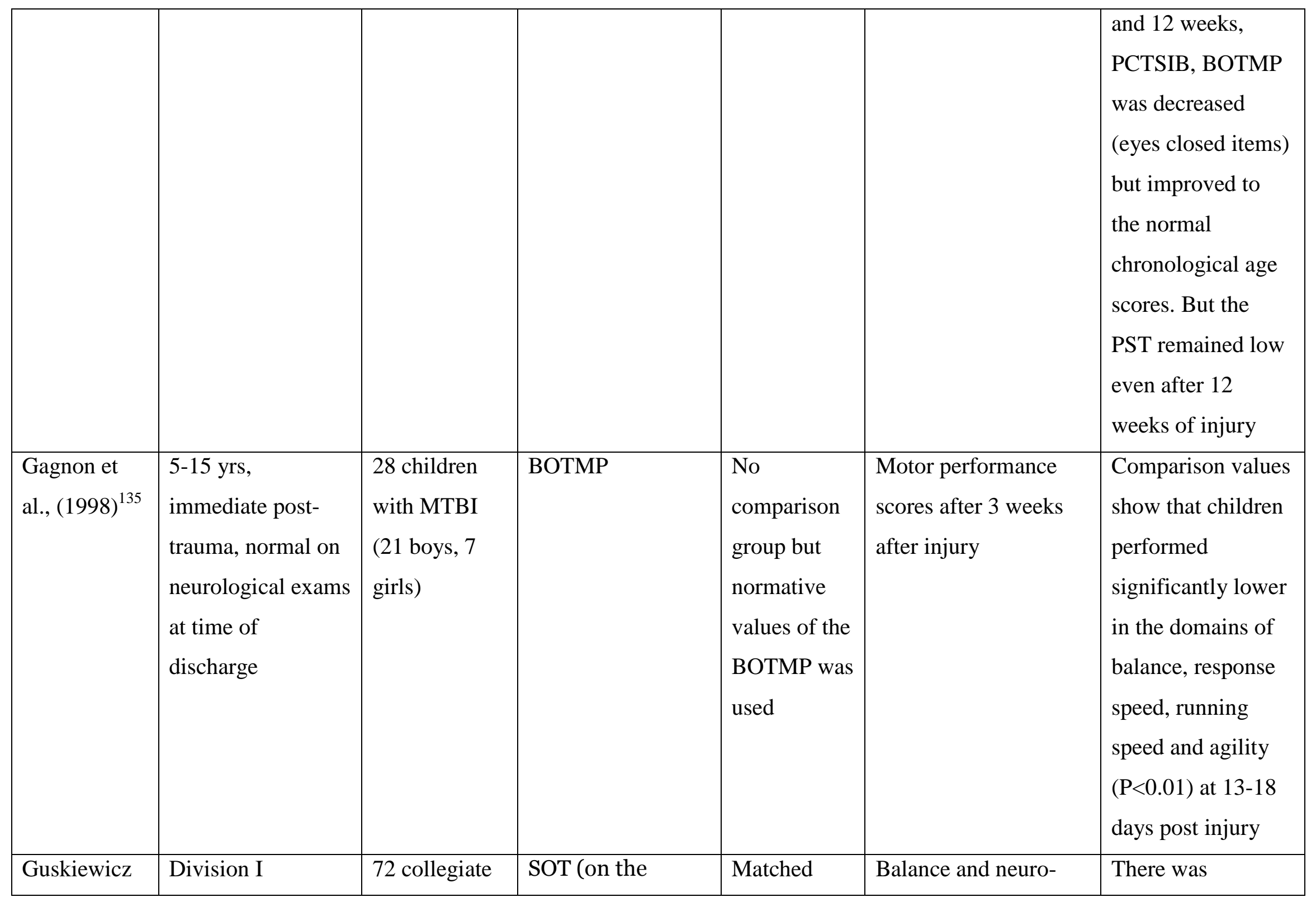




\begin{tabular}{|c|c|c|c|c|c|c|}
\hline $\begin{array}{l}\text { et } \\
\text { al.,(2001) }\end{array}$ & $\begin{array}{l}\text { collegiate athletes } \\
\text { sustained a } \\
\text { concussion }\end{array}$ & $\begin{array}{l}\text { athletes(36 in } \\
\text { each group) }\end{array}$ & $\begin{array}{l}\text { NeuroCom Smart } \\
\text { Balance Master } \\
\text { System) and BESS } \\
\text { Neurocognitive } \\
\text { functioning } \\
\text { measured using- } \\
\text { Trail-Making } \\
\text { Test, Wechsler } \\
\text { Digit Span Test, } \\
\text { Stroop Color } \\
\text { Word Test, and } \\
\text { Hopkins Verbal } \\
\text { Learning Test. }\end{array}$ & $\begin{array}{l}\text { with age, } \\
\text { height and } \\
\text { weight }\end{array}$ & $\begin{array}{l}\text { cognitive findings at } \\
\text { days } 1,3 \text { and } 5 \text { post } \\
\text { injury }\end{array}$ & $\begin{array}{l}\text { significantly } \\
\text { decreased scores in } \\
\text { balance findings on } \\
\text { day } 1 \text { post injury, } \\
\text { using the BESS } \\
\text { and SOT compared } \\
\text { to pre-season and } \\
\text { scores of the } \\
\text { control group }\end{array}$ \\
\hline
\end{tabular}




\begin{tabular}{|c|c|c|c|c|c|c|}
\hline & & & & & & $\begin{array}{l}\text { and more M1 } \\
\text { cortical inhibition }\end{array}$ \\
\hline $\begin{array}{l}\text { Slobounov et } \\
\text { al., }(2005)^{140}\end{array}$ & $\begin{array}{l}48 \text { athletes } 18-25 \\
\text { yrs males pre- } \\
\text { injury testing, } 8 \\
\text { suffered a } \\
\text { concussion } 6 \\
\text { months later }\end{array}$ & $\begin{array}{l}60 \text { athletes } \\
\text { (12 normal } \\
\text { athletes( } \\
\text { mean age } 20 \\
\text { yrs), } 8 \\
\text { concussion) }\end{array}$ & $\begin{array}{l}\text { Virtual reality } \\
\text { environment in } \\
\text { conjunction with } \\
\text { AMTI force plate } \\
\text { and motion } \\
\text { tracking (Flock Of } \\
\text { Birds FOB) } \\
\text { technologies }\end{array}$ & $\begin{array}{l}\text { Uninjured } \\
\text { athletes }\end{array}$ & $\begin{array}{l}\text { Postural responses to } \\
\text { visual field motion } \\
\text { tested on day } 3,10 \text { and } \\
30 \text { after injury }\end{array}$ & $\begin{array}{l}\text { Area of CoP did } \\
\text { not change from } \\
\text { day } 3-30 \text { with } \\
\text { respect to pre- } \\
\text { injury data(P>0.5). } \\
\text { But balance } \\
\text { deficits induced by } \\
\text { visual field motion } \\
\text { was present even } \\
30 \text { days post injury }\end{array}$ \\
\hline $\begin{array}{l}\text { Resch et al., } \\
(2011)^{141}\end{array}$ & $\begin{array}{l}\text { Healthy college } \\
\text { athletes who } \\
\text { suffered a } \\
\text { concussion( } 10 \\
\text { male, } 10 \text { female) }\end{array}$ & 20 atheletes & $\begin{array}{l}\text { SOT on NeuroCom } \\
\text { Smart Balance } \\
\text { Master System, } \\
\text { cognitive task }\end{array}$ & $\begin{array}{l}\text { No } \\
\text { comparison }\end{array}$ & $\begin{array}{l}2 \text { sessions of } \\
\text { testing(one under dual } \\
\text { task and one single } \\
\text { task) } \\
\text { Balance SOT } 6 \\
\text { conditions, cognitive } \\
\text { task response time and } \\
\text { accuracy }\end{array}$ & $\begin{array}{l}\text { Balance improved } \\
\text { during } 2 \text { dual task } \\
\text { conditions (fixed } \\
\text { support and fixed } \\
\text { visual } \\
\text { reference }(\mathrm{P}<0.05) \\
\text { and sway visual } \\
\text { reference }(\mathrm{P}<.001)) \text {, } \\
\text { choice errors were } \\
\text { more numerous in }\end{array}$ \\
\hline
\end{tabular}




\begin{tabular}{|c|c|c|c|c|c|c|}
\hline & & & & & & $\begin{array}{l}\text { dual task vs. single } \\
\text { task }(\mathrm{P}=.03)\end{array}$ \\
\hline $\begin{array}{l}\text { Parker et al., } \\
(2008)^{142}\end{array}$ & $\begin{array}{l}\text { Grade } 2 \text { concussed } \\
\text { athletes }\end{array}$ & $\begin{array}{l}56 \\
\text { participants } \\
28 \text { in each } \\
\text { group(14 } \\
\text { athletes and } \\
14 \text { non } \\
\text { athletes) }\end{array}$ & $\begin{array}{l}\text { Motion Analysis } \\
\text { System (Motion } \\
\text { Analysis } \\
\text { Corporation, Santa } \\
\text { Rosa, CA) }\end{array}$ & $\begin{array}{l}\text { Matched for } \\
\text { age, gender, } \\
\text { height, } \\
\text { weight and } \\
\text { physical } \\
\text { activity }\end{array}$ & $\begin{array}{l}\text { Gait and cognitive } \\
\text { dual task measured at } \\
48 \text { hours, } 5,14 \text { and } 28 \\
\text { days post injury }\end{array}$ & $\begin{array}{l}\text { Athletes walked } \\
\text { slower and swayed } \\
\text { more and faster as } \\
\text { compared to non- } \\
\text { athletes } \\
\text { irrespective of } \\
\text { being injured or } \\
\text { uninjured. Athletes } \\
\text { demonstrated gait } \\
\text { imbalances as well. }\end{array}$ \\
\hline $\begin{array}{l}\text { Keffelgaard } \\
\text { et al., } \\
(2012)^{143}\end{array}$ & $\begin{array}{l}\text { Individuals with an } \\
\text { MTBI 16-65 yrs, } \\
\text { 13-15 GCS, LOC } \\
<30 \text { mins }\end{array}$ & $\begin{array}{l}52 \text { cohort } \\
\text { subjects, } 29 \text { at } \\
4 \text { years of } \\
\text { follow up }\end{array}$ & $\begin{array}{l}\text { Self-reported } \\
\text { balance problems, } \\
\text { R-PCS, } \\
\text { Posturography, } \\
\text { Dynamic Gait } \\
\text { Index, walking } \\
\text { speed and six } \\
\text { minute walk test }\end{array}$ & $\begin{array}{l}\text { No } \\
\text { comparison } \\
\text { group }\end{array}$ & $\begin{array}{l}1 \text { year follow up and } 4 \\
\text { years follow up of } \\
\text { balance measures and } \\
\text { PCS scores }\end{array}$ & $\begin{array}{l}\text { Self-reposted } \\
\text { balance problems } \\
\text { were reported in } \\
31 \% \text { of individuals } \\
\text { that correlated to } \\
\text { the PCS scores. } \\
\text { Performance based } \\
\text { tests showed a } \\
\text { correlation of P= } \\
0.70 \text { on walking }\end{array}$ \\
\hline
\end{tabular}




\begin{tabular}{|c|c|c|c|c|c|c|}
\hline & & & & & & $\begin{array}{l}\text { speed test and } \\
\mathrm{P}=0.43 \text { on the dual } \\
\text { task. }\end{array}$ \\
\hline $\begin{array}{l}\text { Catena et al., } \\
(2007)^{144}\end{array}$ & $\begin{array}{l}\text { Grade } 2 \\
\text { concussion with a } \\
\text { mean age of } \\
22 \pm 4.46 \text { yrs }\end{array}$ & $\begin{array}{l}28 \text { individuals } \\
\text { (14 in each } \\
\text { group) }\end{array}$ & $\begin{array}{l}\text { Motion Analysis } \\
\text { Systems (Motion } \\
\text { Analysis } \\
\text { Corporation, Santa } \\
\text { Rosa, CA, USA), } \\
\text { dual task was the } \\
\text { reaction time task } \\
\text { and sequential } \\
\text { Q\&A task }\end{array}$ & $\begin{array}{l}\text { Non-injured } \\
\text { matched for } \\
\text { age, sex, } \\
\text { height and } \\
\text { weight }\end{array}$ & $\begin{array}{l}\text { Spatial and temporal } \\
\text { parameters of gait } \\
\text { measures, along with } \\
\text { whole body CoM and } \\
\text { CoP trajectories }\end{array}$ & $\begin{array}{l}\text { Concussed } \\
\text { individuals were } \\
\text { seen to adopt } \\
\text { conservative gait } \\
\text { strategies } \\
\text { compared to } \\
\text { uninjured } \\
\text { individuals. Signs } \\
\text { of instability were } \\
\text { seen with CoM } \\
\text { deviations in the } \\
\text { coronal plane with } \\
\text { 13\% increase } \\
\text { during Q\&A and } \\
26 \% \text { increase } \\
\text { during dual task } \\
\text { performance } \\
\text { compared to } \\
\text { uninjured }\end{array}$ \\
\hline
\end{tabular}




\begin{tabular}{|c|c|c|c|c|c|c|}
\hline & & & & & & participants \\
\hline $\begin{array}{l}\text { Catena et al., } \\
(2011)^{145}\end{array}$ & $\begin{array}{l}\text { Grade } 2 \\
\text { concussion avg. } \\
\text { age } 21 \text { yrs }\end{array}$ & $\begin{array}{l}20 \text { athletes } \\
\text { (10 in each } \\
\text { group) }\end{array}$ & $\begin{array}{l}8 \text { camera Motion } \\
\text { Analysis } \\
\text { System(Motion } \\
\text { Analysis } \\
\text { Corporation, Santa } \\
\text { Rosa, CA, USA) }\end{array}$ & $\begin{array}{l}\text { Matched for } \\
\text { age, gender, } \\
\text { height, } \\
\text { weight, level } \\
\text { of education } \\
\text { and athletic } \\
\text { participation }\end{array}$ & $\begin{array}{l}\text { Single level walking, } \\
\text { auditory Stroop test. } \\
\text { Dynamic balance } \\
\text { control during gait } \\
\text { was measured along } \\
\text { with the interaction } \\
\text { between CoM and } \\
\text { CoP recorded }\end{array}$ & $\begin{array}{l}\text { There was } \\
\text { decreased } \\
\text { performance seen } \\
\text { in the concussion } \\
\text { group immediately } \\
\text { after injury. At day } \\
1 \text { reaction time } \\
\text { deficiencies were } \\
\text { seen with reduced } \\
\text { dynamic balance } \\
\text { control. There was } \\
\text { no such correlation } \\
\text { in the control } \\
\text { group }\end{array}$ \\
\hline $\begin{array}{l}\text { Sosnoff et } \\
\text { al., }(2011)^{146}\end{array}$ & $\begin{array}{l}\text { Individuals } \\
\text { diagnosed with } \\
\text { MTBI }\end{array}$ & $\begin{array}{l}224 \\
\text { individuals } \\
\text { with } 62 \\
\text { having at least } \\
1 \text { history of } \\
\text { concussion }\end{array}$ & SOT & $\begin{array}{l}\text { No } \\
\text { comparison } \\
\text { group. But } \\
\text { comparison } \\
\text { was made } \\
\text { between } \\
\text { history of }\end{array}$ & $\begin{array}{l}4 \text { components of } \\
\text { postural dynamics } \\
\text { were calculated } \\
\text { through CoP } \\
\text { excursions in the AP } \\
\text { and ML axis of each } \\
\text { condition }\end{array}$ & $\begin{array}{l}\text { Minimal } \\
\text { differences }(\mathrm{P}>0.5) \\
\text { was noted in the } \\
\text { SOT indices in } \\
\text { both groups of } \\
\text { individuals. In the } \\
\text { group with } \mathrm{h} / \mathrm{o}\end{array}$ \\
\hline
\end{tabular}




\begin{tabular}{|c|c|c|c|c|c|c|}
\hline & & & & $\begin{array}{l}\text { concussion } \\
\text { vs. no } \\
\text { history of } \\
\text { concussion }\end{array}$ & & $\begin{array}{l}\text { concussion AP } \\
\text { postural } \\
\text { irregularity } \\
\text { decreased as } \\
\text { postural difficulty } \\
\text { increased and the } \\
\text { group without h/o } \\
\text { MTBIs displayed } \\
\text { increased postural } \\
\text { irregularity in the } \\
\text { ML direction }\end{array}$ \\
\hline
\end{tabular}




\begin{tabular}{|c|c|c|c|c|c|c|}
\hline $\begin{array}{l}\text { Slobounov et } \\
\text { al., }(2008)^{147}\end{array}$ & $\begin{array}{l}12 \text { student athletes } \\
\text { avg. age } 20.95 \text { yrs, } \\
\text { Were cleared at } \\
\text { day } 30 \text { on } \\
\text { neurological and } \\
\text { neuropsychological } \\
\text { tests and clinical } \\
\text { symptom } \\
\text { resolution }\end{array}$ & $\begin{array}{l}160 \text { total at } \\
\text { risk, } 30 \\
\text { suffered grade } \\
1 \text { MTBI } \\
\text { within } 6 \\
\text { months }\end{array}$ & $\begin{array}{l}\text { Advanced } \\
\text { Mechanical } \\
\text { Technology } \\
\text { Inc.(AMTI) } \\
\text { force plates }\end{array}$ & $\begin{array}{l}\text { No } \\
\text { comparison }\end{array}$ & CoP was analysed & $\begin{array}{l}\text { There was no } \\
\text { significant } \\
\text { difference seen in } \\
\text { CoP measures at } \\
30 \text { days post } \\
\text { injury(P>.05) } \\
\text { There was no } \\
\text { difference seen in } \\
\text { the Virtual Time to } \\
\text { Contact(VTC) } \\
\text { shape, distribution, } \\
\text { nominal values } \\
\text { during the standing } \\
\text { still postural tasks } \\
\text { irrespective of } \\
\text { vision } \\
\text { There was a } \\
\text { significant } \\
\text { difference in the } \\
\text { VTC absolute } \\
\text { range, range of } \\
\text { VTC deflection }\end{array}$ \\
\hline
\end{tabular}




\begin{tabular}{|c|c|c|c|c|c|c|}
\hline & & & & & & $\begin{array}{l}\text { points at } 30 \text { days } \\
\text { post injury }\end{array}$ \\
\hline $\begin{array}{l}\text { Parker et al., } \\
(2007)^{148}\end{array}$ & $\begin{array}{l}\text { Grade } 2 \\
\text { concussion college } \\
\text { aged athletes }\end{array}$ & $\begin{array}{l}58 \text { college } \\
\text { athletes( } 29 \text { in } \\
\text { each group) }\end{array}$ & $\begin{array}{l}\text { Motion Analysis } \\
\text { Systems (Motion } \\
\text { Analysis } \\
\text { Corporation, Santa } \\
\text { Rosa, CA, USA), } \\
\text { dual task with } \\
\text { ImPACT and } \\
\text { neuropsychological } \\
\text { tests }\end{array}$ & $\begin{array}{l}\text { Normal } \\
\text { individuals } \\
\text { matched for } \\
\text { age, sex, } \\
\text { height, } \\
\text { weight, PA }\end{array}$ & $\begin{array}{l}\text { Correlation } \\
\text { coefficients between } \\
\text { gait parameters and } \\
\text { neuropsychological } \\
\text { tests, gait stability and } \\
\text { post concussion } \\
\text { recovery curves over } \\
28 \text { days }\end{array}$ & $\begin{array}{l}\text { There was not a } \\
\text { very high } \\
\text { significance } \\
\text { between } \\
\text { neuropsychological } \\
\text { test and gait } \\
\text { variables and the } \\
\text { recovery curve and } \\
\text { the gait domain } \\
\text { were observed } \\
\text { independently }\end{array}$ \\
\hline $\begin{array}{l}\text { Catena et al., } \\
(2009)^{149}\end{array}$ & $\begin{array}{l}\text { Concussed athletes } \\
\text { avg. age } 21.5 \pm 3.3 \\
\text { yrs }\end{array}$ & $\begin{array}{l}60 \text { athletes } \\
\text { (30(14 female } \\
\text { and } 16 \text { male) } \\
\text { in each group) }\end{array}$ & $\begin{array}{l}8 \text { camera Motion } \\
\text { Analysis } \\
\text { System(Motion } \\
\text { Analysis } \\
\text { Corporation, Santa } \\
\text { Rosa, CA, USA) }\end{array}$ & $\begin{array}{l}\text { Matched for } \\
\text { age, gender, } \\
\text { height, } \\
\text { weight, level } \\
\text { of education } \\
\text { and athletic } \\
\text { participation }\end{array}$ & $\begin{array}{l}\text { Single level walking } \\
\text { gait parameters } \\
\text { (spatial and temporal), } \\
\text { attention divided } \\
\text { walking, obstacle } \\
\text { clearance recorded at } \\
48 \text { hrs, 6th, 14th and } \\
28 \text { th day post injury }\end{array}$ & $\begin{array}{l}\text { At } 48 \text { hrs, } \\
\text { concussion group } \\
\text { walked slower and } \\
\text { there was less } \\
\text { motion seen in the } \\
\text { sagittal plane } \\
\text { during divided } \\
\text { attention. The } \\
\text { obstacle clearance }\end{array}$ \\
\hline
\end{tabular}




\begin{tabular}{|c|c|c|c|c|c|c|}
\hline & & & & & & $\begin{array}{l}\text { task showed great } \\
\text { difference between } \\
\text { the two groups at } \\
48 \text { hrs and 6th day } \\
\text { but subsequently } \\
\text { there was less ML } \\
\text { motion of the CoM } \\
\text { in the concussion } \\
\text { group }\end{array}$ \\
\hline $\begin{array}{l}\text { Martini et } \\
\text { al., }(2011)^{8}\end{array}$ & $\begin{array}{l}\text { Concussion avg. } \\
\text { age of } 20.8 \pm 1.94 \\
\text { yrs }\end{array}$ & $\begin{array}{l}68 \text { individuals } \\
\text { ( } 28 \text { concussed } \\
\text { and } 40 \text { non } \\
\text { concussed) }\end{array}$ & $\begin{array}{l}\text { GAITRite (CIR } \\
\text { System Inc., USA) } \\
\text { Dual task with } \\
\text { Brooks Visuo- } \\
\text { spatial cognitive } \\
\text { task }\end{array}$ & $\begin{array}{l}\text { Individuals } \\
\text { with no h/o } \\
\text { concussion }\end{array}$ & $\begin{array}{l}\text { Gait under single and } \\
\text { dual task } \\
\text { conditions(Normalized } \\
\text { velocity, step length, } \\
\text { stride width, no of } \\
\text { correct from cognitive } \\
\text { task and time in SLS } \\
\text { and DLS for obstacle } \\
\text { clearance }\end{array}$ & $\begin{array}{l}\text { Individuals with } \\
\text { h/o concussion } \\
\text { spend more time in } \\
\text { DLS and } \\
\text { significantly less } \\
\text { time in SLS. They } \\
\text { also had slower } \\
\text { gait velocity. there } \\
\text { was a negative } \\
\text { correlation } \\
\text { between no. of } \\
\text { concussions and } \\
\text { time in SLS and }\end{array}$ \\
\hline
\end{tabular}




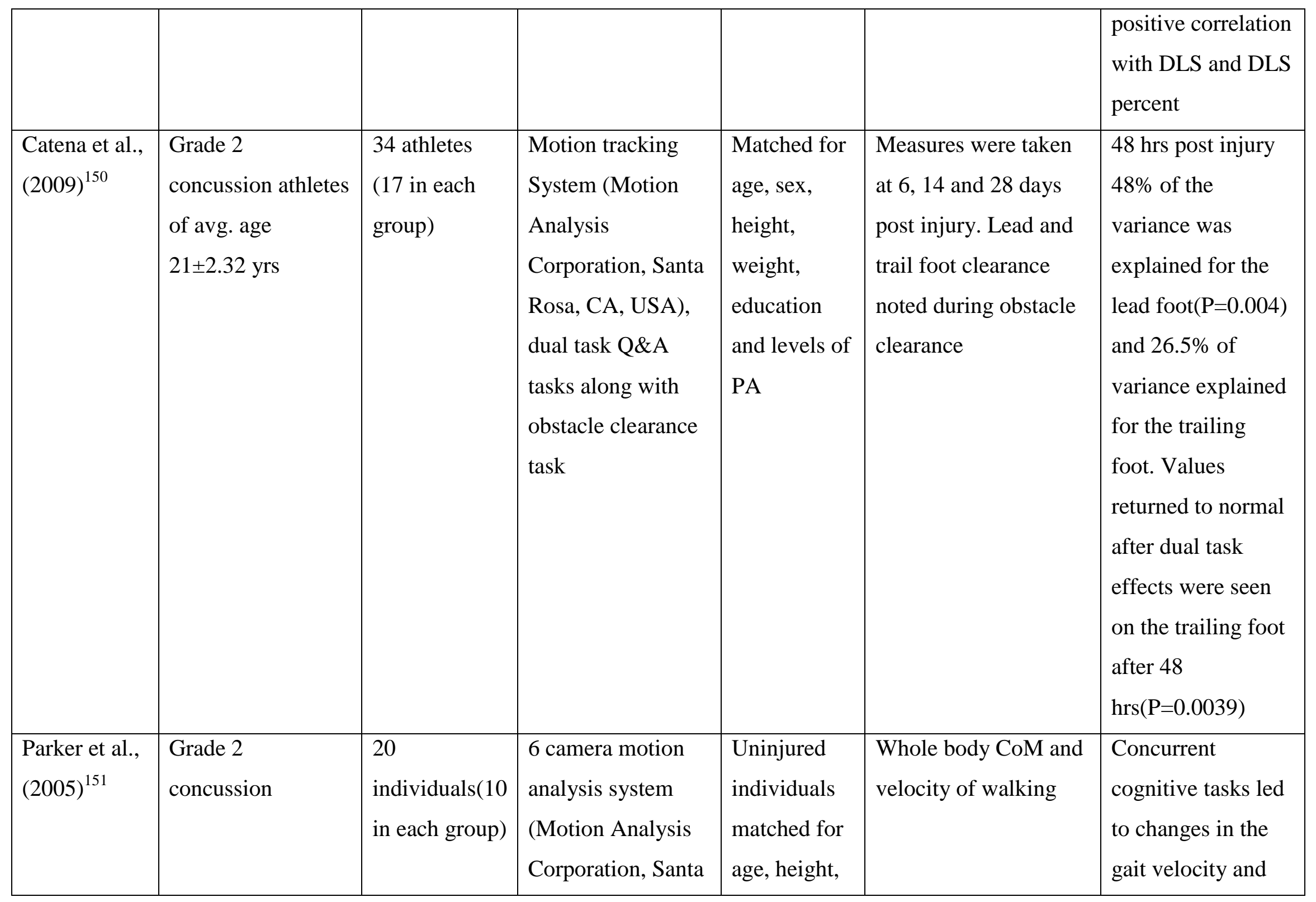




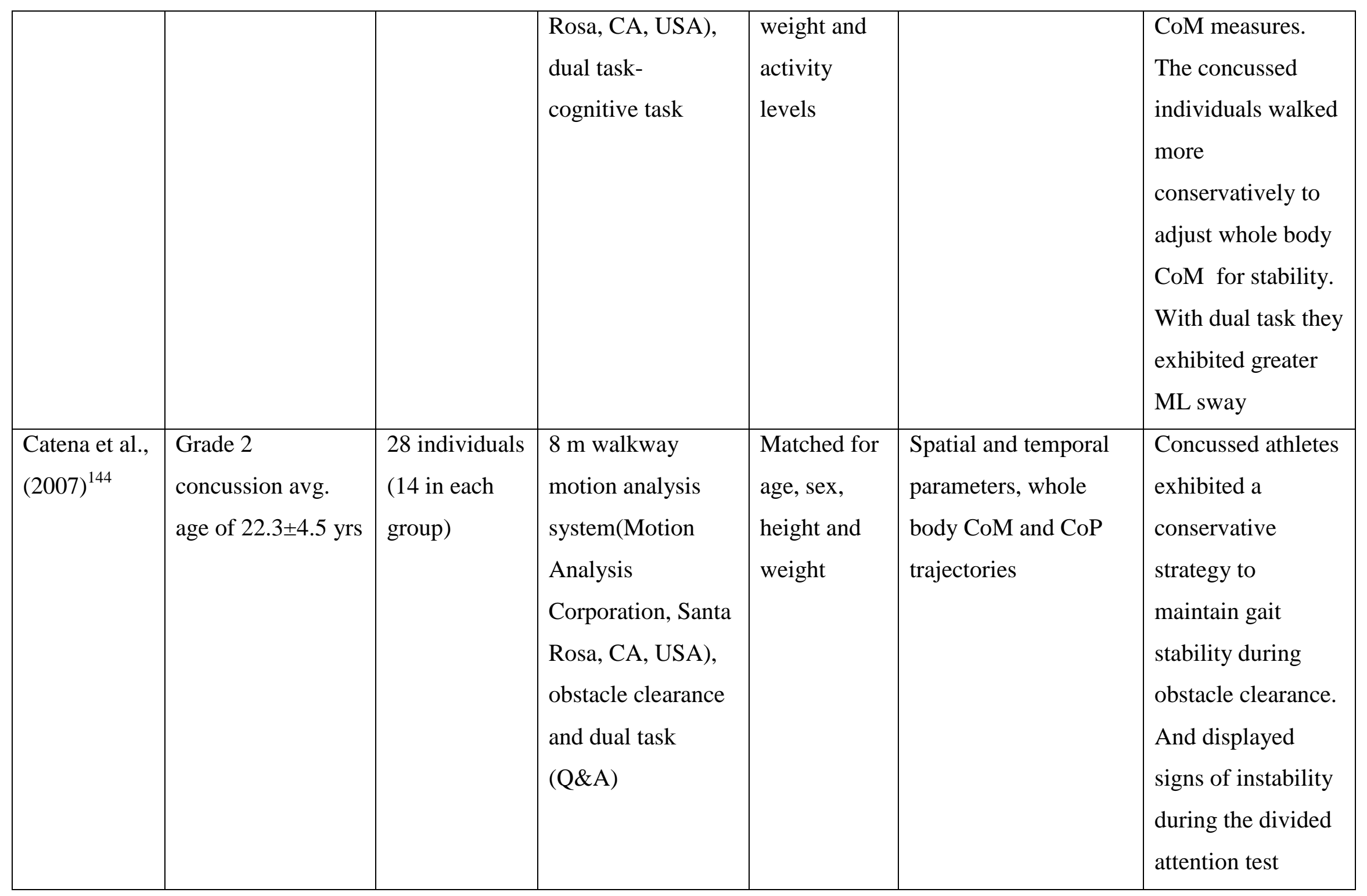


Abbreviations: Avg.: Average, yrs: years, hrs: hours, h/o: History of, PA: Physical activity, BOTMP: Bruininks- Oseretsky Test for Motor Proficiency, PCTSIB: Paediatric Clinical test for Sensory Integration of Balance, SOT: Sensory Organisation Test, PCS: Post Concussion Symptom Scale, CoP: Center of Pressure, AP: Antero-posterior, ML: Medio-lateral, CoM: Center of Mass, DLS: double leg stance, SLS: single leg stance, AMTI: Advanced Mechanical Technologies Inc. 
Gagnon et al. (2004) showed that children continue to have balance deficits even after 12 week post-injury. Authors recommend that these deficit should be taken into account when planning return to activity guidelines especially in activities that require greater balance skills ${ }^{9}$. Slobonov et al., (2005) concluded that there is a residual sensory integration dysfunction at least 30 days post injury in concussed individuals due to deficits in postural control seen with visual field conflicts ${ }^{140}$. Another study by De Beaumont et al. (2011) ${ }^{139}$ showed that concussions are associated with changes in postural control and M1 intra-cortical inhibition captured using transcranial magnetic stimulation. They found that individuals with concussion continued to have slow CoP oscillations that were random. Individuals with a history of concussion tested after six months of injury showed altered postural dynamics measured using the Sensory Organisation Test (SOT) compared to those with no history of concussions. It was concluded that postural control deficits tend to persist long after the acute stage of injury resolution ${ }^{146}$.

It is also found that concussions have observable and measurable effect on gait stability and control $^{144}$. Various authors have concluded that there is a requirement of a more sensitive method to test any additional balance deficits that may not be detected on regular testing and gait measures under dual task paradigms are said to be sensitive measures to capture residual deficits $^{133}$. Resch et al., 2011 concluded that balance is either maintained or improved using dual task paradigms. Another study done by Catena et al., (2009) ${ }^{149}$ concluded that divided attention while walking and obstacle crossing is able to better distinguish gait adaptations immediately after an mTBI. Parker et al., 2007 concluded that a multi-factorial approach is warranted that includes cognitive and motor tasks, in order to fully understand the effects of a concussion and to determine appropriate and safe return to activity guidelines ${ }^{148}$. Also, Catena et al., 2007 stated that it is useful to use gait paradigms with cognitive testing to detect gait stability in younger individuals who have sustained a concussion ${ }^{6}$.

\subsection{Assessment of balance in children and adolescents after an mTBI:}

Balance in mTBI individuals has been assessed under both static and dynamic conditions. Clinical measures of balance, recommended in mTBI management protocols, tend to capture balance deficits in the acute stages of injury ${ }^{152,153}$, whereas, more sophisticated measures have identified balance deficits even three months after injury as depicted in the previous section. 
Some of the commonly used clinical balance measures after mTBI are as described and discussed for their applicability with the pediatric and adolescent population.

\subsubsection{Clinical measures:}

The most commonly used clinical measures for balance are the Balance Error Scoring System (BESS) ${ }^{85}$ and the Bruininks- Oseretsky Test-2 (BOT-2) Balance subtest ${ }^{86}$. The BESS is used to measure static postural stability. The measure was developed to assess stability among individuals after an head injury and to be used in the absence of any sophisticated tool such as a force platform. This test was found to be an easy to administer, inexpensive clinical balance test which has helped identify balance deficits in many post-concussion studies ${ }^{88,152,154,155}$. The BESS consists of 6 items that include double leg stance, single leg stance and tandem stance, on two surfaces (foam-Length:10', Width:10' and height:2.5' ${ }^{1}$ and firm ground) with eyes closed. Scoring is based on the number of errors committed per item. The number of errors are scored out of 10 . The average normal score for adults was found to be 12.03 \pm 7.34 . Each component has its own normal score. For children, a study conducted by McLeod., (2006) found that the mean score total score, on 50 athletes aged 9-14 years, was 15.54+5.82. Males had an higher score than females with a difference of about 2.5 points. Younger children (9-11 years) had a higher score than older children (12-14 years) with a difference of approximately 3.5 points ${ }^{156}$. In the context of the study, it is important to understand the internal consistency, construct validity, the inter-rater and intra rater reliability, its validity to administer in children and adolescents with mTBI as well as the Minimal Detectable Change (MDC) to help clinicians use the scales. The inter-rater and intra-rater reliability for the BESS total scores reveal an Intra Class Correlation (ICC) of 0.57 and 0.74 respectively. The inter-rater reliability for 6 different stance positions had ICC values between 0.44 and 0.83 . The minimum detectable change for the total BESS score for inter-rater and intra-rater were found to be 9.4 and 7.3 respectively ${ }^{85}$. The authors concluded that the subsets of the test are reliable whereas the overall BESS score is not. And a change of greater than 9.4 and 7.3 for inter-rater and intra-rater needs to be seen before the problem is attributed to postural instability rather than to the scorer. Hence,

\footnotetext{
${ }^{1}$ Power Systems AIREX Balance Pad 81,000, Knoxville, TN, USA
} 
BESS is not very widely used in clinical practices. Furthermore, BESS is found to be most sensitive (sensitivity 0.34 ) initially after the injury with a difference of 5.7 points. The scores returned to preseason levels within 3-7 days post injury. In the Collegiate athletes $24 \%$ were found to be impaired after 2 days of injury in comparison to only $9 \%$ after 7 days of injury ${ }^{154}$. Hence, it is believed that BESS is most sensitive during the acute injury phase when used along with the Standardized Assessment of Concussion ${ }^{152,154}$. The BOT-2 is a test that uses engaging, goal- directed activities to measure a wide array of motor skills in individuals between the age of $4-21$ years ${ }^{86}$. The BOT-2 can be administered in 4 different ways which include complete form, short form, selecting composites or selecting the subtests. The subtests and composite structures of the scale highlights motor performance in the following functional areas- stability, mobility, strength, coordination and object manipulation. There are 4 motor- area composites in which each comprises of two of the eight BOT-2 subtests. For this thesis we will focus on the balance subset. The balance items test the static and dynamic balance without external perturbations. The items mainly test the individuals anticipatory postural control in a feed-forward mechanism. Raw scores are converted into point scores. The point scores are converted into derived scores that include standard score, confidence interval, percentile rank and descriptive category for the particular age and sex of the child compared to normative values. In the context of the study, it is important to understand the internal consistency, construct validity, the inter-rater and intra rater reliability, its validity to administer in children and adolescents with mTBI as well as the Minimal Detectable Change (MDC) to help clinicians use the scales. The BOT-2 has been found to be a reliable measure to testing balance in children after an mTBI. Bruininks., (2005) reported the split-half reliability for internal consistency shows that that the reliability coefficients for the subscale, composite, total motor composite and short form scores range between 0.70 to 0.90 . The test-retest reliability for cognitive, language and motor scales was assessed twice by the same assessor over a period of 7-42 days on 134 children. The correlation scores ranged from 0.69 to 0.80 for the subscale scores, from the middle to upper 0.80 s for the total motor composite and short form reliability. It also varied based on the age of the child. Inter-rater reliability was measured by two assessors on the same child at the same time and the reliability coefficient was found to be between 
$0.92-0.99^{86}$. From the above reliability measures, the BOT-2 is seen to be a reliable instrument to measure balance in children. A study done by Wuang et al., (2009) examined the internal consistency, test-retest reliability and responsiveness of the BOT-2 in 100 children with intellectual disability (age 4-12 years). They found test-retest reliability and internal consistency for the total scale were excellent, with an ICC $=0.99$ (9\%5CI) and Cronbach's alpha of 0.92. Responsiveness was acceptable for all the BOT-2 measures except for the balance subtest that was found to be insignificant ${ }^{157}$. The other method to measure postural control is the modified Clinical Test for Sensory Integration of Balance (CTSIB) ${ }^{158}$. It is an accepted balance test to be conducted on static surfaces. The test helps clinicians evaluate the various components of balance and how the various systems compensate when there is a compromise of balance. The three systems that are challenged in this are the visual, somatosensory and the vestibular systems. The test consists of four components. Eyes open firm surface, Eyes closed firm surface, Eyes open foam surface, eyes closed foam surface. Each condition is performed for 30 seconds once. The sway index is being measured using this test. It is scored on a 4 point scale where 1-minimal sway and 4-fall. The higher the sway index the poorer the balance and hence more likely to fall. The test-retest reliability was found to be excellent ICC- $0.79-0.82$ in children of average age 12.2 years with $\mathrm{mTBI}^{9}$. There is still a lot of research that needs to be done with regard to finding the normative values for children and testing the validity and internal consistency of the measure in children with mTBI.

\subsubsection{Instrumented clinical measure:}

The Sensory Organisation test (SOT) (NeuroCom, division of Natus, OR, USA) is the most commonly reported instrumented clinical measure to test balance in $\mathrm{mTBI}^{88}$. The instrument effectively challenges the visual, somatosensory and vestibular systems. This is done by eliminating the useful information that the subject gets from any of the three systems through a calibrated 'Sway Referencing' of either the support surface or the visual input. This effectively creates a sensory conflict situation. Hence, it eliminates the vestibular system and challenges the CNS. The SOT uses six different conditions, each performed 3 times to assess balance. It consists of three 20 second trials with three different visual conditions (eyes open, eyes closed, sway referenced) and 2 different 
surfaces (fixed and sway referenced). The sway reference tilts according to the individual's CoG. The scoring is based on the overall equilibrium score, sensory analysis, strategy analysis and CoG alignment. The SOT has been used to find balance issues in mTBI. It has been seen that the vestibular sensory system that is most affected after an mTBI due to inability of the system to resolve sensory conflicts ${ }^{88}$. It has been hypothesized that the individuals may ignore the altered environmental conditions and choose a motor response as a compensatory strategy, which will lead to further injury due to the lack of sensory integration ${ }^{133}$.

A study done by Cavanaugh., (2005) ${ }^{159,160}$ found that by applying entropy techniques to the SOT data, athletes who show no signs of balance deficits are shown to have symptoms that persist for 3or 4 days. Although the SOT provides useful information regarding sensory deficits the accessibility and practicality of the instrument is still under question ${ }^{133}$.

\subsubsection{Dual task and gait measures:}

A functional method to assess balance after an $\mathrm{mTBI}$ is to measure the gait patterns under virtual reality conditions or divided attention ${ }^{133}$. Dual task models involve performing two tasks simultaneously. It can involve both motor and cognitive components which can be performed under cognitive-motor, cognitive-cognitive or motor-motor tasks. More frequently used models of dual task testing is performing motor tasks in conjunction with cognitive tasks such as simple Q and A tasks, Stroop task or with visual or auditory distractions ${ }^{144,145,151}$. It has been concluded from preliminary findings of various studies that dual tasks conditions can challenge the otherwise healthy individual but its clinical utility and applicability needs to be established ${ }^{133}$.

\subsection{Conclusion:}

Mild TBI management is a gradual step-wise process and there is persistent debate about the proper guidelines for its assessment and management. This is reported to be even more problematic in children due to the developing brain and possible long term consequences of early injuries. Experts believe that evaluation and management approaches should be multi-factorial in nature $^{64,78,152,154}$, especially in the context that that up to $50 \%$ of the time symptoms are underreported by children and adolescents. There is a need for a comprehensive assessment regimen 
that includes grading of symptoms and clinical balance assessments along with neuropsychological tests that are currently considered to be a valuable assessment tools $^{88,152,154,161}$. Guskiewicz (2011) states that balance assessments can provide clinicians with an objective measure, that will help them remove all guesswork by uncovering less obvious consequences and assisting in allowing safe return to activities ${ }^{133}$. It is therefore important to find clinical balance measures that are able to capture the more subtle balance deficits, that are currently only detected with more sophisticated tools and that would be applicable in the pediatric and adolescent population. 


\section{CHAPTER 3: OBJECTIVE, HYPOTHESIS AND EXPECTED CONTRIBUTION}

Objective: The objective of the study is to compare the ability of selected clinical static and dynamic balance measures to detect differences between children who are clinically recovered from an mTBI and healthy controls.

Hypothesis: There will be no differences seen on the various balance measures between the mTBI group and control group, indicating the stated clinical recovery of the mTBI group. If differences are present then, dynamic measures of balance and measures under dual task conditions will be more sensitive at predicting group differences.

Expected contribution: Through this study, we will contribute further evidence to the importance of balance testing in children and adolescents after an mTBI. By testing various aspects of balance using easy to administer, inexpensive measures, we hope to provide clinicians a more objective method to base return to physical activity decisions. Through this study, we also will better understand the recovery of balance function among children and youth, a domain that has not been as widely studied in this population when compared to collegiate athletes and young adults with mTBI. This study will help characterize various aspects of balance deficits in children and youth who are otherwise considered fully recovered from their mTBI. In addition, it will contribute to identify which balance measures are more sensitive to detecting group differences and provide clinicians additional measures to incorporate in everyday practice. 


\section{CHAPTER 4: MANUSCRIPT: Assessing Balance in Children After a Mild Traumatic Brain Injury: Choosing the Right Assessment}

\subsection{ABSTRACT:}

Objective: The objective of the study is to compare the ability of selected clinical static and dynamic balance measures to detect differences between children who are clinically recovered from an mTBI and healthy controls.

Setting: The Montreal Children's Hospital, Concussion Clinic.

Participants: Twenty-seven children aged 8-17years who were clinically recovered from mTBI and twenty-two age/gender matched controls.

Design: Cross-sectional.

Main Measures: Balance was measured using three clinical measures: Brunininks-Osteresky Test for Motor Proficiency, Second edition- Balance subtest (BOT-2); Balance Error Scoring System (BESS); Community Balance and Mobility Scale (CB\&M). In addition, three gait paradigms - Self-Selected Pace (SSP), Tandem Walking (TW) and Obstacle Crossing (OC) was assessed using the GAITRite walkway (CIR Systems, USA) under single and dual task condition (tested using an arithmetic task). Differences between groups on the various balance measures were analysed using independent sample t-tests at 0.05 significance with Bonferroni corrections. Discriminant analysis was done to predict the best measure of balance that predicts which group an individual belongs to. Dual task cost (DTC) between groups on motor and cognitive task was analysed using repeated measures ANOVA as well as independent sample t-tests at $\alpha=0.05$.

Results: There were no differences in the age, gender and levels of physical activity between groups. The mTBI group had worse performance $(\mathrm{p}<0.05)$ on all three clinical measures of balance. Specific parameters for each gait paradigm found the mTBI group to be significantly negatively affected compared to the control group ( $\mathrm{p}<0.05)$. Both the BESS and tandem walking had good prediction for discriminating which group an individual belonged to. No differences were found between groups on DTC in motor tasks. Whereas, DTC in accuracy of the cognitive task was found to be significantly reduced during self-selected paced walking in the mTBI group. 
Conclusion: Findings from this study provides further evidence that assessment of balance skills could enhance clinical decision-making for safe return to physical activities. Furthermore, it emphasizes that clinical balance assessments may need to include both static and dynamic paradigms to capture performance difficulties and prevent premature return to physical activities. 


\subsection{Introduction:}

Balance deficits have been documented repeatedly ${ }^{1}$ immediately after mild traumatic brain injury (mTBI) and are now well recognized as important by most concussion experts ${ }^{2}$. Balance is therefore considered an essential component of a thorough assessment for clinical return to play decision making ${ }^{3}$ after an mTBI, in conjunction with the more traditionally used neuro-cognitive testing and post-concussion symptom reporting.

Balance is an integral part of everyday activities. It can be defined as the ability of the body to maintain the Line of Gravity (LoG) within a Base of Support (BoS) ${ }^{4}$. Effective postural control involves either reactive or predictive strategies. Predictive strategies encompass voluntary movements to any anticipated disturbances that could cause imbalance, whereas reactive strategies are generally a response to unpredicted disturbances 5 . To maneuver various environments, the ability to maintain balance allows the body to self-evaluate joint position, movement direction and speed based on a combination of somato-sensory, visual, and vestibular inputs to the central nervous system ${ }^{6,7}$. It is noted that integration of the three sensory systems and maturation to adult like postural control, of the three systems namely; visual, vestibular and somato-sensory continues to take place from birth through puberty ${ }^{8}$. Along with the sensory systems, the motor system helps maintain balance by aligning the body within the BoS using muscular forces ${ }^{9}$. For the body to maintain a state of equilibrium it is essential for all the systems that regulate balance to interact in unison to bring the $\mathrm{CoG}$ within the $\mathrm{BoS}^{10}$. Since many of everyday activities require movement, it is essential to measure both static and dynamic aspects of postural control. In case of injury to the central nervous system, there can be problems of integration of the multitude of incoming sensory information that leads to excess dependence on one or more sensory systems rather than an integration of the three systems together ${ }^{11,12}$.

Various deficits have been detected using both static and dynamic measures of balance even after three months following an mTBI.. Gagnon et al. (2004), found that children with mTBI continued to have postural deficits on the Bruininks- Osteresky Test for Motor Proficiency (BOTMP), Postural Stress Test (PST) and Pediatric Clinical Test of Sensory Interaction of Balance (P-CTSIB) up to 12 weeks post-injury as compared to uninjured age/gender matched controls $^{13}$. Other studies conducted, noted balance deficits in young collegiate athletes using high technology tools under controlled laboratory environments ${ }^{14,15}$. 
The most commonly used clinical balance test to measure static balance in individuals after an mTBI is the Balance Error Scoring System (BESS) ${ }^{16}$. Other measures of static balance include using the Sensory Organisation Test $(\mathrm{SOT})^{17}$ and the Clinical Test of Sensory Interaction of Balance $(\mathrm{CTSIB})^{18}$. The SOT requires the use of force plates and its applicability into many clinical set-ups is difficult ${ }^{9}$. It would be useful to test the sensitivity of easy to administer, cost effective tools in aiding return to physical activity decision making in clinics.

Dynamic balance is commonly measured using gait evaluations. Testing performed under virtual reality conditions with divided attention or dual task methods, is also said to detect residual subtle deficits in this population ${ }^{9}$. During dual task conditions involving a cognitive task and gait, concussed athletes have been shown to adopt slower and more conservative gait strategies as compared to a control group ${ }^{19}$. Parker et al. (2005), examined gait stability after a concussion during a course of 28 days after injury, under single and dual task conditions using a simple cognitive task, and found that young adults with a concussion showed slower walking speeds during dual task conditions throughout the testing period (up to 28 days) and that deficits in walking velocity were also seen up to 4 weeks after the injury. Injured individuals also exhibited greater sway velocity and displacement at 28 days post injury during dual task conditions ${ }^{20}$. Although gait measures in self selected paced walking under single task conditions are found to be different between individuals with mTBI and healthy controls in the acute phase of injury, they tend to recover over a period of time ${ }^{21}$. A study found that collegiate athletes, who had sustained an mTBI many years prior to testing, performed worse on both single task and dual task paradigms during gait ${ }^{22}$. These findings are interesting but their applicability to the pediatric population remains to be determined. Indeed, most of the studies are conducted with collegiate athletes or young adults. It is therefore of interest to explore the performance of children and adolescents under similar single task and dual task conditions.

Based on the above studies it is clear that balance deficits have been shown to persist long after the injury ${ }^{14,23,24}$. Children and youth are usually returned to physical activities based on the resolution of their self-reported post concussive symptoms ${ }^{2,25}$ as well as based on their performance on clinical balance tests that are found to be more sensitive in detecting balance deficits at the acute phase of the injury ${ }^{26-28}$. It is therefore essential to provide clinicians with tools that are more reliable at detecting residual deficits, to improve their confidence in the fact 
that children and adolescents are in fact completely deficit-free before their return to pre-injury levels of participation.

It is therefore important to introduce more sensitive balance measures in a clinical set-up that are cost-effective, easy to administer and sensitive enough to detect subtle balance deficits. The objective of this study was to compare static and dynamic balance between children who are clinically recovered from an mTBI and healthy controls using various clinical balance measures and to further explore which of the balance measures would be more sensitive in detecting differences between groups, so as to provide clinicians with better tools to help improve decision making regarding readiness to return to physical activities.

The aim of this project is not to compare the clinical balance measures to the gold standard measures rather it is to explore the sensitivity of the selected clinical tests to detect balance deficits in clinically recovered children. As noted in literature that gold standard measures are found to detect balance deficits even after many months of the injury. Hence, the project does not aim to compare the clinical balance measures to gold standard but to understand if there is in fact balance deficits that persisted and if the clinical scales were sensitive to detect balance deficits at the latter stages of injury.

\subsection{Methodology:}

\subsubsection{Sample:}

Twenty-seven children between the age of 8-17 years (mean age $13.2 \pm 2.20$ years), with a diagnosed mTBI were recruited from the Montreal Children's Hospital Concussion Clinic. Children and youth were enrolled if they were clinically recovered from the injury, which was defined as 1) being asymptomatic at rest for a minimum of one week as measured by the PostConcussion Symptom Scale Revised (PCS-R) ${ }^{29}$ and 2) being cleared for gradual return to physical activity by the treating clinician, because balance and cognition were also considered to be recovered. Children and youth were excluded if they presented with: 1) more than three

lifetime concussions, 2) Attention Deficit Hyperactive Disorder ${ }^{30}$ or Developmental Coordination Disorder ${ }^{31}$ and 3) pre- or co-existing orthopedic and neurological conditions affecting balance. 
Twenty-two healthy children (mean age $13.6 \pm 2.56$ years) were also recruited and matched based on their age, gender and level of physical activity, to injured participants. Level of physical activity was determined using the Activity Rating Scale ${ }^{32}$, a single 5-level question used in large epidemiological studies to ascertain level of participation. The injured group was tested on the same day as their final appointment at the Concussion Clinic. Post-concussion symptom levels were obtained using the PCS-R $\mathrm{R}^{33,34}$. No significant differences ( $\left.\mathrm{p}>0.05\right)$ were found between the mTBI and control group for symptom levels at the time of testing, confirming the stated recovery of the mTBI group. Demographic characteristics of the groups are presented in Table 4.1.

The project was approved by the McGill University Health Centre Pediatric Research Ethics Board (study number 12-190-PED). Informed consent and assent was obtained prior to participation.

\subsubsection{Measures of balance and mobility:}

Balance was measured using three clinical scales: the Bruininks-Osteresky Test for Motor Proficiency Second Edition - balance subtest (BOT-2) ${ }^{35}$, the Balance Error Scoring System $(\mathrm{BESS})^{16}$ and the Community Balance and Mobility Scale $(\mathrm{CB} \& \mathrm{M})^{36}$. In addition, mobility was measured using three gait paradigms under single and dual task conditions: self-selected pace (SSP), obstacle crossing (OC), and tandem walking (TW) using the GAITRite® ${ }^{1}$ walkway .

The primary balance outcome was the BOT-2- balance subtest. It measures static and dynamic balance without external perturbations and can be administered to individuals between the age of 4-21 years ${ }^{35}$. It includes nine items testing the ability to stand and walk using a narrow base of support, with and without the use of visual feedback. Items are scored in terms of time spent in a position, or by recording the number of correct steps taken, depending on the item. If the child was unable to perform a task successfully on the first trial, a second trial was done, as per test instructions and best of the two trials was taken for the final item score. Item scores were converted to point scores and then transformed to normalized scale scores. The last two items standing with on a beam tandem and standing on a beam single leg stance eyes closed on the BOT-2 are clinically found to be more challenging than the other items and were analysed separately.. Although the BOT2 has not yet been reported in the literature with the mTBI

\footnotetext{
${ }^{1}$ CIR Systems, NJ, USA
} 
population, psychometrics for the BOT-2 were found to be as follows: inter-rater reliability was found to be high in individuals between the age of 4-21 years for all subtests of the complete form $^{37}$. Test-retest reliability assessed on three groups over a period of 7-42 days showed a Pearson's product correlation of $<.80$ on the subtests. And very little learning effect was seen on the balance and coordination skills ${ }^{37}$.

Children's performance on the BESS, the CB\&M and the three gait paradigms (SSP, OC, TW) was taken as secondary outcome measures. The BESS is a measure of static balance that was developed for individuals with mTBI. The BESS consists asking the child to stand in three positions (double leg support, single leg support, and tandem position) on a firm surface (floor) and a foam surface ${ }^{2}$ (Length: 10" Width: 10" Height: 2.5") with eyes closed for 20 seconds. The number of errors that individuals make while maintaining the position is counted and constitutes the test score. An error is defined as a postural adjustment such as removing hands off the iliac crest, opening eyes, falling, abduction or flexion of the hips >30 degrees, lifting the forefoot or heel off or staying out of testing position for greater than 5 seconds $^{38}$. The maximum number of errors per task is 10. BESS-total is the number of errors that are committed under all six conditions combined with a maximum of 60 . There is a paucity of literature describing the normative values of the BESS in children and adolescents with an mTBI. Normative values for young adults have been reported to be around $10.97 \pm 5.05$ (average number of errors) ${ }^{39}$. Testretest measures for the BESS on young athletes aged 9-14 were found to be adequate $(\mathrm{ICC}=0.70)^{40}$. Excellent inter-rater reliability was seen for all conditions $(\mathrm{ICC}=0.87$ 0.98 ) and the total score $(\mathrm{ICC}=0.98)^{41}$. And convergent validity between BESS and Sensory Organization Test(SOT) was validated in individuals with an $\mathrm{mTBI}^{40}$.

Although we have chosen two static measures of balance and we have chosen the various gait paradigms for walking, we thought it was appropriate to assess children and adolescents with the CB\&M because it is a scale that measures high level balance tasks. The scale encompasses challenging tasks that involve multitasking and movement sequencing ${ }^{42}$. Since, most children and adolescents are highly athletic and active it was important for us to test them on a more challenging task. The CB\&M was developed to measure balance and mobility in individuals with TBI with the aim of mimicking the challenges encountered in a

\footnotetext{
${ }^{2} \operatorname{AIREX}^{\mathrm{TM}}$
} 
community setting. It is a thirteen-item scale that has components of both static and dynamic balance and where most items are performed along an $8 \mathrm{~m}$ line. As per test suggestion, for children between ages 8-11 years, the instructions were modified to a simpler language and the weights to be carried for item 11 was reduced from $7.51 \mathrm{bs}$ to $51 \mathrm{bs}{ }^{42}$. Scoring for the CB\&M was based on the scoring grid of the scale. The total score was out of 96 . Normative values in children between ages of $8-11$ years were found to be $70.1-82.9^{42}$. There is paucity of normative values in adolescents, hence normative values are compared to young adults and found to be $88.71 \pm 3.53^{43}$. The validity and reliability of the scale in brain injury patients was found to discriminate between a wide range of balance abilities in a high-functioning, ambulatory patients ${ }^{36}$. Excellent test-retest validity was seen in children and adolescents within 10 days of injury( $(\mathrm{ICC}=0.90)^{44}$. Also, excellent inter rater validity $(\mathrm{ICC}=0.93)$ as well as excellent internal consistency for the primary assessor's baseline score(Cronbach's alpha= $0.89)$ was reported in the same group of individuals ${ }^{44}$.

The GAITRite system consists of a walkway (length of $4.87 \mathrm{~m}$ ) that automates the measurement of temporal and spatial-two dimensional gait parameters through pressure activated sensors. The area of the foot placement/object is determined by the number of sensors activated, by the distance between these sensors and the time for activation/deactivation ${ }^{3}$. Validity of the GAITRite walkway was established using algorithms of body-worn sensors (gyroscopes) in young healthy adults and ICC correlations were found to be excellent for both temporal measures: stride time, swing time and stance time (ICC $\geq 0.84$ ) and spatial measures: velocity (taken as a spatial measure on the GAITRite) and stride length (ICC $\geq 0.88$ ). Also, concurrent validity was found to be excellent at three different walking speeds with comfortable walking observed to be the best ${ }^{45}$. In children it has been found that the inter-trial reliability range from poor to excellent and clinically relevant error was found to be acceptable for all parameters across age groups ${ }^{46}$. Reliability of the gait parameters under single and dual task condition (using a cognitive task) was done in adults with mild cognitive impairment. The study found that the mean velocity decreased significantly compared to single task condition $(\mathrm{p}=0.005)$ and temporal parameters such as stride time, step time and time on double support was highly variable $^{47}$. There are no such studies done in children assessing the reliability of the measures

\footnotetext{
${ }^{3}$ GAITRite ${ }^{\circledR}$ Manual Version 3.9 (9/6/2007)
} 
when an additional task is added.

Children and adolescents were tested on the three clinical balance measures and on gait measures at the time of recovery. The participants were tested on the BOT-2- balance subtest and BESS measures first. They were then asked to perform all three gait tasks administered in the order of SSP walking, SSP walking with cognitive task, OC and OC with cognitive task and finally TW and TW in conjunction with the cognitive task. They were assessed on the CB\&M at the end of the session. The session took overall an hour and a half to complete. All tasks were administered by a trained research assistant. For children with mTBI, performance on the BOT2 balance subtest alone, was assessed as part of their clinical appointment by the treating clinician, which took 5-7 minutes. BESS tasks were performed on the firm surface and on the foam, of aforementioned dimensions and the task took overall 10 minutes to complete. For the $\mathrm{CB} \& \mathrm{M}$, the children and adolescents were given instructions based on their age which was completed in approximately 20 minutes. The overall assessment on the GAITRite walkway took approximately 40 minutes . Adequate rest periods were given between tasks.

For all three paradigms, SSP, OC and TW, children were instructed to walk along the center of the mat at a comfortable pace (as they would walk in a school hallway). Dual task conditions involved performing the above three gait paradigms along with a simple self-paced mental arithmetic task, which consisted of starting from a randomly generated number from 100-1, and counting backwards by threes for the distance of the walkway. Performance on the arithmetic task was first noted in sitting for 8 seconds before the start of the trials to help compare to, and understand, the effect of the dual task on cognitive performance. Two trials of each paradigm under single and dual task conditions were recorded.

The OC task consisted of placing a PVC pipe, approximately $2.5 \mathrm{~cm}$ in diameter and long enough to cover the width of the mat, at the center of the walkway. Central point of placement of the obstacle on the mat using exact $\mathrm{x}, \mathrm{y}$ coordinates was noted a priori, to aid in later calculations regarding foot placement prior to and after obstacle crossing. The obstacle height was set at $10 \%$ of the height of the child ${ }^{48}$. For the TW paradigm, a line was set up using tape in the center of the walkway along its length. Children were instructed to walk along the line without looking at their 
feet while not allowing the toe touch the heel of the leading foot to ensure recording of footprints by the GAITRite ${ }^{\circ}$ software.

For SSP, the variables obtained were velocity $(\mathrm{cm} / \mathrm{sec})$, stride width $(\mathrm{cm})$, step length $(\mathrm{cm})$ and percentage time on double support. For OC, the variables calculated were velocity across the entire walkway $(\mathrm{cm} / \mathrm{sec})$, velocity at the obstacle $(\mathrm{cm} / \mathrm{sec})$ (defined as the step length by step time of an entire gait cycle at the obstacle), distance of the lead and trail lower extremities from the obstacle along the horizontal axis (lead lower extremity defined as the limb that crosses the obstacle first, and trail is the limb that crosses last but that is used for single limb support during the crossing of the lead limb) and single support time (sec) of the trail and lead limb during obstacle crossing. Variables chosen for analysis of TW were velocity $(\mathrm{cm} / \mathrm{sec})$ and percentage time on double support. The above parameters were chosen as they closely reflect the ability of an individual to maintain proper dynamic stability ${ }^{49-53}$. For the analysis of performance under dual task conditions, a change in absolute performance between single and dual task conditions of a particular variable of each paradigm was considered and named "Dual Task Cost"(DTC). Motor DTC was defined by motor performance under single task condition minus motor performance under dual task condition. Cognitive tasks was measured with accuracy percentage (defined as the number of correct answers/number of answersX100) and response rate (defined as number of answers divided by the duration of the task) of answers. Cognitive DTC was defined as performance of the task under single task condition i.e. in sitting minus performance under dual task condition.

\subsubsection{Data Analysis:}

Descriptive summary statistics (mean, standard deviation) were calculated for each variable and are presented in table 4.2. Differences in performance on the individual balance and mobility tests between the groups were determined using independent sample T-tests with $\alpha=0.05$ with Bonferroni corrections. A Discriminant Function Analysis was then conducted to determine the extent to which performance on balance measures and gait paradigms under single task condition accurately predicted whether children belonged to the recovered mTBI group or not at $\alpha=0.05$.

A repeated measures ANOVA was used to determine the difference in DTC between groups for velocity across three gait paradigms, as well as for the performance on the arithmetic task 
(accuracy and response rate). Differences in DTC for other variables of SSP, OC and TW, were analysed using independent sample t-test at $\alpha=0.05$. Statistical analysis was performed using SPSS version 17.0.

\subsection{Results:}

As shown in Table 4.2, the mTBI group performed significantly worse on overall scores of the BOT-2 and CB\&M, and had significantly more errors on the BESS compared to the controls. Differences between the groups on the BESS yielded the largest effect size (Cohen's $\mathrm{d}=1.27$ ).

Secondary analysis of the two specific items on the BOT-2 namely; heel to toe standing on the beam $(p=0.018)$ and standing on one leg eyes closed on the beam $(p=0.001)$ were found to be significantly different between groups with the control group having better performance on both items.

When examining the three gait paradigms and the performance on the arithmetic task under single task conditions (Table 4.2), there were some significant differences between the groups. For SSP, there was no significant difference found between groups on velocity, step length or percentage time on double support, whereas stride width, was wider in the mTBI group compared to the controls $(\mathrm{p}=0.001)$ with a large effect size $(\mathrm{d}=0.97)$. During OC, distance of the lead limb from the obstacle showed that the mTBI group had greater horizontal clearance of the lead foot $(\mathrm{p}=0.043 ; \mathrm{d}=-0.60)$. Single support time on the trail limb was significantly decreased in the mTBI group $(\mathrm{p}=0.006 ; \mathrm{d}=0.77)$. Both variables chosen for TW were significantly different between the groups with the mTBI group walking slower $(\mathrm{p}=0.003, \mathrm{~d}=-0.90)$ and spending more time in double support than the control group $(\mathrm{p}=0.002 ; \mathrm{d}=0.94)$. Significant differences were found between groups on the response rate on the arithmetic task while performing the task in sitting without the dual task component $(\mathrm{t}=-2.426, \mathrm{p}=0.019)$.

Discriminant analysis and cross validation procedures were conducted to predict how well the clinical measures and gait paradigms discriminated between the groups. Log determinants for both groups were found to be similar and Box $M$ tests showed that there was equality assumed of the covariance matrices $(\mathrm{p}=0.265)$. Discriminate function revealed a significant association between the groups and the balance measures, accounting for $55.1 \%$ of between group variability. Detailed analysis of structured matrix showed that the BESS total score (.581), stride 
width during SSP walking (.446) as well as velocity (-.414) and percentage time on double support (.422) during tandem walking to be the best predictors of group membership. However, the BOT-2, CB\&MS and variables considered for obstacle crossing were shown to be poorer predictors. Cross validation classification showed that overall $77.6 \%$ of children could be correctly classified for all balance measures tested as seen in Table 4.3.

Means and standard deviations of DTC on parameters of SSP, OC and TW are presented in Table 4.4. There were no differences in DTC between the mTBI and control groups for walking velocity in any condition $(\mathrm{F}(1,49)=1.255, \mathrm{p}=0.268, \eta 2=0.026)$. There was, however, a significant difference of DTC across conditions $(\mathrm{F}(1.743,49)=26.071, \mathrm{p}=0.000, \eta 2=0.357)$. Post hoc testing revealed that DTC was higher in SSP and OC than in TW for both groups $(\mathrm{p}<0.05)$. There was no significant interaction was found between group and DTC on the three gait conditions for velocity $(\mathrm{F}(1.73,49)=2.713, \mathrm{p}=0.080, \eta 2=0.055)$.

A significant group $\mathrm{x}$ condition interaction was found for DTC in the accuracy percentage of the cognitive task $(\mathrm{F}(2,49)=5.217, \mathrm{p}=0.007, \eta 2=0.100)$. Children with mTBI had significantly higher DTC than the control children for SSP walking $(\mathrm{p}=0.004)$ and there was a trend for differences for the OC between groups ( $\mathrm{p}=0.071)$. Testing of three conditions for each group separately revealed that there was significant difference in DTC on accuracy percentage within the mTBI group $(\mathrm{F}(2,49)=3.396, \mathrm{p}=0.041, \eta 2=0.116)$. Post hoc testing revealed that the $\mathrm{mTBI}$ group had greater DTC on the accuracy on the cognitive task while walking in SSP compared to OC and TW $(\mathrm{p}<0.05)$.

Finally, there was no interaction between group and DTC when looking at the response rate on the cognitive task $(\mathrm{F}(2,49)=1.163, \mathrm{p}=0.317, \eta 2=0.024)$. There was no difference between the groups seen in the DTC on the rate of performance of the cognitive task across the conditions (F $(1,49)=0.888, p=0.351, \eta 2=0.019)$. Testing of three conditions within groups revealed that there was no significant difference in DTC on response rate of the cognitive task within groups $(\mathrm{F}(2,49)=0.033, \mathrm{p}=0.968, \eta 2=0.001)$.

\subsection{Discussion:}

Results from our study indicate that balance deficits can still be identified, using clinical measures, in children and adolescents with mTBI, even after they are considered clinically 
recovered and have been cleared for gradual return to physical activities. Balance deficits are seen during both static and dynamic tasks but mostly in those that require a limited BOS and in the absence of vision. Also, children and youth showed problems in tasks requiring anticipatory control such as when performing complex walking activities These findings suggest that limiting the assessment of balance to one single aspect may be not sufficient to make effective return to activities decisions and further testing needs to be done to ensure the individuals complete readiness to return to physical activity. We hypothesized, if the group differences were present, that dynamic balance tasks would be best at differentiating the groups. Adding a dual task component would make the tasks more challenging, hence would further detect subtle differences in the groups. We found that static measures of balance along with dynamic measure found differences between groups and the cost of the dual task was not as sensitive to detect such subtleties.

Children and youth in the recovered mTBI group were found to have poorer performance levels on all three clinical balance measures but the BESS yielded the largest effect size for differences between groups. The children and adolescents in the mTBI group fell within the normal range of scores on the BOT-2 balance subtest $( \pm 1.0 \mathrm{SD})$, but specific item differences between the groups showed they may have difficulties with tasks involving decreased base of support (BoS) (standing on a narrow beam) and those performed in the absence of vision compared to healthy controls as noted in the single leg stance with eyes closed task where the mTBI group had a score of $2.30 \pm 1.10$ compared to the control group with a score of $3.59 \pm 1.37$. This confirms similar findings of a previous study where, children with an mTBI of similar age (7-16 years), had significantly worse performance on similar tasks compared to age matched controls at 12 weeks after the injury ${ }^{13}$. Since postural control strategies involves complex integration of multiple areas the $\mathrm{CNS}^{54}$, poor performance on balance measures may indicate that individuals with an mTBI have issues integrating the incoming sensory information to generate an appropriate motor output to maintain balance. To adapt to the lack of postural control, they may tend to adopt a wider BoS to compensate for the displacement of Center of Gravity (CoG) and inability to integrate the sensory systems effectively they may tend to rely more on visual input to maintain balance.

The reliance on visual input is further illustrated by the poor performance of the mTBI children on the BESS who had on average at least 7 more errors compared to the control group, which is 
tested entirely with eyes closed. However, the poor performance may not be completely explained by the absence of vision, but can be also be explained by difficulties in somatosensory systems or vestibular systems. Indeed, the BESS is performed under conditions of unstable support surface (foam) which provides altered somatosensory information and requires the action of the vestibular system as a reference for alignment in relation to gravity. It has been reported in a review paper that vestibular deficits can outlast other impairments such as symptom presentation or cognitive issues ${ }^{9}$. This could support our findings that children and adolescents were not able to perform tasks that required a change in supporting surface without the availability of visual information (standing on a beam single leg eyes closed, or on the foam) and could further relate to issues in the vestibular system. In a study conducted to examine the postural stability of collegiate athletes after mTBI, authors report that injured individuals tend to exhibit acute balance deficits due to their inability to use their vestibular system effectively in conditions where there is a change in surface under normal or absent visual information ${ }^{55}$.

There is very little work on normative values of the BESS in children and youth ${ }^{39,56}$. It is of note however, that even children and adolescents in the control group had a slightly higher number of errors on the BESS than what is reported for young adults ${ }^{39}$. This points to a continuing development of balance, especially in the vestibular system, that has been shown to develop through adolescence ${ }^{57}$. Although the BESS appears promising as a clinical measure with this population, further study may be required to validate the use of the BESS as a standard clinical tool in this population, as BESS has been shown to have practice and learning effects in athletes $^{39,40}$.

Group differences seen on the CB\&Mshow that both static and dynamic components of balance are affected in mTBI children and adolescents. While the BOT-2 and BESS tested the feedback mechanism of postural control, CB\&M tests the feed-forward mechanism of balance testing. The fact that children exhibit problems with anticipatory balance control has been supported by a previous study, where children after an mTBI tended to perform worse than the control group on tasks that involved anticipatory postural control ${ }^{13}$. Hence, the mTBI group showed significant deficits in functional balance as well as indicate further problems with performing tasks with a narrow BoS as most items on the CB\&M are carried out on a line. 
Prior studies had emphasized the potential sensitivity of gait assessments in detecting lasting impairments ${ }^{9}$. In our study, injured children were able to walk as fast and with as long steps as children from the control group but that they spontaneously adopted a wider stance to walk (at $7.08 \mathrm{~cm} \pm 2.26$ compared to the control group that had $4.97 \mathrm{~cm} \pm 2.07$ ) This is in line with prior studies ${ }^{19,21}$ showing that even if individuals with concussion have slower walking velocity as compared to individuals without a concussion 48 hours after the injury, velocity tends to reach close to normal values by 28 days $^{21}$. Differences in stride width between groups, may indicates the need for children with mTBI to have a wider BoS while walking to maintain balance, as highlighted in the more static tests..

The requirement of greater BoS is emphasized further with performance during TW. The variables percentage time on double support and BoS are of clinical relevance while testing balance $^{52}$. It is of interest to note that our study showed, greater percentage time on double support and decreased velocity during tandem walking suggesting a conservative approach to walking with narrow BoS. These findings along with greater stride width during SSP, and findings from the BOT-2 subtests, BESS and CB\&M, further support the fact that the mTBI group requires greater BoS. It is prudent to note here that our study provides further evidence on the requirement of testing tandem walking and balance in tandem stance in children and youth after a mTBI. This supports the inclusion of testing tandem balance in recommended tools such the Sports Concussion Assessment Tool -3rd Edition².

Obstacle crossing strategies has also been shown to be a good indicator of balance problems ${ }^{58}$. Distance of the lead limb from the obstacle was seen to be greater for children with mTBI and single support time on the trail foot was found to be greater for the control group. This could indicate that the uninjured group had more control of their lead foot during obstacle clearances vs. the mTBI group who had larger clearance distance. In a study based on healthy young and older adults, authors found that when individuals walked slower and with more control, they tended to step closer to the obstacle ${ }^{59}$. This indicates that adults had greater time to plan and execute clearance strategies. This is supported by our findings that indicate that the control group spent greater time on the trail foot to plan and execute a proper and safe clearance strategy. Whereas, a decrease in single support time on the trail foot for the mTBI group may indicate that they tended to reduce the time spent on a position that required greater manipulation of Center of 
Mass $(\mathrm{CoM})$ within a narrow $\mathrm{BoS}^{60}$. This indicates lack of proper balance in the mTBI group and further supports the lack of adequate anticipatory postural control strategies.

Discriminant analysis revealed that the total number of errors on the BESS and two variables of tandem walking (velocity and double support time) are the best predictors of which group an individual belonged to. The analysis reveals that our study can identify a model, based on common clinical balance measures, that predicts up to $77 \%$ that balance findings are different between groups, even though the mTBI group was clinically recovered and was expected to perform similarly to the control group. These findings support the notion that subtle balance deficits persist beyond the expected recovery period and that children who sustained an mTBI remain different than healthy controls when current guidelines would likely clear them for complete return to physical activities.

The results for this study did not identify differences in DTC between the groups for most of the variables measured. Our results contradict studies that have found the mTBI group to have greater balance deficits under dual task conditions at least 28 days after the injury during various gait conditions compared to healthy controls ${ }^{21,61,62}$. A lack of significant differences between the groups on DTC may indicate that our cognitive task may not be challenging enough to identify balance deficits under dual task conditions, even though it was sensitive enough to differentiate differences between groups under single task condition. Previous work conducted with children has shown that as the complexity of the concurrent cognitive task increases, there is a greater cost on motor performance and that children tend to prioritize the cognitive component ${ }^{52}$. This has been supported by our findings in within group analysis where it was seen that velocity was affected across conditions in both groups more than cognition. A greater DTC in SSP and OC compared to TW on velocity in both the groups could indicate that there was a learning effect across the tasks as they were administered consecutively. A decrease in accuracy in mTBI gorup in SSP and a trend noticed in the control group could indicate that individuals tended to improve under dual task conditions, which has been reported in an earlier study where authors noticed an improvement in performance under dual task conditions ${ }^{63}$. Hence, it would be of interest to test the groups using other methods of dual task that involve visual and auditory distractions while performing gait tasks. 
Clear recommendations cannot be made at this stage, but it is recommended that clinicians incorporate testing tandem walking as part of their protocol. Also recommended is that clinicians look particularly at the more challenging tasks of the BOT-2. Incorporating BESS in the clinical practice needs to be considered only after realizing the validity of the scale in the population. Also, it is seen that the BESS has a learning effect, which may not be a great tool to use if it is used for monitoring balance at every session.

It may not be necessary to sit children and adolescents out if they continue to persist with balance deficits after remaining asymptomatic for a week, but if the balance performance is much below expected scores on various components of balance testing then it would be recommended to actively train the balance deficits and progress slowly on the gradual return to physical activity protocol.

\subsection{Study Limitations:}

Limitations of the study included the fact that children and adolescents were recruited consecutively from a single center. Although this center is a publicly funded program that provides care to a diverse population, the results may not account for a wider variation in the population. Gender matching was attempted in the beginning of the study but due to convenience sampling of the control group, one group of adolescents boys got under represented. Although, balance is found to reach adult like strategies during the age group described for this study, it may be a limiting factor as boys have a different balance abilities after attaining puberty, where they tend to perform moderately better than females. Many of the tests used do not have normative values, preventing comparisons of performance for children of both groups to the general population. Further research needs to be done to establish normative values for the above measures especially in adolescents. For the functional gait testing, only temporal and twodimensional spatial parameters were tested using the GAITRite. Also, the reliability of adding an cognitive task to the walking task using a GAITRite ${ }^{\mathrm{TM}}$ walkway system, is unknown in children. The control group serves as a reference, hence this should not affect the results as much. For this study,video measures would have allowed a greater understanding of the balance strategies adopted by both groups.

\subsection{Conclusion:}


In conclusion, from the results of the study, it is clear that children and adolescents with an mTBI show persistent balance deficits, even after resolution of symptoms. It is thus important to include both static and dynamic balance measures that challenge the three systems that help maintain balance. The BESS and tandem tasks can be incorporated as a part of regular clinical testing. Finally, we can see from this study that there may be issues with overall lack of integration of the three systems to maintain balance, that go undetected with simple balance tests. There is a further need to study the various systems that contribute to maintaining balance either separately and/or as a whole in children and adolescents after an mTBI. This could add to our understanding of the underlying reason for balance deficits in this population along with the compensatory mechanisms adopted by these individuals to maintain proper postural control. Through this understanding, it would help further enhance clinical rehabilitation as well as return to physical activity decision making, to prevent further injury. 


\section{References}

1. Guskiewicz KM. Postural stability assessment following concussion: one piece of the puzzle. Clinical Journal of Sport Medicine. 2001;11(3):182-189.

2. McCrory P, Meeuwisse WH, Aubry M, et al. Consensus statement on concussion in sport: the 4th International Conference on Concussion in Sport held in Zurich, November 2012. British journal of sports medicine. 2013;47(5):250-258.

3. Guskiewicz KM, Valovich McLeod TC. Pediatric sports-related concussion. Physical Medicine \& Rehabilitation. 2011;3(4):353-364.

4. $\quad$ Bell F. Principles of mechanics and biomechanics: Nelson Thornes; 1998.

5. Pollock AS, Durward BR, Rowe PJ, Paul JP. What is balance? Clinical rehabilitation. 2000;14(4):402-406.

6. Riemann BL, Lephart SM. The sensorimotor system, part II: the role of proprioception in motor control and functional joint stability. Journal of athletic training. 2002;37(1):80.

7. Irrgang J, Whitney S, Cox E. Balance and proprioceptive training for rehabilitation of the lower extremity. J Sport Rehabil. 1994;3(1):68-83.

8. Assaiante C, Mallau S, Viel S, Jover M, Schmitz C. Development of postural control in healthy children: a functional approach. Neural plasticity. 2005;12(2-3):109-118.

9. Guskiewicz KM. Balance assessment in the management of sport-related concussion. Clinics in sports medicine. 2011;30(1):89.

10. Latash ML. Progress in Motor Control: Structure-function relations in voluntary movements: Human Kinetics; 2002.

11. Nashner LM, Black FO, Wall C. Adaptation to altered support and visual conditions during stance: patients with vestibular deficits. The journal of Neuroscience. 1982;2(5):536-544.

12. Shumway-Cook A, Horak FB. Assessing the Influence of Sensory Interaction on Balance Suggestion from the Field. Physical Therapy. 1986;66(10):1548-1550.

13. Gagnon I, Swaine B, Friedman D, Forget R. Children show decreased dynamic balance after mild traumatic brain injury. Archives of physical medicine and rehabilitation. 2004;85(3):444-452. 
14. Slobounov S, Cao C, Sebastianelli W, Slobounov E, Newell K. Residual deficits from concussion as revealed by virtual time-to-contact measures of postural stability. Clinical neurophysiology: official journal of the International Federation of Clinical Neurophysiology. 2008;119(2):281.

15. De Beaumont L, Mongeon D, Tremblay S, et al. Persistent motor system abnormalities in formerly concussed athletes. Journal of athletic training. 2011;46(3):234-240.

16. Finnoff JT, Peterson VJ, Hollman JH, Smith J. Intrarater and interrater reliability of the Balance Error Scoring System (BESS). $P M \& R$ : the journal of injury, function, and rehabilitation. 2009;1(1):50.

17. Ford-Smith CD, Wyman JF, Elswick R, Fernandez T, Newton RA. Test-retest reliability of the sensory organization test in noninstitutionalized older adults. Archives of physical medicine and rehabilitation. 1995;76(1):77-81.

18. Westcott SL, Crowe TK, Deitz JC, Richardson PK. Test-retest reliability of the pediatric clinical test of sensory interaction for balance (P-CTSIB). Physical \& occupational therapy in pediatrics. 1994;14(1):1-22.

19. Catena RD, van Donkelaar P, Chou L-S. Cognitive task effects on gait stability following concussion. Experimental Brain Research. 2007;176(1):23-31.

20. Parker TM, Osternig LR, Lee H-J, Donkelaar Pv, Chou L-S. The effect of divided attention on gait stability following concussion. Clinical biomechanics. 2005;20(4):389395.

21. Parker TM, Osternig LR, Van Donkelaar P, Chou L. Gait stability following concussion. Medicine and science in sports and exercise. 2006;38(6):1032.

22. Martini DN, Sabin MJ, DePesa SA, et al. The Chronic Effects of Concussion on Gait. Archives of physical medicine and rehabilitation. 2011;92(4):585-589.

23. Slobounov S, Sebastianelli W, Moss R. Alteration of posture-related cortical potentials in mild traumatic brain injury. Neuroscience letters. 2005;383(3):251-255.

24. Slobounov S, Slobounov E, Newell K. Application of virtual reality graphics in assessment of concussion. Cyberpsychology \& Behavior. 2006;9(2):188-191.

25. Guskiewicz KM, Valovich McLeod TC. Pediatric sports-related concussion. $P M \& R$. 2011;3(4):353-364. 
26. McCREA M, Barr WB, Guskiewicz K, et al. Standard regression-based methods for measuring recovery after sport-related concussion. Journal of the International Neuropsychological Society. 2005;11(1):58-69.

27. McCrea M, Guskiewicz K, Marshall S, Barr W, Randolph C, Cantu R. Acute effects and recovery time following concussion in collegiate football players. Journal of the American Medical Association. 2003;290(19):2556-2563.

28. Slobounov S, Sebastianelli W, Hallett M. Residual brain dysfunction observed one year post-mild traumatic brain injury: Combined EEG and balance study. Clinical Neurophysiology. 2012;123(9):1755-1761.

29. Lovell MR, Iverson GL, Collins MW, et al. Measurement of symptoms following sportsrelated concussion: reliability and normative data for the post-concussion scale. Applied neuropsychology. 2006;13(3):166-174.

30. Piek JP, Pitcher TM, Hay DA. Motor coordination and kinaesthesis in boys with attention deficit-hyperactivity disorder. Developmental medicine \& child neurology. 1999;41(3):159-165.

31. Geuze RH. Static balance and developmental coordination disorder. Human Movement Science. 2003;22(4):527-548.

32. Sallis JF, Patterson TL, Buono MJ, Nader PR. Relation of cardiovascular fitness and physical activity to cardiovascular disease risk factors in children and adults. American Journal of Epidemiology. 1988;127(5):933-941.

33. Chen J-K, Johnston KM, Collie A, McCrory P, Ptito A. A validation of the post concussion symptom scale in the assessment of complex concussion using cognitive testing and functional MRI. Journal of Neurology, Neurosurgery \& Psychiatry. 2007;78(11):1231-1238.

34. Kontos AP, Elbin R, Schatz P, et al. A Revised Factor Structure for the Post-Concussion Symptom Scale Baseline and Postconcussion Factors. The American Journal of Sports Medicine. 2012;40(10):2375-2384.

35. Bruininks RH. Bruininks-Oseretsky Test of Motor Proficiency, (BOT-2). Minneapolis, MN: Pearson Assessment. 2005. 
36. Howe J, Inness E, Venturini A, Williams J, Verrier M. The Community Balance and Mobility Scale-a balance measure for individuals with traumatic brain injury. Clinical rehabilitation. 2006;20(10):885-895.

37. Deitz JC, Kartin D, Kopp K. Review of the Bruininks-Oseretsky test of motor proficiency, (BOT-2). Physical \& occupational therapy in pediatrics. 2007;27(4):87-102.

38. http://fs.ncaa.org/Docs/health_safety/BESS\%20manual\%20310.pdf.

39. Iverson GL, Kaarto ML, Koehle MS. Normative data for the balance error scoring system: Implications for brain injury evaluations. Brain Injury. 2008;22(2):147-152.

40. Bell DR, Guskiewicz KM, Clark MA, Padua DA. Systematic review of the balance error scoring system. Sports Health: A Multidisciplinary Approach. 2011;3(3):287-295.

41. McLeod TCV, Perrin DH, Guskiewicz KM, Shultz SJ, Diamond R, Gansneder BM. Serial administration of clinical concussion assessments and learning effects in healthy young athletes. Clinical Journal of Sport Medicine. 2004;14(5):287-295.

42. Wright MJ, Bos C. Performance of Children on the Community Balance and Mobility Scale. Physical \& occupational therapy in pediatrics. 2012;32(4):416-429.

43. Clegg H, Fernande S, Parsley D, Welch T, Zbarsky K. Community balance and mobility scale: age-related reference values. 2009.

44. Wright FV, Ryan J, Brewer K. Reliability of the Community Balance and Mobility Scale (CB\&M) in high-functioning school-aged children and adolescents who have an acquired brain injury. Brain Injury. 2010;24(13-14):1585-1594.

45. Greene BR, Foran TG, McGrath D, Doheny EP, Burns A, Caulfield B. A Comparison of Algorithms for Body-Worn Sensor-Based Spatiotemporal Gait Parameters to the GAITRite Electronic Walkway. Journal of applied biomechanics. 2012;28(3):349-355.

46. Thorpe DE, Dusing SC, Moore CG. Repeatability of Temporospatial Gait Measures in Children Using the GAITRite Electronic Walkway. Archives of physical medicine and rehabilitation. 2005;86(12):2342-2346.

47. Montero-Odasso M, Casas A, Hansen KT, et al. Quantitative gait analysis under dualtask in older people with mild cognitive impairment: a reliability study. Journal of neuroengineering and rehabilitation. 2009;6(1):35.

48. Catena RD, van Donkelaar P, Chou L-S. Altered balance control following concussion is better detected with an attention test during gait. Gait \& posture. 2007;25(3):406-411. 
49. McFadyen BJ, Malouin F, Dumas F. Anticipatory locomotor control for obstacle avoidance in mid-childhood aged children. Gait \& posture. 2001;13(1):7-16.

50. Katz-Leurer M, Rotem H, Keren O, Meyer S. The effect of variable gait modes on walking parameters among children post severe traumatic brain injury and typically developed controls. NeuroRehabilitation. 2011;29(1):45-51.

51. Rinehart NJ, Tonge BJ, Iansek R, et al. Gait function in newly diagnosed children with autism: cerebellar and basal ganglia related motor disorder. Developmental medicine \& child neurology. 2006;48(10):819-824.

52. Cherng R-J, Liang L-Y, Hwang I-S, Chen J-Y. The effect of a concurrent task on the walking performance of preschool children. Gait \& posture. 2007;26(2):231-237.

53. Alderson L, Watson T, Main E. Assessment of dynamic walking balance in children with acquired brain injury. Physical therapy reviews. 2007;12(1):3-20.

54. Horak FB, Henry SM, Shumway-Cook A. Postural perturbations: new insights for treatment of balance disorders. Physical Therapy. 1997;77(5):517-533.

55. Guskiewicz KM, Ross SE, Marshall SW. Postural stability and neuropsychological deficits after concussion in collegiate athletes. Journal of athletic training. 2001;36(3):263.

56. Perrin DH. Repeat administration elicits a practice effect with the Balance Error Scoring System but not with the Standardized Assessment of Concussion in high school athletes. 2003.

57. Hirabayashi S-i, Iwasaki Y. Developmental perspective of sensory organization on postural control. Brain and development. 1995;17(2):111-113.

58. Catena RD, van Donkelaar P, Halterman CI, Chou L-S. Spatial orientation of attention and obstacle avoidance following concussion. Experimental Brain Research. 2009;194(1):67-77.

59. Draganich LF, Kuo CE. The effects of walking speed on obstacle crossing in healthy young and healthy older adults. Journal of biomechanics. 2004;37(6):889-896.

60. Lowrey CR, Watson A, Vallis LA. Age-related changes in avoidance strategies when negotiating single and multiple obstacles. Experimental Brain Research. 2007;182(3):289-299. 
61. Parker TM, Osternig LR, van Donkelaar P, Chou L-S. Recovery of cognitive and dynamic motor function following concussion. British journal of sports medicine. December 1, 2007 2007;41(12):868-873.

62. Parker TM, Osternig LR, van Donkelaar P, Chou L-S. Balance control during gait in athletes and non-athletes following concussion. Medical engineering \& physics. 2008;30(8):959-967.

63. Broglio SP, Tomporowski PD, Ferrara MS. Balance performance with a cognitive task: a dual-task testing paradigm. Med Sci Sports Exerc. 2005;37(4):689-695. 
Tables:

Table 4.1: Demographics of the samples

\begin{tabular}{|c|c|c|c|c|c|}
\hline Variables & mTBI Group & Control Group & $\begin{array}{l}\text { Statistical } \\
\text { Test value }\end{array}$ & p value & Confidence Intervals at $95 \%$ \\
\hline $\begin{array}{l}\text { Age } \\
(\text { Mean } \pm \text { SD) } \\
\text { Gender }(\%)\end{array}$ & $13.15 \pm 2.20$ & $13.59 \pm 2.56$ & $\mathrm{t}=-0.653$ & 0.518 & {$[-1.81,0.92]$} \\
\hline Boys: & $70.30 \%$ & $36.36 \%$ & $\chi 2=3.115$ & 0.078 & \\
\hline Girls: & $29.63 \%$ & $54.54 \%$ & & & \\
\hline $\begin{array}{l}\text { PCS } \\
(\text { Mean } \pm \text { SD })\end{array}$ & $1.26 \pm 1.89$ & $4.73 \pm 9.32$ & $\mathrm{t}=-1.891$ & 0.065 & {$[-7.16,0.22]$} \\
\hline $\begin{array}{l}\text { ARS } \\
(\text { Mean } \pm \text { SD) }\end{array}$ & $4.07 \pm 0.66$ & $3.64 \pm 1.00$ & $\mathrm{t}=1.820$ & 0.075 & {$[-0.05,0.92]$} \\
\hline
\end{tabular}


Table 4.2: Group performance (means \pm SD) on the three clinical balance measures and gait parameters measured under single task and dual task conditions

\begin{tabular}{|c|c|c|c|c|c|c|}
\hline Balance measures & $\begin{array}{l}\text { mTBI group } \\
(\text { Mean } \pm \text { SD) }\end{array}$ & $\begin{array}{c}\text { Control } \\
\text { group } \\
(\text { Mean } \pm \text { SD) }\end{array}$ & $\begin{array}{c}\text { t } \\
\text { values }\end{array}$ & $\begin{array}{c}\mathbf{p} \\
\text { value }\end{array}$ & $\begin{array}{c}\text { Confidence intervals at } \\
\qquad 95 \%\end{array}$ & $\begin{array}{c}\text { Effect } \\
\text { size: } \\
\text { Cohen's d }\end{array}$ \\
\hline \multicolumn{7}{|l|}{ Clinical Balance Tests } \\
\hline \multicolumn{7}{|l|}{ BOT-2- Balance Subtest } \\
\hline Total Point score & $33.30 \pm 2.20$ & $35.09 \pm 2.05$ & $2.932 *$ & 0.005 & {$[-3.03,-0.56]$} & -0.84 \\
\hline Standing on beam tandem & $3.70 \pm 0.61$ & $4.00 \pm 0.00$ & $2.530 *$ & 0.18 & {$[-0.537,-0.056]$} & -0.70 \\
\hline Standing SLS on beam EC & $2.30 \pm 1.10$ & $3.59 \pm 1.37$ & $3.669 *$ & 0.001 & {$[-2.01,-0.59]$} & -1.04 \\
\hline \multicolumn{7}{|l|}{$\underline{\text { BESS }}$} \\
\hline \multicolumn{7}{|l|}{$\underline{\text { CB\&M }}$} \\
\hline Total & $84.63 \pm 5.37$ & $88.64 \pm 3.71$ & $2.969 *$ & 0.005 & {$[-6.72,-1.29]$} & -0.87 \\
\hline \multicolumn{7}{|l|}{ Gait Paradigms } \\
\hline \multicolumn{7}{|l|}{ Self-Selected Pace (SSP) } \\
\hline $\begin{array}{l}\text { Velocity } \\
(\mathrm{cm} / \mathrm{sec})\end{array}$ & $106.80 \pm 19.31$ & $113.20 \pm 16.49$ & -1.232 & 0.224 & {$[-16.86,4.06]$} & -0.36 \\
\hline $\begin{array}{l}\text { Stride width } \\
(\mathrm{cm})\end{array}$ & $7.08 \pm 2.26$ & $4.97 \pm 2.07$ & $0.891 *$ & 0.001 & {$[0.86,3.38]$} & 0.97 \\
\hline $\begin{array}{l}\text { Step length } \\
(\mathrm{cm})\end{array}$ & $63.52 \pm 8.72$ & $64.10 \pm 6.22$ & -0.261 & 0.795 & {$[-5.03,3.87]$} & -0.08 \\
\hline
\end{tabular}




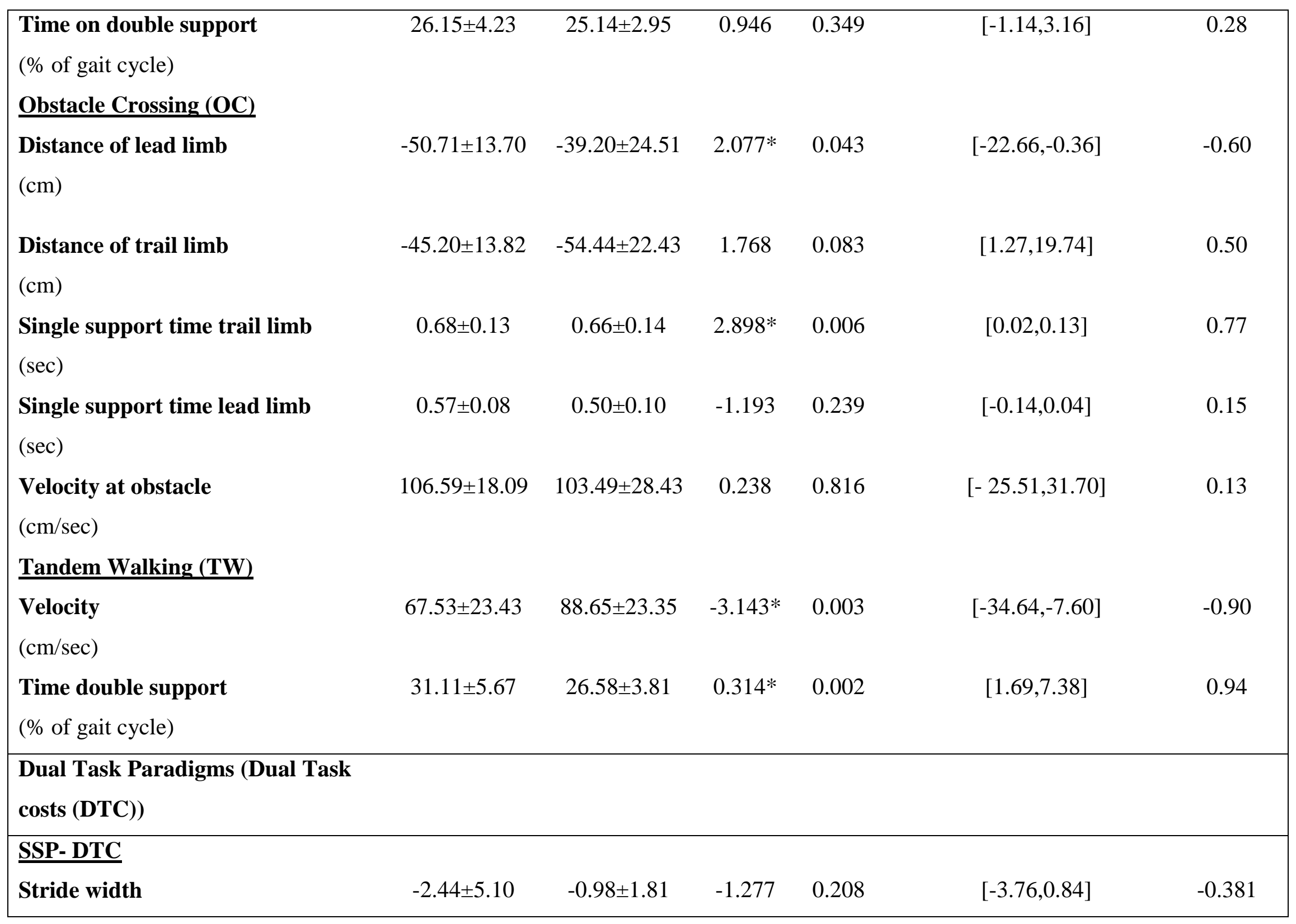




\begin{tabular}{|c|c|c|c|c|c|c|}
\hline \multicolumn{7}{|l|}{$(\mathrm{cm})$} \\
\hline $\begin{array}{l}\text { Step length } \\
(\mathrm{cm})\end{array}$ & $7.47 \pm 5.70$ & $6.35 \pm 5.22$ & .731 & 0.479 & {$[-2.05,4.29]$} & 0.204 \\
\hline $\begin{array}{l}\text { \% time on double support } \\
\text { OC-DTC }\end{array}$ & $-4.34 \pm 4.58$ & $-2.48 \pm 3.75$ & -1.533 & 0.132 & {$[-4.31,0.58]$} & 0.444 \\
\hline $\begin{array}{l}\text { Distance of lead limb } \\
(\mathrm{cm})\end{array}$ & $-1.18 \pm 3.30$ & $-0.69 \pm 2.17$ & -0.590 & 0.558 & {$[-2.13,1.17]$} & -0.175 \\
\hline $\begin{array}{l}\text { Distance of trail limb } \\
(\mathrm{cm})\end{array}$ & $0.05 \pm 1.39$ & $-0.35 \pm 1.25$ & 1.56 & 0.307 & {$[-0.37,1.16]$} & 0.302 \\
\hline $\begin{array}{l}\text { Single support time trail limb } \\
(\mathrm{sec})\end{array}$ & $-0.12 \pm 0.15$ & $-0.15 \pm 0.18$ & 0.572 & 0.570 & {$[-0.68,0.12]$} & 0.181 \\
\hline $\begin{array}{l}\text { Single support time lead limb } \\
(\mathrm{sec})\end{array}$ & $-0.07 \pm 0.10$ & $-0.13 \pm 0.18$ & -0.120 & 0.125 & {$[-0.018,0.14]$} & 0.412 \\
\hline $\begin{array}{l}\text { Velocity at obstacle } \\
(\mathrm{cm} / \mathrm{sec})\end{array}$ & $20.68 \pm 17.75$ & $21.27 \pm 17.66$ & 1.032 & 0.905 & {$[-10.84,9.62]$} & -0.033 \\
\hline \multicolumn{7}{|l|}{ TW-DTC } \\
\hline \% time double support & $-0.45 \pm 4.64$ & $-1.22 \pm 1.96$ & .724 & 0.472 & {$[-1.37,2.90]$} & 0.216 \\
\hline
\end{tabular}

*: statistical significance at $\mathrm{p}<0.05 ; \mathrm{SLS}=$ Single Leg Stance, EC=Eyes Closed, DTC=Dual Task Cost 
Table 4.3: Classification results of the discriminant analysis

\section{Classification Results ${ }^{b, c}$}

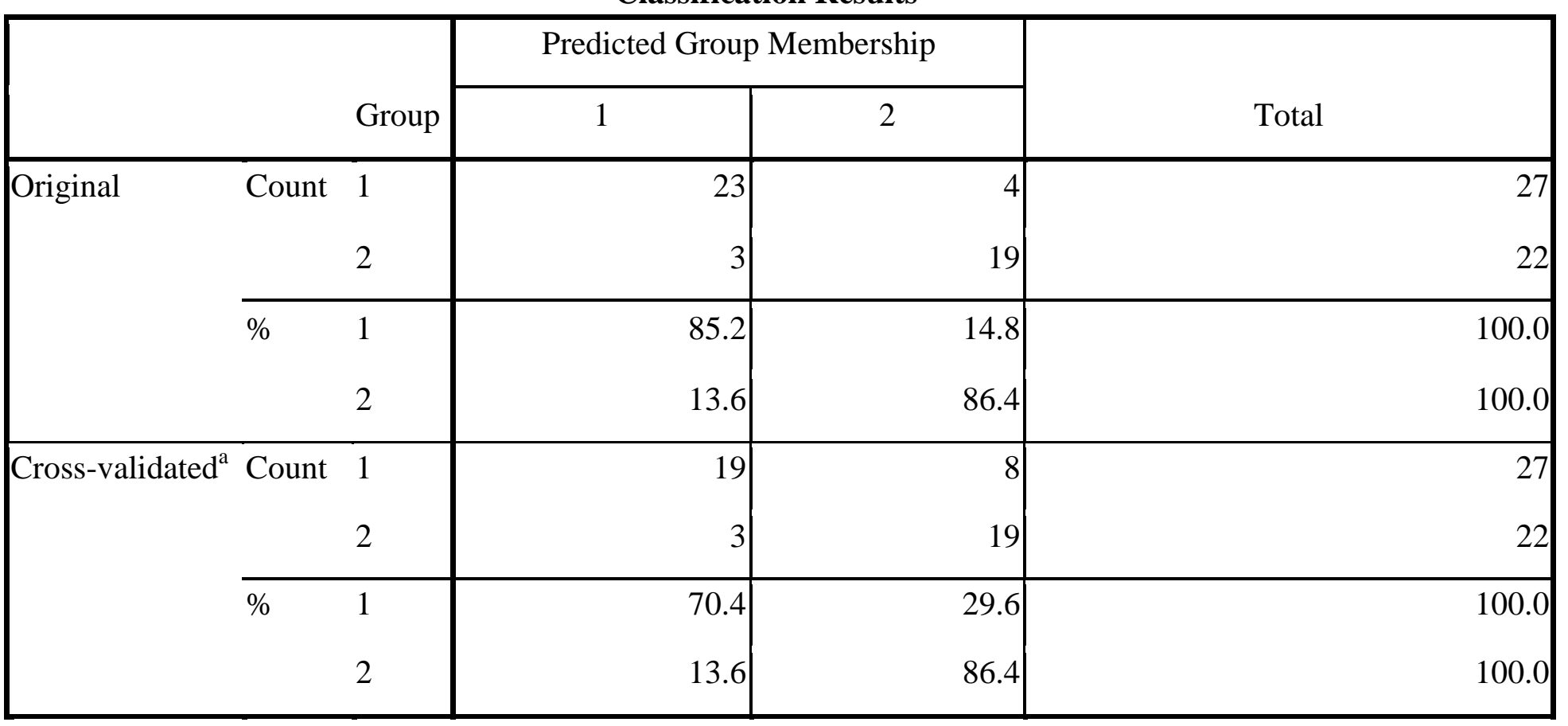

Where 1- mTBI group and 2- Control group

a. Cross validation is done only for those cases in the analysis. In cross validation, each case is classified by the functions derived from all cases other than that case.

b. $85.7 \%$ of original grouped cases correctly classified.

c. $77.6 \%$ of cross-validated grouped cases correctly classified. 
Table 4.4: Means and SDs of DTC variables used in repeated measures ANOVA:

\begin{tabular}{|c|c|c|}
\hline Variables & $\begin{array}{l}\text { mTBI Group } \\
(\text { Mean } \pm \text { SD) }\end{array}$ & $\begin{array}{l}\text { Control Group } \\
\text { (Mean } \pm \text { SD) }\end{array}$ \\
\hline \multicolumn{3}{|l|}{ SSP- DTC } \\
\hline $\begin{array}{l}\text { Velocity } \\
(\mathrm{cm} / \mathrm{sec})\end{array}$ & $26.28 \pm 16.45$ & $26.71 \pm 17.40$ \\
\hline $\begin{array}{l}\text { Accuracy } \\
(\%)\end{array}$ & $8.54 \pm 11.50$ & $0.50 \pm 6.71$ \\
\hline $\begin{array}{l}\text { Response rate } \\
\text { (sec) } \\
\text { OC- DTC }\end{array}$ & $0.41 \pm 0.42$ & $0.43 \pm 0.41$ \\
\hline $\begin{array}{l}\text { Velocity } \\
(\mathrm{cm} / \mathrm{sec})\end{array}$ & $22.81 \pm 13.70$ & $23.87 \pm 17.85$ \\
\hline $\begin{array}{l}\text { Accuracy } \\
(\%)\end{array}$ & $1.17 \pm 11.36$ & $6.95 \pm 10.29$ \\
\hline $\begin{array}{l}\text { Response rate } \\
\text { (sec) } \\
\text { TW-DTC }\end{array}$ & $0.35 \pm 0.33$ & $0.49 \pm 0.35$ \\
\hline $\begin{array}{l}\text { Velocity } \\
(\mathrm{cm} / \mathrm{sec})\end{array}$ & $4.90 \pm 15.45$ & $15.45 \pm 15.06$ \\
\hline $\begin{array}{l}\text { Accuracy } \\
(\%)\end{array}$ & $1.61 \pm 9.36$ & $2.45 \pm 14.01$ \\
\hline $\begin{array}{l}\text { Response rate } \\
(\mathrm{sec})\end{array}$ & $0.38 \pm 0.34$ & $0.48 \pm 0.45$ \\
\hline
\end{tabular}




\section{CHAPTER 5: CONCLUSION}

Proper management of individuals with an mTBI and their safe return to physical activities is being emphasized greatly in research and in the public. There is a growing recognition of the importance of a multi-disciplinary team approach in the management of mTBI patients and that balance testing be incorporated as an objective measure to test these individuals. More high technology methods of balance testing have revealed that children and adolescents tend to have persisting balance deficits even after three months of injury. Hence, there is the need for more sensitive clinical measures to assess balance before prematurely deciding to return an individual to complete physical activity.

Our study has revealed that children and adolescents, who were considered clinically recovered and ready for return to physical activities, still showed balance deficits compared to healthy age/gender matched controls. Poor performance on all three clinical balance measures reveal that children and youth with mTBI still suffer persistent balance deficits and premature return to physical activities may lead to increased risk of injury.

These deficits were further highlighted while testing gait paradigms under single task conditions. Our results revealed that children and adolescents had problems in performing tasks eyes closed as well as tasks that involved changing surface and narrowing BoS. Also, through the various gait paradigms it was noted that they tend to adopt a wider BoS and have poorer and more conservative strategies of balance while being challenged under more narrow and unstable conditions. The BESS and tandem walking were found to be the most sensitive measures for predicting group differences. It may be recommended that clinicians consider the assessment of tandem walking and incorporate the BESS as part of their practice. This further adds evidence to the SCAT-3, where conditions of the BESS and tandem walking are prescribed as part of assessment protocol.

With regards to the dual task component, further research needs to be carried out by using a more sensitive and challenging task to detect group differences under dual task conditions, if present. Our study sheds further light into the possible causes of poor balance that need to be further explored. Finally, it confirms that symptom resolution and recovery simple balance measures alone may not be sufficient for clinicians to arrive at effective, objective and safe return to 
physical activity decisions. It is important to consider other aspects of balance as well to ensure that the individual is not at risk of suffering further injury based on premature decision making. 


\section{References}

1. Guskiewicz KM, Valovich McLeod TC. Pediatric sports-related concussion. Physical Medicine \& Rehabilitation. 2011;3(4):353-364.

2. http://www.cdc.gov/mmwr/preview/mmwrhtml/mm6039a1.htm?s_cid=mm6039a1_w.

3. McCrory P, Johnston K, Meeuwisse W, et al. Summary and agreement statement of the 2nd International Conference on Concussion in Sport, Prague 2004. British journal of sports medicine. 2005;39(4):196-204.

4. McCrory P, Meeuwisse WH, Aubry M, et al. Consensus statement on concussion in sport: the 4th International Conference on Concussion in Sport held in Zurich, November 2012. British journal of sports medicine. 2013;47(5):250-258.

5. Parker TM, Osternig LR, Van Donkelaar P, Chou L. Gait stability following concussion. Medicine and science in sports and exercise. 2006;38(6):1032.

6. Catena RD, van Donkelaar P, Chou L-S. Altered balance control following concussion is better detected with an attention test during gait. Gait \& posture. 2007;25(3):406-411.

7. Robert C, van Donkelaar Paul CL-S. Different gait tasks distinguish immediate vs. longterm effects of concussion on balance control. Journal of neuroengineering and rehabilitation.6.

8. Martini DN, Sabin MJ, DePesa SA, et al. The Chronic Effects of Concussion on Gait. Archives of physical medicine and rehabilitation. 2011;92(4):585-589.

9. Gagnon I, Swaine B, Friedman D, Forget R. Children show decreased dynamic balance after mild traumatic brain injury. Archives of physical medicine and rehabilitation. 2004;85(3):444-452.

10. Halstead ME, Walter KD. Sport-related concussion in children and adolescents. Pediatrics. 2010;126(3):597-615.

11. Grady MF, Master CL, Gioia GA. Concussion pathophysiology: rationale for physical and cognitive rest. Pediatric annals. Sep 2012;41(9):377-382.

12. Daneshvar DH, Riley DO, Nowinski CJ, McKee AC, Stern RA, Cantu RC. Long Term Consequences: Effects on Normal Development Profile after Concussion. Physical medicine and rehabilitation clinics of North America. 2011;22(4):683. 
13. Falk A-C, Cederfjäll C, Von Wendt L, Söderkvist BK. Management and classification of children with head injury. Child's Nervous System. 2005;21(6):430-436.

14. Tator CH. Let's Standardize the Definition of Concussion and Get Reliable Incidence Data. The Canadian Journal of Neurological Sciences. 2009;36(4):405-406.

15. Carroll L, Cassidy JD, Peloso P, et al. Prognosis for mild traumatic brain injury: results of the WHO Collaborating Centre Task Force on Mild Traumatic Brain Injury. Journal of rehabilitation medicine. 2004;36(0):84-105.

16. Faul M, Xu L, Wald M, Coronado V. Traumatic brain injury in the United States: Emergency department visits, hospitalizations and deaths 2002-2006. Atlanta, GA: Centers for Disease Control and Prevention, National Center for Injury Prevention and Control. 2010.

17. Gessel LM, Fields SK, Collins CL, Dick RW, Comstock RD. Concussions among United States high school and collegiate athletes. Journal of athletic training. 2007;42(4):495.

18. Meehan WP, 3rd, Mannix R. Pediatric concussions in United States emergency departments in the years 2002 to 2006. The Journal of pediatrics. Dec 2010;157(6):889893.

19. Langlois JA, Rutland-Brown W, Wald MM. The epidemiology and impact of traumatic brain injury: a brief overview. The Journal of head trauma rehabilitation. Sep-Oct 2006;21(5):375-378.

20. Bakhos LL, Lockhart GR, Myers R, Linakis JG. Emergency department visits for concussion in young child athletes. Pediatrics. Sep 2010;126(3):e550-556.

21. https://secure.cihi.ca/free_products/ntr_head_injuries_2006_e.pdf.

22. Gordon KE, Dooley JM, Wood EP. Descriptive epidemiology of concussion. Pediatric neurology. May 2006;34(5):376-378.

23. http://www.thechildren.com/health-info/safety-and-wellness/mild-traumatic-brain-injurymtbi.

24. http://www.thechildren.com/health-info/safety-and-wellness/mch-trauma-concussion-kit.

25. Kraus JF. Epidemiological features of brain injury in children: Occurrence, children at risk, causes and manner of injury, severity, and outcomes. Traumatic head injury in children. 1995:22-39. 
26. Holland B, Haas D, Norman D, Brant-Zawadzki M, Newton T. MRI of normal brain maturation. American Journal of Neuroradiology. 1986;7(2):201-208.

27. Buzzini SRR, Guskiewicz KM. Sport-related concussion in the young athlete. Current opinion in pediatrics. 2006;18(4):376-382.

28. McKeever CK, Schatz P. Current issues in the identification, assessment, and management of concussions in sports-related injuries. Applied neuropsychology. 2003;10(1):4-11.

29. Swaine BR, Tremblay C, Platt RW, Grimard G, Zhang X, Pless IB. Previous head injury is a risk factor for subsequent head injury in children: a longitudinal cohort study. Pediatrics. 2007;119(4):749-758.

30. Guskiewicz KM, McCrea M, Marshall SW, et al. Cumulative effects associated with recurrent concussion in collegiate football players. The journal of the American Medical Association. 2003;290(19):2549-2555.

31. Guskiewicz KM, Weaver NL, Padua DA, Garrett WE. Epidemiology of concussion in collegiate and high school football players. The American Journal of Sports Medicine. 2000;28(5):643-650.

32. Covassin T, Swanik CB, Sachs ML. Sex differences and the incidence of concussions among collegiate athletes. Journal of athletic training. 2003;38(3):238.

33. Straume-Naesheim TM, Andersen TE, Dvorak J, Bahr R. Effects of heading exposure and previous concussions on neuropsychological performance among Norwegian elite footballers. British journal of sports medicine. 2005;39(suppl 1):i70-i77.

34. Mansell J, Tierney RT, Sitler MR, Swanik KA, Stearne D. Resistance training and headneck segment dynamic stabilization in male and female collegiate soccer players. Journal of athletic training. 2005;40(4):310.

35. Tierney RT, Sitler MR, Swanik CB, Swanik KA, Higgins M, Torg J. Gender differences in head-neck segment dynamic stabilization during head acceleration. Medicine and science in sports and exercise. 2005;37(2):272-279.

36. Meehan III WP, Bachur RG. Sport-related concussion. Pediatrics. 2009;123(1):114-123.

37. Ropper AH, Gorson KC. Concussion. New England Journal of Medicine. 2007;356(2):166-172. 
38. Lovell MR, Collins MW, Maroon JC, et al. Inaccuracy of symptom reporting following concussion in athletes. Medicine \& Science in Sports \& Exercise. 2002;34(5):S298.

39. Goodman D, Gaetz M, Meichenbaum D. Concussions in hockey: there is cause for concern. Medicine and science in sports and exercise. 2001;33(12):2004.

40. Giza CC, Hovda DA. The neurometabolic cascade of concussion. Journal of athletic training. 2001;36(3):228.

41. Gurkoff GG, Giza CC, Hovda DA. Lateral fluid percussion injury in the developing rat causes an acute, mild behavioral dysfunction in the absence of significant cell death. Brain research. 2006;1077(1):24-36.

42. Thompson HJ, Lifshitz J, Marklund N, et al. Lateral fluid percussion brain injury: a 15year review and evaluation. Journal of neurotrauma. 2005;22(1):42-75.

43. Schmidt OI, Heyde CE, Ertel W, Stahel PF. Closed head injury — an inflammatory disease? Brain research reviews. 2005;48(2):388-399.

44. Yuen TJ, Browne KD, Iwata A, Smith DH. Sodium channelopathy induced by mild axonal trauma worsens outcome after a repeat injury. Journal of neuroscience research. 2009;87(16):3620-3625.

45. Udomphorn Y, Armstead WM, Vavilala MS. Cerebral blood flow and autoregulation after pediatric traumatic brain injury. Pediatric neurology. 2008;38(4):225-234.

46. Donat CK, Walter B, Kayser T, et al. Effects of lateral fluid percussion injury on cholinergic markers in the newborn piglet brain. International Journal of Developmental Neuroscience. 2010;28(1):31-38.

47. McKeag DB, Kutcher JS. Concussion consensus: raising the bar and filling in the gaps. Clinical Journal of Sport Medicine. 2009;19(5):343.

48. Crane AT, Fink KD, Smith JS. The effects of acute voluntary wheel running on recovery of function following medial frontal cortical contusions in rats. Restorative Neurology and Neuroscience. 2012;30(4):325-333.

49. Lee MA, Perriello Jr VA. Adolescent Concussions--Management Guidelines for Schools. Connecticut medicine. 2009;73(3):171.

50. Grady MF. Concussion in the adolescent athlete. Current problems in pediatric and adolescent health care. 2010;40(7):154-169. 
51. Bergsneider M, Hovda DA, Shalmon E, et al. Cerebral hyperglycolysis following severe traumatic brain injury in humans: a positron emission tomography study. Journal of neurosurgery. 1997;86(2):241-251.

52. Wilde EA, McCauley SR, Barnes A, et al. Serial measurement of memory and diffusion tensor imaging changes within the first week following uncomplicated mild traumatic brain injury. Brain imaging and behavior. 2012:1-10.

53. Blumbergs PC, Jones NR, North JB. Diffuse axonal injury in head trauma. Journal of neurology, neurosurgery, and psychiatry. 1989;52(7):838.

54. Gardner A, Iverson GL, Stanwell P. A Systematic Review of Proton Magnetic Resonance Spectroscopy in Sport-Related Concussion. Journal Neurotrauma. Sep 182013.

55. Ford JH, Giovanello KS, Guskiewicz KM. Episodic memory in former professional football players with a history of concussion: an event-related functional neuroimaging study. Journal Neurotrauma. Oct 15 2013;30(20):1683-1701.

56. Dimou S, Lagopoulos J. Towards objective markers of concussion in sport: a review of white matter and neurometabolic changes in the brain following sports-related concussion. Journal Neurotrauma. Nov 242013.

57. De Beaumont L, Beauchemin M, Beaulieu C, Jolicoeur P. Long-term attenuated electrophysiological response to errors following multiple sports concussions. Journal of Clinical Experimental Neuropsychology. 2013;35(6):596-607.

58. Koberda JL, Moses A, Koberda P, Koberda L. Clinical Advantages of Quantitative Electroencephalogram (QEEG)-Electrical Neuroimaging Application in General Neurology Practice. Clinical EEG and neuroscience : official journal of the EEG and Clinical Neuroscience Society (ENCS). Mar 262013.

59. Mechtler LL, Shastri KK, Crutchfield KE. Advanced neuroimaging of mild traumatic brain injury. Neurologic clinics. Feb 2014;32(1):31-58.

60. Strain J, Didehbani N, Cullum CM, et al. Depressive symptoms and white matter dysfunction in retired NFL players with concussion history. Neurology. Jul 2 2013;81(1):25-32.

61. Mendez MF, Owens EM, Reza Berenji G, Peppers DC, Liang LJ, Licht EA. Mild traumatic brain injury from primary blast vs. blunt forces: post-concussion consequences and functional neuroimaging. NeuroRehabilitation. 2013;32(2):397-407. 
62. Nariai T, Inaji M, Tanaka Y, et al. PET molecular imaging to investigate higher brain dysfunction in patients with neurotrauma. Acta neurochirurgica. Supplement. 2013;118:251-254.

63. Blinman TA, Houseknecht E, Snyder C, Wiebe DJ, Nance ML. Postconcussive symptoms in hospitalized pediatric patients after mild traumatic brain injury. Journal of pediatric surgery. 2009;44(6):1223-1228.

64. McCrory P, Meeuwisse W, Johnston K, et al. Consensus statement on Concussion in Sport-the 3rd International Conference on Concussion in Sport held in Zurich, November 2008. South African Journal of Sports Medicine. 2009;21(2).

65. Anderson V, Catroppa C, Morse S, Haritou F, Rosenfeld J. Outcome from mild head injury in young children: A prospective study. Journal of clinical and experimental neuropsychology. 2001;23(6):705-717.

66. Silver J, McAllister T, Arciniegas D. Depression and cognitive complaints following mild traumatic brain injury. American Journal of Psychiatry. 2009;166(6):653-661.

67. Chamelian L, Feinstein A. The effect of major depression on subjective and objective cognitive deficits in mild to moderate traumatic brain injury. The Journal of neuropsychiatry and clinical neurosciences. 2006;18(1):33-38.

68. Iverson GL, Brooks BL, Collins MW, Lovell MR. Tracking neuropsychological recovery following concussion in sport. Brain Injury. 2006;20(3):245-252.

69. Kirkwood MW, Yeates KO, Wilson PE. Pediatric sport-related concussion: a review of the clinical management of an oft-neglected population. Pediatrics. 2006;117(4):13591371.

70. Miles L, Grossman RI, Johnson G, Babb JS, Diller L, Inglese M. Short-term DTI predictors of cognitive dysfunction in mild traumatic brain injury. Brain Injury. 2008;22(2):115-122.

71. Wilde E, McCauley S, Hunter J, et al. Diffusion tensor imaging of acute mild traumatic brain injury in adolescents. Neurology. 2008;70(12):948-955.

72. Zhang K, Johnson B, Pennell D, Ray W, Sebastianelli W, Slobounov S. Are functional deficits in concussed individuals consistent with white matter structural alterations: combined FMRI \& DTI study. Experimental Brain Research. 2010;204(1):57-70. 
73. Holli KK, Wäljas M, Harrison L, et al. Mild traumatic brain injury: tissue texture analysis correlated to neuropsychological and DTI findings. Academic Radiology.

2010;17(9):1096-1102.74. FitzGerald DB, Crosson BA. Diffusion weighted imaging and neuropsychological correlates in adults with mild traumatic brain injury.

International Journal of Psychophysiology. 2011;82(1):79-85.

75. Kleffelgaard I, Roe C, Sandvik L, Hellstrom T, Soberg HL. Measurement properties of the high-level mobility assessment tool for mild traumatic brain injury. Phys Ther. Jul 2013;93(7):900-910.

76. Ruijs MBM, Keyser A, Gabreëls FJM. Long-term sequelae of brain damage from closed head injury in children and adolescents. Clinical Neurology and Neurosurgery. 1990;92(4):323-328.

77. Cohen JS, Gioia G, Atabaki S, Teach SJ. Sports-related concussions in pediatrics. Current opinion in pediatrics. 2009;21(3):288-293.

78. Guskiewicz KM, Bruce SL, Cantu RC, et al. National Athletic Trainers' Association position statement: management of sport-related concussion. Journal of Athletic Training. 2004;39(3):280-297.

79. Lovell MR, Iverson GL, Collins MW, et al. Measurement of symptoms following sportsrelated concussion: reliability and normative data for the post-concussion scale. Applied Neuropsychology. 2006;13(3):166-174.

80. Gioia GA. Pediatric assessment and management of concussions. Pediatric annals. 2012;41(5):198-203.

81. Schatz P, Pardini JE, Lovell MR, Collins MW, Podell K. Sensitivity and specificity of the ImPACT Test Battery for concussion in athletes. Archives of Clinical Neuropsychology. 2006;21(1):91-99.

82. Collie A, Maruff P, Makdissi M, McCrory P, McStephen M, Darby D. CogSport: reliability and correlation with conventional cognitive tests used in postconcussion medical evaluations. Clinical Journal of Sport Medicine. 2003;13(1):28-32.

83. Broglio SP, Ferrara MS, Macciocchi SN, Baumgartner TA, Elliott R. Test-retest reliability of computerized concussion assessment programs. Journal of Athletic Training. 2007;42(4):509-514.84. Brown CN, Guskiewicz KM, Bleiberg J. Athlete 
characteristics and outcome scores for computerized neuropsychological assessment: a preliminary analysis. Journal of athletic training. 2007;42(4):515.

85. Finnoff JT, Peterson VJ, Hollman JH, Smith J. Intrarater and interrater reliability of the Balance Error Scoring System (BESS). PM\&R. 2009;1(1):50-54.

86. Bruininks RH. Bruininks-Oseretsky Test of Motor Proficiency, (BOT-2). Minneapolis, MN: Pearson Assessment. 2005.

87. Schatz P, Moser RS. Current issues in pediatric sports concussion. The Clinical Neuropsychologist. 2011;25(6):1042-1057.

88. Guskiewicz KM, Ross SE, Marshall SW. Postural stability and neuropsychological deficits after concussion in collegiate athletes. Journal of athletic training. 2001;36(3):263.

89. Hurley RA, McGowan JC, Arfanakis K, Taber KH. Traumatic axonal injury: novel insights into evolution and identification. The Journal of neuropsychiatry and clinical neurosciences. 2004;16(1):1-7.

90. Lee B, Newberg A. Neuroimaging in traumatic brain imaging. NeuroRx. 2005;2(2):372383.

91. Munson S, Schroth E, Ernst M. The role of functional neuroimaging in pediatric brain injury. Pediatrics. 2006;117(4):1372-1381.

92. Lovell MR, Pardini JE, Welling J, et al. Functional Brain Abnormalities Are Related to Clinical Recovery and Time to Return-to-Play in Athletes. Neurosurgery. 2007;61(2):352.

93. Johnston KM, Ptito A, Chankowsky J, Chen JK. New frontiers in diagnostic imaging in concussive head injury. Clinical Journal of Sport Medicine. 2001;11(3):166-175.

94. McClincy MP, Lovell MR, Pardini J, Collins MW, Spore MK. Recovery from sports concussion in high school and collegiate athletes. Brain Injury. 2006;20(1):33-39.

95. Sim A, Terryberry-Spohr L, Wilson KR. Prolonged recovery of memory functioning after mild traumatic brain injury in adolescent athletes. 2008 .

96. Farace E, Alves WM. Do women fare worse: a metaanalysis of gender differences in traumatic brain injury outcome. Journal of neurosurgery. 2000;93(4):539-545. 
97. Covassin T, Stearne D, Elbin III R. Concussion history and postconcussion neurocognitive performance and symptoms in collegiate athletes. Journal of athletic training. 2008;43(2):119.

98. Slobounov S, Slobounov E, Sebastianelli W, Cao C, Newell K. Differential rate of recovery in athletes after first and second concussion episodes. Neurosurgery. 2007;61(2):338-344.

99. Lovell M. The management of sports-related concussion: current status and future trends. Clinics in sports medicine. 2009;28(1):95-111.

100. Purcell L. What are the most appropriate return-to-play guidelines for concussed child athletes? British journal of sports medicine. 2009;43(Suppl 1):i51-i55.

101. Hrysomallis C. Balance Ability and Athletic Performance. Sports Medicine. Mar 2011 2011;41(3):221-232.

102. Bahr R, Holme I. Risk factors for sports injuries - a methodological approach. British journal of sports medicine. 2003;37(5):384-392.

103. Shumway-Cook A, Woollacott MH. Motor control: translating research into clinical practice: Lippincott Williams \& Wilkins; 2006.

104. Bell F. Principles of mechanics and biomechanics: Nelson Thornes; 1998.

105. Pollock AS, Durward BR, Rowe PJ, Paul JP. What is balance? Clinical rehabilitation. 2000;14(4):402-406.

106. Dewey D, Tupper DE. Developmental motor disorders: A neuropsychological perspective: Guilford Press; 2004.

107. Woollacott MH, Tang P-F. Balance control during walking in the older adult: research and its implications. Physical Therapy. 1997;77(6):646-660.

108. Horak FB, Henry SM, Shumway-Cook A. Postural perturbations: new insights for treatment of balance disorders. Physical Therapy. 1997;77(5):517-533.

109. Maki BE, McIlroy WE. The role of limb movements in maintaining upright stance: the “change-in-support” strategy. Physical Therapy. 1997;77(5):488-507.

110. Levangie PK, Norkin CC. Joint structure and function: a comprehensive analysis: FA Davis Philadelphia, PA; 2001.

111. Irrgang J, Whitney S, Cox E. Balance and proprioceptive training for rehabilitation of the lower extremity. J Sport Rehabil. 1994;3(1):68-83. 
112. Woollacott M, Shumway-Cook A. Attention and the control of posture and gait: a review of an emerging area of research. Gait \& posture. 2002;16(1):1-14.

113. Peterka R. Sensorimotor integration in human postural control. Journal of neurophysiology. 2002;88(3):1097-1118.

114. Jacobson GP, Newman CW, Kartush JM. Handbook of balance function testing: Singular; 1997.

115. Berthoz A, Lacour M, Soechting J, Vidal P. The role of vision in the control of posture during linear motion. Prog Brain Res. 1979;50:197-209.

116. Steindl R, Kunz K, Schrott-Fischer A, Scholtz A. Effect of age and sex on maturation of sensory systems and balance control. Developmental medicine \& child neurology. 2006;48(6):477-482.

117. Shumway-Cook A, Woollacott MH. The growth of stability: postural control from a developmental perspective. Journal of Motor Behavior. 1985.

118. Fitzpatrick RC, Day BL. Probing the human vestibular system with galvanic stimulation. Journal of Applied Physiology. 2004;96(6):2301-2316.

119. Ludman H. Vertigo and Imbalance. ABC of Ear, Nose and Throat. 2012;253:44.

120. Nashner LM, Black FO, Wall C. Adaptation to altered support and visual conditions during stance: patients with vestibular deficits. The journal of Neuroscience. 1982;2(5):536-544.

121. Paulus W, Straube A, Brandt T. Visual stabilization of posture physiological stimulus characteristics and clinical aspects. Brain. 1984;107(4):1143-1163.

122. Allum J, Honegger F, Pfaltz C. The role of stretch and vestibulo-spinal reflexes in the generation of human equilibriating reactions. Progress in brain research. 1989;80:399409.

123. Pozzo T, Berthoz A, Lefort L. Head stabilization during various locomotor tasks in humans. Experimental Brain Research. 1990;82(1):97-106.

124. Forssberg H, Nashner L. Ontogenetic development of postural control in man: adaptation to altered support and visual conditions during stance. The journal of Neuroscience. 1982;2(5):545-552. 
125. Kirshenbaum N, Riach C, Starkes J. Non-linear development of postural control and strategy use in young children: a longitudinal study. Experimental Brain Research. 2001;140(4):420-431.

126. Nougier V, Bard C, Fleury M, Teasdale N. Contribution of central and peripheral vision to the regulation of stance: developmental aspects. Journal of experimental child psychology. 1998;68(3):202-215.

127. Assaiante C, Mallau S, Viel S, Jover M, Schmitz C. Development of postural control in healthy children: a functional approach. Neural plasticity. 2005;12(2-3):109-118.

128. Rival C, Ceyte H, Olivier I. Developmental changes of static standing balance in children. Neuroscience letters. 2005;376(2):133-136.

129. Sutherland D. The development of mature gait. Gait \& posture. 1997;6(2):163-170.

130. Shaw NA. The neurophysiology of concussion. Progress in Neurobiology. 2002;67(4):281-344.

131. Conn PM. Neuroscience in medicine: Humana Press; 2008.

132. Ingersoll CD, Armstrong CW. The effects of closed-head injury on postural sway. Medicine and science in sports and exercise. 1992;24(7):739.

133. Guskiewicz KM. Balance assessment in the management of sport-related concussion. Clinics in sports medicine. 2011;30(1):89.

134. Rinne MB, Pasanen ME, Vartiainen MV, Lehto TM, Sarajuuri JM, Alaranta HT. Motor performance in physically well-recovered men with traumatic brain injury. Journal of rehabilitation medicine. 2006;38(4):224-229.

135. Gagnon I, Forget R, Sullivan SJ, Friedman D. Motor performance following a mild traumatic brain injury in children: an exploratory study. Brain Injury. 1998;12(10):843853.

136. Campbell M, Parry A. Balance disorder and traumatic brain injury: preliminary findings of a multi-factorial observational study. Brain Injury. 2005;19(13):1095-1104.

137. Kaufman KR, Brey RH, Chou L-S, Rabatin A, Brown AW, Basford JR. Comparison of subjective and objective measurements of balance disorders following traumatic brain injury. Medical engineering \& physics. 2006;28(3):234-239.

138. Gagnon I, Friedman D, Swaine B, Forget R. Balance Findings in a Child before and after a Mild Head Injury. The Journal of head trauma rehabilitation. 2001;16(6):595-602. 
139. De Beaumont L, Mongeon D, Tremblay S, et al. Persistent motor system abnormalities in formerly concussed athletes. Journal of athletic training. 2011;46(3):234-240.

140. Slobounov S, Sebastianelli W, Moss R. Alteration of posture-related cortical potentials in mild traumatic brain injury. Neuroscience letters. 2005;383(3):251-255.

141. Resch JE, May B, Tomporowski PD, Ferrara MS. Balance performance with a cognitive task: a continuation of the dual-task testing paradigm. Journal of athletic training. 2011;46(2):170.

142. Parker TM, Osternig LR, van Donkelaar P, Chou L-S. Balance control during gait in athletes and non-athletes following concussion. Medical engineering \& physics. 2008;30(8):959-967.

143. Kleffelgaard I, Roe C, Soberg HL, Bergland A. Associations among self-reported balance problems, post-concussion symptoms and performance-based tests: a longitudinal followup study. Disability and rehabilitation. 2012;34(9):788-794.

144. Catena RD, van Donkelaar P, Chou L-S. Cognitive task effects on gait stability following concussion. Experimental Brain Research. 2007;176(1):23-31.

145. Catena RD, van Donkelaar P, Chou L-S. The effects of attention capacity on dynamic balance control following concussion. Journal of neuroengineering and rehabilitation. 2011;8:8-8.

146. Sosnoff JJ, Broglio SP, Shin S, et al. Previous mild traumatic brain injury and posturalcontrol dynamics. Journal of athletic training. 2011;46(1):85.

147. Slobounov S, Cao C, Sebastianelli W, Slobounov E, Newell K. Residual deficits from concussion as revealed by virtual time-to-contact measures of postural stability. Clinical neurophysiology: official journal of the International Federation of Clinical Neurophysiology. 2008;119(2):281.

148. Parker TM, Osternig LR, van Donkelaar P, Chou L-S. Recovery of cognitive and dynamic motor function following concussion. British journal of sports medicine. December 1, 2007 2007;41(12):868-873.

149. Catena RD, Van Donkelaar P, Chou LS. Journal of NeuroEngineering and Rehabilitation. Journal of neuroengineering and rehabilitation. 2009;6:25. 
150. Catena RD, van Donkelaar P, Halterman CI, Chou L-S. Spatial orientation of attention and obstacle avoidance following concussion. Experimental Brain Research. 2009;194(1):67-77.

151. Parker TM, Osternig LR, Lee H-J, Donkelaar Pv, Chou L-S. The effect of divided attention on gait stability following concussion. Clinical biomechanics. 2005;20(4):389395.

152. McCREA M, Barr WB, Guskiewicz K, et al. Standard regression-based methods for measuring recovery after sport-related concussion. Journal of the International Neuropsychological Society. 2005;11(1):58-69.

153. McCrea M, Guskiewicz K, Marshall S, Barr W, Randolph C, Cantu R. Acute effects and recovery time following concussion in collegiate football players. Journal of the American Medical Association. 2003;290(19):2556-2563.

154. McCrea M, Guskiewicz K, Marshall S, et al. Acute effects and recovery time following concussion in collegiate football players. Journal of the American Medical Association. 2003;290(19):2556-2563.

155. Riemann BL, Guskiewicz KM. Effects of mild head injury on postural stability as measured through clinical balance testing. Journal of athletic training. 2000;35(1):19.

156. McLeod TCV, Barr WB, McCrea M, Guskiewicz KM. Psychometric and measurement properties of concussion assessment tools in youth sports. Journal of athletic training. 2006;41(4):399.

157. Wuang Y-P, Lin Y-H, Su C-Y. Rasch analysis of the Bruininks-Oseretsky Test of Motor Proficiency-in intellectual disabilities. Research in developmental disabilities. 2009;30(6):1132-1144.

158. Shumway-Cook A, Horak FB. Assessing the Influence of Sensory Interaction on Balance Suggestion from the Field. Physical Therapy. 1986;66(10):1548-1550.

159. Cavanaugh J, Guskiewicz K, Giuliani C, Marshall S, Mercer V, Stergiou N. Detecting altered postural control after cerebral concussion in athletes with normal postural stability. British journal of sports medicine. 2005;39(11):805-811.

160. Cavanaugh JT, Guskiewicz KM, Stergiou N. A nonlinear dynamic approach for evaluating postural control: new directions for the management of sport-related cerebral concussion. Sports Medicine. 2005;35(11):935-950. 
161. Guskiewicz KM. Postural stability assessment following concussion: one piece of the puzzle. Clinical Journal of Sport Medicine. 2001;11(3):182-189. 


\section{APPENDICES}

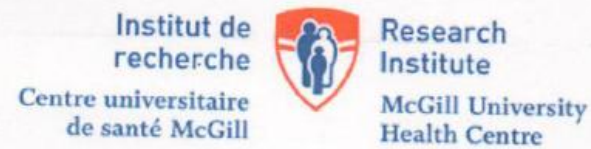

March 13, 2013

Dr. Isabelle Gagnon

MUHC - MCH

Room C-833

\section{Re: MUHC Authorization to Conduct Human Subjects Research 12-190-PED}

Dear Dr. Gagnon:

We are writing to confirm that the study titled "Relationship between Balance and Self- Efficacy Related to Physical Activities in Children after a Mild Traumatic Brain Injury" was submitted for all institutional reviews required by McGill University Health Centre policy.

The Pediatric (PED) Research Ethics Board (REB) has notified us that ethical approval to conduct your study has been provided.

Please refer to the MUHC Study Code 12-190-PED in all future correspondence relating to this study.

Important Note: You are required to advise the MUHC once the study has been initiated. Please complete the Study Status Report through the eReviews system to indicate the date the study became active. Instructions for accessing and using the eReviews system are available on
the RI MUHC portal.

On behalf of the MUHC, we wish you every success with the conduct of the research.

Sincerely,

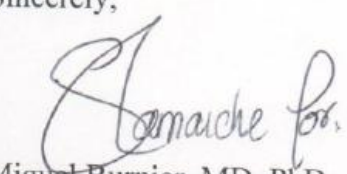

Miguet Burnier, MD, PhD

General Director for Clinical Research

The Research Institute of the McGill University Health Centre

Enclosure

cc: REB Study File

RI MUHC Study File 


\title{
INFORMED CONSENT
}

\section{Relationship between Balance and Self- Efficacy Related to Physical Activities in Children after a Mild Traumatic Brain Injury}

\author{
Principal Investigator: $\quad$ Dr Isabelle Gagnon, $\mathrm{PhD}$ \\ Researcher, Trauma \& General Pediatrics, \\ Montreal Children's Hospital, McGill University Health Center \\ Assistant Professor, School of Physical and Occupational Therapy \\ McGill University
}

Sponsor/Funded By: $\quad$ Dr. Isabelle Gagnon's internal funds

"You" means "you/your child".

\section{Purpose and General information}

The purpose of the study is to test balance in children and teens who have had a Mild Traumatic Brain Injury, or concussion and to see whether their performance relates to their self-confidence when practicing sports or physical activities. We want to compare this group of children and teens to other children who have not had an injury.

Your participation will involve you to be tested at the Concussion Clinic of the Montreal Children's Hospital. Your child will be tested on the same day as your regular appointment and will require about 90 minutes extra time. We will also ask your child to answer a short questionnaire on that day and once more after he/she has completely returned to physical activity. On the second day of testing, you and your child will not be required to visit the hospital as we will do this via telephone.

\section{Study Procedures}


This study will be done in a quiet room at the Montreal Children's Hospital by a research assistant. First, we will test balance using several methods. There will be 3 different physiotherapy tests that ask your child to perform a variety of tasks such as standing on one leg or standing on a balance beam. Breaks will be given at different times during the testing. This part should last approximately 90 minutes.

During one of the breaks, your child will be asked to fill out a simple questionnaire regarding their self-confidence regarding physical activity participation. The questionnaire should take no longer than 10 minutes to complete.

Your child will be required to answer the above questionnaire once again after approximately 12-14 days. This will be done via telephone.

Your child's hospital records will also be looked at by the investigators to get information needed for the study.

\section{Possible Risks and Discomforts}

There are no risks associated with your child's participation in this study other than the possible frustration and the fact that your child may be mildly upset if they cannot perform the tasks to their optimum potential.

\section{Possible Benefits}

You may or may not benefit from being in this study, but you (he/she) may contribute to new medical knowledge that may benefit other children in the future.

\section{Compensation}

You will not be paid for your participation; however you will receive compensation for out-ofpocket expenses, such as parking, public transportation, and babysitting for up to $\$ 25.00 /$ per study visit. 


\section{Voluntary participation}

Your participation is voluntary and you should not feel any obligation. You may agree now and are free to withdraw from this study at any time. Refusal to join or withdrawal from the study will not affect your care at this hospital. If you discontinue your participation, please contact Dr. Isabelle Gagnon, Principal Investigator, at 514-412-4400 x22001 or Krithika Sambasivan, research assistant, at 514-802-3515.

During the course of the study you will be informed of any new findings which may affect your willingness to continue participation in this study.

\section{Confidentiality}

All information obtained during the study will be kept confidential as required or permitted by law and will be kept for 5 years. Your personal identity will remain confidential, as you will only be identified by a subject identification number.

Your name and other personal identifying information will not be used in any reports, presentations or publications.

If the results of this study are published, you will not be identified in any way. Your personal information will be kept strictly confidential except as required or permitted by law. Representatives from Health Canada, the sponsor, and the McGill University Health Centre Research Ethics Office Quality Assurance, may have access to your records as it pertains to this study. The research team will have access to your hospital records.

\section{Quality Assurance Program}

The MUHC has implemented a Quality Assurance Program that includes active continuing review of projects (on site visits) conducted within our establishment. Therefore, it must be noted that all human subject research conducted at the MUHC or elsewhere by its staff, is subject to MUHC Routine and Directed Quality Improvement Visits.

\section{Contact person}

Dr. Isabelle Gagnon- (514) 412-4407 x22001

Krithika Sambasivan- (514) 802- 3515

For additional information regarding your (child's) rights as a research subject, you may contact the hospital's Patient Representative (ombudsman), Patricia Boyer (514) 412-4400 ext. 22223, 
who is independent of the investigator, and works to protect patients' rights.

\section{Consent}

I have read this information and consent form and have had the opportunity to ask questions which have been answered to my satisfaction before signing my name. I acknowledge that I will receive a copy of the Information and Consent Form for future reference. I agree to (have my child) participate in the research study.

Participant's name:

Parent or legal guardian's printed name:

Parent or legal guardian's signature:

Relationship to child:

Date: (dd/month/yy)

Name of the person who obtained consent

Signature of the person who obtained consent 
Date: $\quad(d d / m o n t h / y y)$

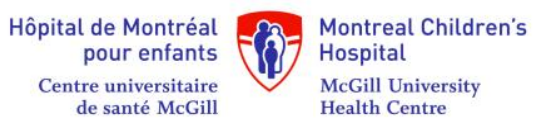

Assent Form (for $7-17$ year olds)

\section{Relationship between Balance and Self-efficacy Related to Physical Activities in} Children after a Mild Traumatic Brain Injury

Principal Investigator: Dr Isabelle Gagnon, PhD

Researcher, Trauma \& Child Development Programs

Montreal Children's Hospital

Assistant Professor

School of Physical and Occupational Therapy

McGill University

Sponsor/Funded By: Dr. Isabelle Gagnon's Internal funds

You are invited to participate in a study about how balance relates to self-confidence in children and teens after a Mild Traumatic Brain Injury.

\section{What is This Study About?}

The reason we are doing this study is to compare the balance and self-confidence levels of children with a brain injury to that of children without injuries. 


\section{What Will I Have To Do?}

You will be tested on the same day as your Concussion Clinic appointment. The test will require about 90 minutes. The research assistant will test your balance by asking you to do things like stand on one foot or stand on a balance beam. You will also answer some questions about your how confident you feel when you practice your physical activities. Once you have returned to all your activities, we will call you to ask you those same questions again.

\section{What are the possible risks and discomforts?}

There are no risks involved with taking part in this study, but you may feel frustrated if you have trouble with some of the tests.

\section{What are the possible benefits?}

You will not receive any benefits but we may learn from the information you provide and we may be able to help other children in the future.

\section{Will I Get Paid?}

You will not be paid for your participation.

\section{What are my options?}

You have the choice to be in this study or not and you should not feel any pressure to agree. You can agree now and are always free to change your mind. No one will be mad at you. Your doctor will still continue to give you the care you need, even if you don't want to be in the study. If you decide to stop your participation, please contact Dr. Isabelle Gagnon or Krithika Sambasivan at 514-412-4400 ×22001. 
During the course of the study you will be informed of any new findings which may affect your willingness to continue in this study.

\section{Who Will know What I Did?}

All information obtained during the study will be kept confidential (and where it will be stored) as required or permitted by law and will be kept for five years. Your personal identity will remain confidential, as you will only be identified by a subject identification number.

Your name and other personal identifying information will not be used in any reports, presentations or publications.

If the results of this study are published, you will not be identified in any way. Your personal information will be kept strictly confidential except as required or permitted by law. As required by Health Canada, and representatives of the McGill University Health Centre Research Ethics Office Quality Assurance, may have access to your records as it pertains to this study. The research team will have access to your hospital records.

\section{Who Can I Contact if I Have Questions?}

Dr. Isabelle Gagnon- 514-412-4400 ×22001

Krithika Sambasivan- (514) 802-3515 
Assent:

I have read this information and have had the opportunity to ask questions which have been answered to my satisfaction before signing my name. I agree to participate in the research study.

Participant's name:

Participant's signature:

Date: (dd/month/yy)

Name of the person who explained the assent

Signature of the person who explained the assent

Date: (dd/month/yy) 


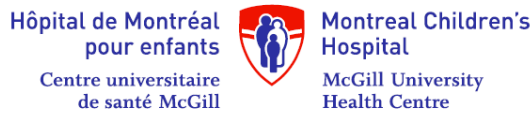

Relationship between Balance and Self-efficacy related to Physical Activity in Children after a Mild Traumatic Brain Injury

Information Letter for Parents

Description of the study:

Your child's friend had recently had a Mild Traumatic Brain Injury or a concussion.

A Mild Traumatic Brain Injury affects many systems in the body and causes varied symptoms. One of the symptoms that they present with is, a problem in their balance. Any issues with balance can lead to restrictions in a variety of physical activities and children find it hard to go back to these activities. We want to study the balance deficits of these children compared to those who have no injury (ages 7-16 years). We have also found that an injury of this nature reduces the child's self-confidence while getting back to physical activities. We are interested in seeing whether there is a relationship between the balance issues and self-confidence. Since there are not many studies of this nature done we would like to know how these children perform compared to the uninjured children. This will help us understand the impact of a Mild Traumatic Brain Injuries. With these results we hope to find more reliable techniques to assess the fitness of the child, that will help prevent further injuries.

Your child's participation:

We would like to evaluate your child on one day for about 90 minutes. Your child will be required perform a few balance tests and answer a self-confidence questionnaire. The balance tests involve various tests such as standing on one foot, walking on a single line, walking while being challenged with mental tasks, etc. There are no risks involved in the performance of these tests. Adequate breaks will be given if required. The evaluation will take place at the Concussion Clinic, Room\# 737, Montreal Children's Hospital (2300 Rue Tupper, Montreal H3H 1P3). There will be a follow- up session after 12-14 days. Your child will be required to answer the same questionnaire again. This will be done via telephone. A date will be provided to you for the follow- up session.

Your participation will be of valuable help to the children who suffer this injury. It will help us understand and learn about balance deficits and the role of self-confidence in safe return to physical activities. This will prevent children from sustaining further injury, that are known to have more severe consequences. We will be happy to answer any further question you may have regarding the study and/or the nature of your participation. Please contact us with any questions or to participate.

We would like to thank you for your time and attention.

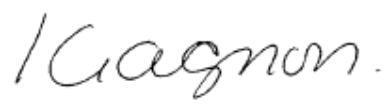

Isabelle Gagnon PhD

Principal Investigator

Assistant Professor 
School of P/OT

McGill University

Clinician-Scientist

Trauma Program and Physiotherapy

Montreal Children's Hospital-MUHC (C-811)

514-412-4400 ext 22001

Isabelle.gagnon8@mcgill.ca 